\title{
Recent Advances on Coumarin-based Photoinitiators of Polymerization
}

\author{
Frédéric Dumura* \\ a Aix Marseille Univ, CNRS, ICR, UMR 7273, F-13397 Marseille, France \\ frederic.dumur@univ-amu.fr
}

\begin{abstract}
During the past decades, a breakthrough has been obtained in the development of photoinitiators activable under low light intensity and in the visible range. In the search for new structures, biosourced or bioinspired molecules have been examined as potential candidates for photoinitiation. In this field, coumarins that can be found in numerous flowers, fruits, vegetables and plant species were determined as highly efficient photoinitiators of polymerization. Especially, these structures were determined as acting as efficiency photoinitiators in Type I and Type II initiating systems. In this review, an overview of the recent development on visible light coumarin-based photoinitiators of polymerization is provided. To evidence the interest of these structures, comparisons with reference photoinitiating systems will be provided.
\end{abstract}

\section{Keywords}

Photoinitiator; coumarin; photopolymerization; LED; low light intensity; ketocoumarin; bioinspired structure

\section{Introduction}

During the past decades, photopolymerization has become an active research field due to the wide range of applications in which this polymerization technique is now involved.[13] Indeed, photopolymerization is commonly used in optics, coatings, adhesives, microelectronics, medical and 3D/4D printing.[4-10] Especially, 3D/4D printing which is an additive technique enabling to fabricate plastic species of various sizes and shapes by polymerization of successive layers has given a revival of interest to this old polymerization technique initially based on UV-active photoinitiating systems.[11-14] Compared to the traditional thermal polymerization which requires the reaction to be carried out in solution, the conversion of the liquid monomer as a polymeric solid can be obtained in solvent-free conditions, avoiding the release of volatile organic compounds (VOCs) and thus making photopolymerization a zero-VOC technology.[2] Parallel to this, a spatial and a temporal control of the polymerization process can be obtained, meaning that the polymerization only occurs on the irradiated zone and during the time the light is switched on (See Figure 1).[15,16] Interest for photopolymerization done in the visible range and under low light intensity is also supported by the recent development of cheap, lightweight, compact and energy-saving new irradiation setups that are the light-emitting diodes (LEDs). Parallel to this, no ozone is 
produced during the polymerization process, contrarily to what happens when UV light is used for irradiation.[17] The production of ozone during polymerization and the use of noxious UV light are currently the focus of numerous safety concerns. To end, a higher light penetration can be obtained in the visible range than in the UV range, as shown in the Figure 2. Thus, if the light penetration remains limited in the near-UV/visible range (ca $600 \mu \mathrm{m}$ ), this latter can reach $5 \mathrm{~cm}$ at $800 \mathrm{~nm}$, enabling to polymerize thick samples. [18,19] Therefore, visible light photopolymerization exhibits several advantages compared to the traditional and still widely used UV photopolymerization. Besides, contrarily to UV photopolymerization that was making use of colorless photoinitiators producing colorless coatings, visible light photopolymerization utilizes photoinitiators absorbing in the visible range and therefore of colored compounds. As a drawback of this approach, visible light photoinitiators often impose the color to the final coatings, what constitutes a severe limitation for further developments. Consequently, photoinitiators capable to bleach during the polymerization process are thus actively researched.[20-22]

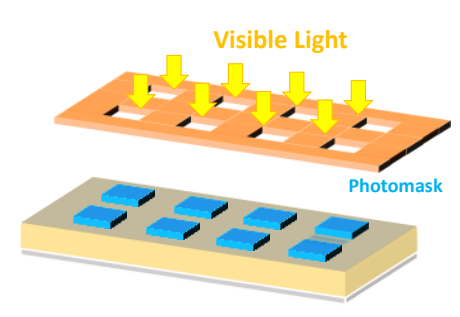

Spatial control

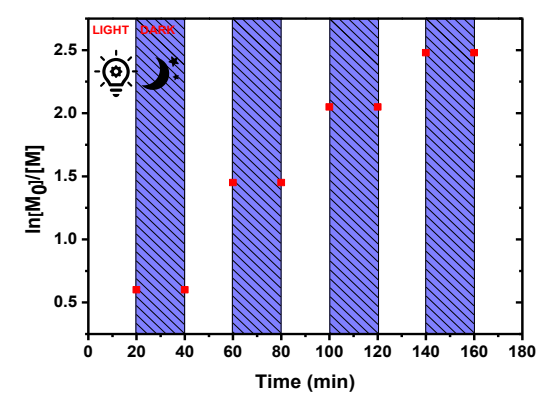

Temporal control

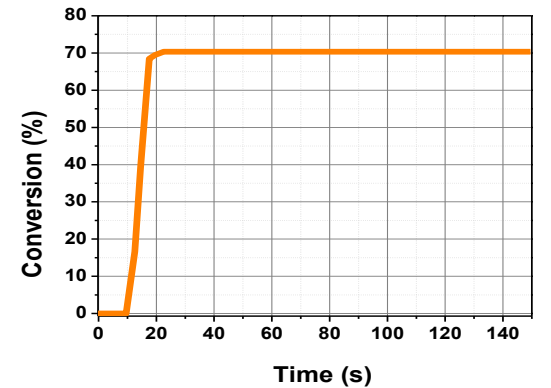

High polymerization speed

Figure 1. The different characteristics of photopolymerization.

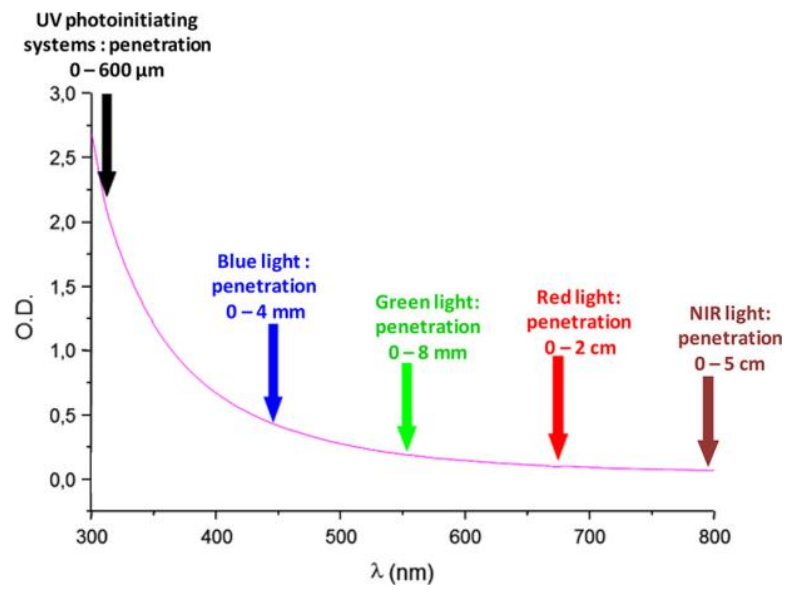

Figure 2. Light penetration in a polystyrene latex with an average diameter of $112 \mathrm{~nm}$.

Reprinted with permission from Bonardi et al.[18] 
Over the years, a wide range of structures have thus been examined for this purpose and naphthalimides,[23-35] squaraines,[36-39] iron complexes,[40-46] thioxanthones,[47-56] 2,3-diphenylquinoxaline derivatives,[57,58] iridium complexes,[59-65] perylenes,[66-68] chalcones,[69-79] pyrenes,[80-85] porphyrins,[86,87] push-pull dyes,[46,88-98] copper complexes,[99-109] coumarins,[110-119] acridones,[120,121] iodonium salts,[23,122-127] diketopyrrolopyrroles,[128-130] phenothiazines,[131] chromones and flavones,[132-134] helicenes,[135,136], carbazoles,[137-144] acridine-1,8-diones,[145-147] benzophenones,[148153] dihydroanthraquinones,[154] cyanines,[155-158] zinc complexes,[159] cyclohexanones,[160-163] and camphorquinones,[164,165] have thus been examined as potential structures capable to bleach. If photobleaching of photoinitiators is difficult to obtain, one strategy consists in using photoinitiators absorbing in the near-UV/visible range so that these molecules are only slightly colored. In this field, coumarins that exhibit activities ranging from antiviral and antimicrobial to anticancer and anticoagulant[166] have also been examined as photoinitiators of polymerization. Coumarins are plant secondary metabolites produced via the phenylpropanoid pathway and these structures are mostly involved in the structural or chemical defenses of plants constantly exposed to a plethora of threats in their environments.[167-171] The first coumarin was extracted by Vogel as soon as 1820 from Coumarouna odorata (now named Dipteryx odorata).[172,173] Due to their high photoluminescence properties, coumarins were notably used as fluorescent probes,[174] sensitizers for solar cells,[175] sensors,[176] or dopants for organic light-emitting diodes.[177] Coumarins are also extensively used as anticoagulant,[178] anticancer,[179] and antibacterial agents,[180] making these structures appealing candidates for pharmacological applications. Concerning photopolymerization, the first report mentioning the use of coumarins as photoinitiators was reported in 1996 by Schnabel and coworkers and the polymerization of oxiranes using an onium salt as a cationic initiator was examined.[181,182] Since this pioneering work, the scope of applications of coumarins has been drastically widened, and coumarins are now used as photoinitiators for dental and biomaterials applications.[183] Coumarins are also capable to undergo a reversible $[2 \pi \mathrm{s}+2 \pi \mathrm{s}]$ cycloaddition reaction so that their incorporations into polymers could impart intrinsic healability and shape-memory properties to the resulting polymers.[114,184,185] Notably, reversibility of the photochemical dimerization of coumarins in polyesters containing coumarins has been clearly demonstrated.[186] Thus, upon irradiation at $350 \mathrm{~nm}$, dimerization of coumarins could be obtained whereas the symmetric cleavage of the cyclobutane linkage between coumarins could be obtained by irradiating at $254 \mathrm{~nm}$. Reversible dimerization ability of coumarins was notably extensively used in the design of polymers exhibiting electro-optical properties but also in the design of biopolymers.[187] More recently, various monomers bearing coumarins as side-groups were polymerized for various applications.[188,189] Investigations of coumarins as photoinitiators of polymerization were not limited to one-photon polymerization and several structures were also proposed for two-photon polymerization.[190-193] In this review, an overview of the recent advances in photoinitiating systems comprising coumarins as photosensitizers is provided. Notably, coumarins proved to 
be versatile structures since Type I and Type II photoinitiators were designed with this scaffold. Notably, structural modifications could be done at various positions so that the absorption spectra of coumarins could be finely tuned (See Figure 3). Notably, extension of the aromaticity by introduction of polyaromatic groups, or the introduction of various groups at the 3-position of coumarins was extensively investigated to design coumarin-based photoinitiators. To evidence the interest of these structures, comparison with benchmark photoinitiators will also be provided.

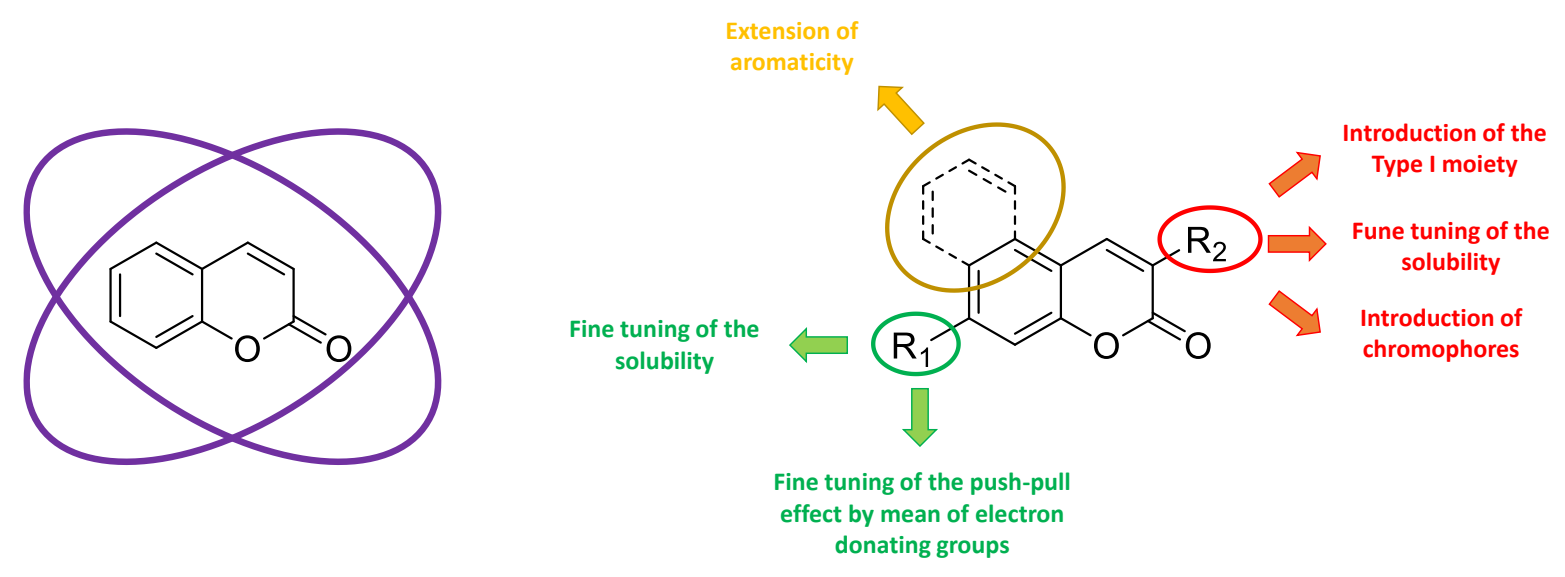

Figure 3. Chemical structure of coumarin and the different possible modifications.

\section{Coumarins as photoinitiators of polymerization}

\subsection{Coumarins as visible light photoinitiators of polymerization}

One of the first report mentioning the use of coumarins as photoinitiators has been reported in 1996 by Schnabel and coworkers.[181] In this work, a laser beam at $488 \mathrm{~nm}$ was used to excite 3-(2'-benzimidazolyl)-7-N,N-diethylaminocoumarin (C1) or 9-trifluoromethyl2,3,6,7-tetrahydro- $1 H, 5 H$-[1] benzopyrano[6,7,8,i,j]-chinolizin-11-one (C2) incorporated in two-component photoinitiating systems comprising N-ethoxy-isoquinolinium hexafluorophosphate $\left(\mathrm{EIQ}^{+} \mathrm{PF}_{6}\right)^{-}$, diphenyliodonium hexafluorophosphate $\left(\mathrm{Ph}_{2} \mathrm{I}^{+} \mathrm{PF}_{6}{ }^{-}\right)$, or triphenylsulfonium hexafluorophosphate $\left(\mathrm{Ph}_{3} \mathrm{~S}^{+} \mathrm{PF}_{6}\right)$ as the onium salts (See Figure 4). A good adequation of the emission of the laser beam with the absorption spectra of the two dyes could be found, the absorption maxima of C1and C2 respectively peaking at 415 and $435 \mathrm{~nm}$. Interestingly, the monomer conversion remained limited, close to $60 \%$, due to the consumption of the coumarins during the polymerization process, but also due to the limited solubility of the onium salts in the resins. A strong influence of oxygen on the monomer conversion was also evidenced, even if the cationic polymerization is known to be insensitive to oxygen inhibition. Two-component photoinitiating systems based on $\mathrm{C} 1$ proved to be less sensitive to oxygen, compared to those based on C2. Introduction of tributylamine or 2,6-ditert-butyl-4-methylpyridine in resins could retard or even inhibit the polymerization of cyclohexene oxide, 4-vinyl cyclohexene dioxide or 1,4-butanediol-diglycidyl ether, 
demonstrating that protons were produced during irradiation and that amines were acting as proton scavengers. An efficient post-polymerization could also be evidenced with the different systems, a cyclohexene oxide conversion being still detected $120 \mathrm{~h}$ and $160 \mathrm{~h}$ after the end of the irradiation with the two component $\mathrm{C}_{1} / \mathrm{EIQPF}_{6}$ and $\mathrm{C}_{2} / \mathrm{EIQPF}_{6}$ photoinitiating systems respectively.

Photosensitizers<smiles>CCN(CC)c1ccc2cc(-c3nc4ccccc4[nH]3)c(=O)oc2c1</smiles><smiles>O=c1cc(C(F)(F)F)c2cc3c4c(c2oc1=O)CCCN4CCC3</smiles>

Epoxy monomers<smiles>C(CCOCC1CO1)COCC1CO1</smiles>

1,4-butanediol-diglycidyl ether<smiles>C1COC2CC2C1</smiles>

cyclohexene oxide

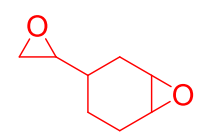

4-vinylcyclohexene dioxide

Cationic initiators

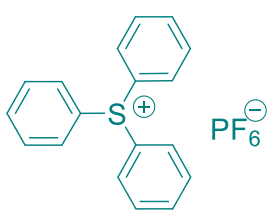

$\mathrm{Ph}_{3} \mathrm{~S}^{\oplus} \mathrm{PF}_{6}^{\ominus}$<smiles>[P-]c1cccc([Hg]c2ccccc2)c1</smiles>

$\mathrm{Ph}_{2} \mathrm{PPF}_{6}^{\ominus}$

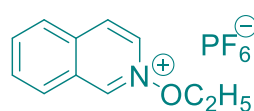

$\mathrm{EIQ}^{\oplus} \mathrm{PF}_{6}^{\ominus}$

Figure 4. The different coumarins C1 and C2, monomers and additives used in 1996 by Schnabel and coworkers.

3-(2'-Benzothiazoryl)-7-diethylaminocoumarin (C3), due to its remarkable photochemical reactivity was examined as photoinitiator in several studies in the early 2000s, and its photoinitiating ability was compared to that of another coumarin, namely 3,3'carbonyl-bis-7-diethylaminocoumarin (C4) (See Figure 5).[194] Notably, reactivity of C3 was examined with additives such as ( $\left.\eta_{6-c h l o r o b e n z e n e}\right)\left(\eta_{5}\right.$-cyclopentadienyl)iron (II) hexafluorophosphate (complex 2) or cyano-N-phenylglycine (CPG).[195]

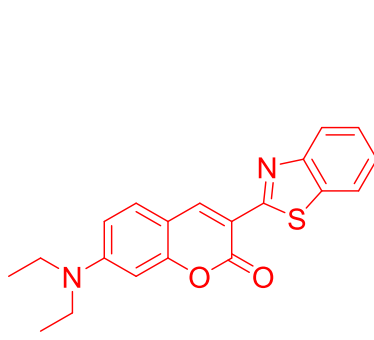

C3

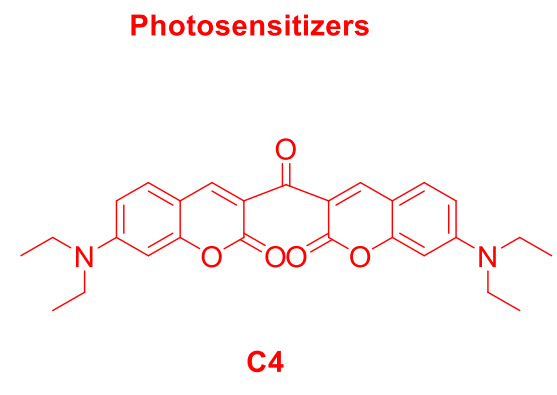

C4
Additives

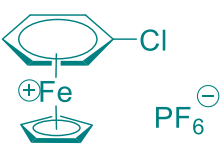<smiles>N#Cc1cccc(NCC(=O)O)c1</smiles>

Complex 2

Figure 5. Chemical structures of $\mathrm{C} 3$ and $\mathrm{C} 4$. 
Interestingly, efficiency of the three-component coumarin/iron arene complex/amine photoinitiating system was two-fold higher than that of the two-component coumarin/iron arene complex photoinitiating system during the free radical polymerization of methyl methacrylate upon visible light irradiation with a high-pressure mercury lamp. High efficiency of the three-component photoinitiating system was assigned to radicals derived from (3-cyanophenyl)glycine. Notably, upon excitation of coumarins, a photoinduced electron transfer from coumarin towards the iron arene complex occurred, reducing the metallocene. The reduced complex can abstract a hydrogen atom from (3-cyanophenyl)glycine, generating the initiating species (See Scheme 1). Noticeably, C4 proved to be more efficient than C3, resulting from a more favorable electron transfer from the coumarin to the metallocene.[196] These results were confirmed in another study in which polymethyl-substituted ferrocenes were used as additives.[197]

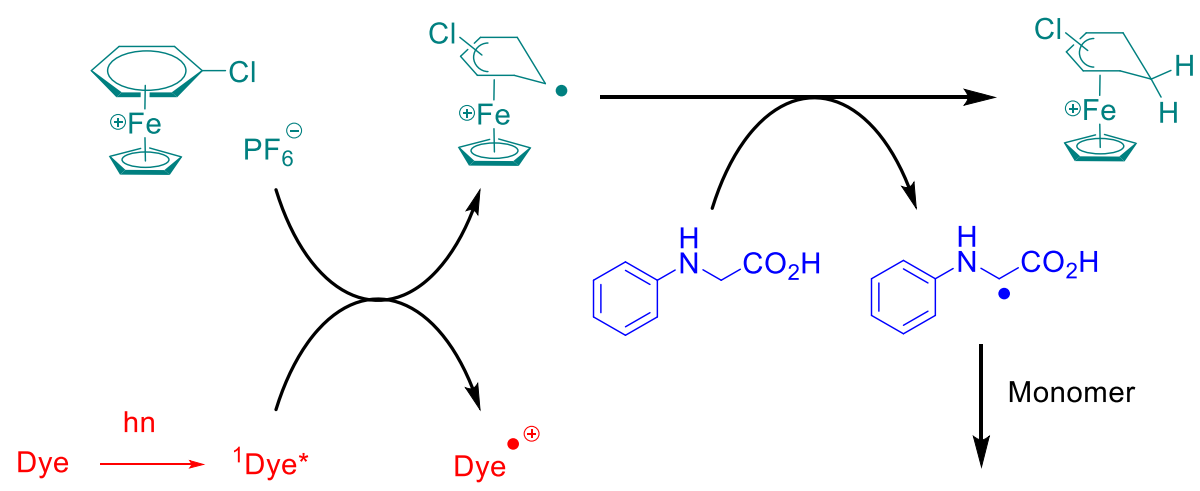

Polymerization

Scheme 1. Mechanism supporting the polymerization process.

In 2000, an interesting study demonstrated that coumarins can operate via various reactions pathways upon irradiation at $405 \mathrm{~nm}$. Notably, several additives were used, namely chlorohexaaryl-bis-imidazole (BI),[198] bis( $\eta^{5}$-cyclopentadienyl)-bis-[2,6-difluoro-3-(1H-pyrr1-yl)phenyl] titanium (Ti), a ketoxime ester i.e. 2-(((ethoxy-carbonyl)oxy)imino)-1phenylpropan-1-one (PDO) and two hydrogen donors (HD), namely benzo[d]oxazole-2-thiol (MBO) and benzo[d]thiazole-2-thiol (MBT) (See Figure 6). In order the coumarins to photosensitize the different additives, polymerization reactions as well as elucidation of the photochemical mechanism were carried out at $405 \mathrm{~nm}$, the different additives not absorbing at this wavelength. 


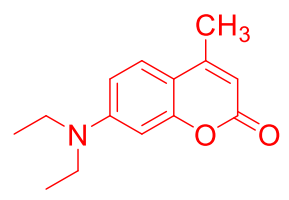

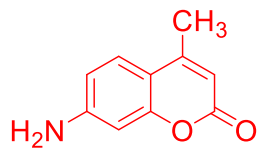

C6

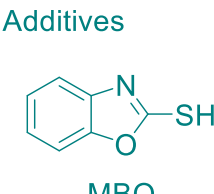

MBO

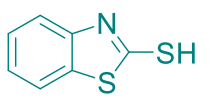

MBT

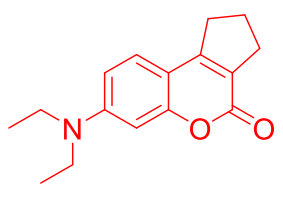

C7

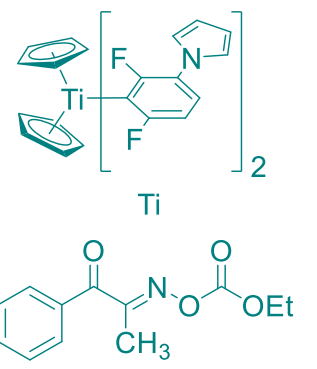

PDO

Figure 6. Chemical structures of coumarins $\mathrm{C} 5, \mathrm{C} 6$ and $\mathrm{C} 7$ and the different additives.

Determination of the free energy change for the electron transfer reaction of coumarins 7-diethylamino-4-methylcoumarin $\quad \mathrm{C} 5, \quad$ 7-amino-4-methylcoumarin $\quad \mathrm{C} 6 \quad$ and 7dimethylaminocyclopenta[c]coumarin $\mathrm{C} 7$ revealed $\Delta \mathrm{G}$ to be negative, evidencing that radicals could be generated by mean of an electron transfer reaction from coumarins with the different additives (BI, Ti and PDO). Conversely, ketocoumarin (C4) led to an energy transfer with chlorohexaaryl-bis-imidazole (BI) and to a hydrogen abstraction with the benzoxazole derivative.[194] In the case of Ti and PDO, the low efficiency of the electron transfer resulted in the low production of initiating radicals and the quasi-absence of monomer conversion. Overall, different mechanisms were proposed and these mechanisms are presented in the Scheme 2 . 
For Coumarins $\mathrm{C} 5, \mathrm{C} 6$ and $\mathrm{C} 7$

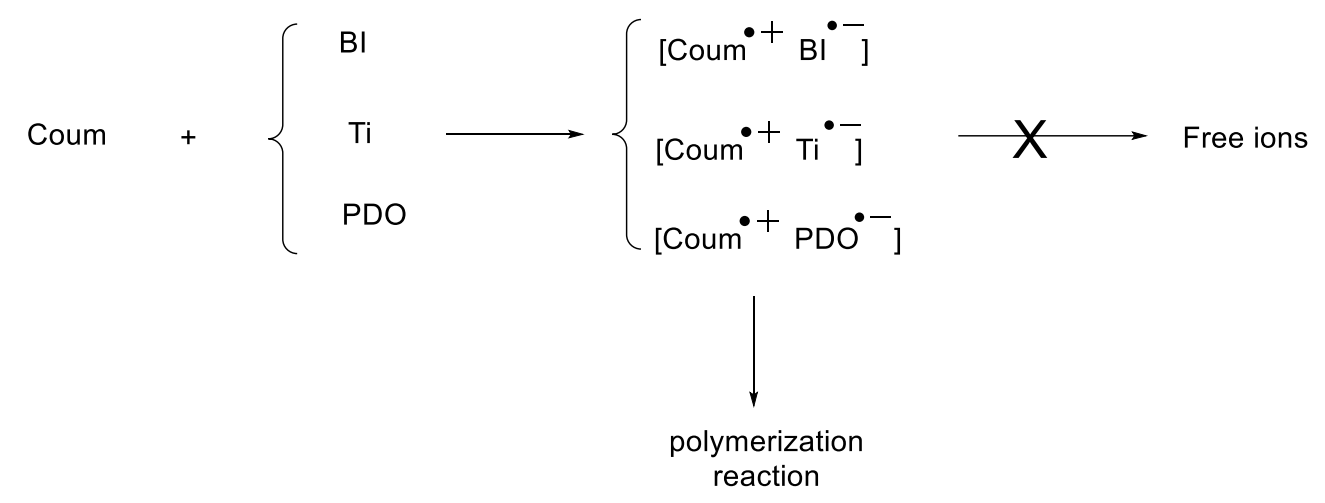

For Coumarin C4

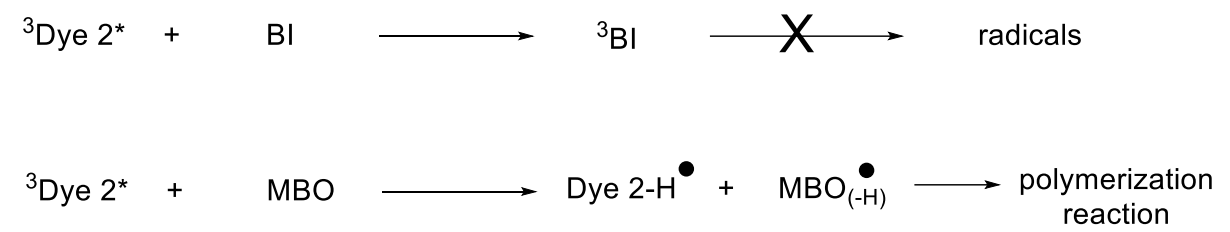

Scheme 2. The different photoinitiating pathways depending on the coumarins C1-C4 used.

Generation of radicals by visible light photoinduced electron transfer of coumarins towards the UV photoinitiator 2-chlorohexaaryl-bis-imidazole (BI) was notably demonstrated with a series of three coumarins namely 3-acetyl-7-(diethylamino)coumarin (C8), 3-(2benzimidazolyl)-7-(diethylamino)-coumarin (C1) and 7-diethylamino-3-(2'-Nmethylbenzimidazolyl)coumarin (C9) absorbing in the visible range (absorption maxima located at 433, 438 and $418 \mathrm{~nm}$ for C8, C1 and C9 respectively) during the photopolymerization of methyl methacrylate (MMA) (See Figure 7).[199] In the ground state, no interaction between 2-chlorohexaaryl-bis-imidazole (BI) and the different coumarins could be determined, as no shift of the absorption maxima of coumarins could be determined, excluding the formation of a charge transfer complex. Upon increase of the concentration of BI, a clear reduction of the MMA conversion upon visible light irradiation was evidenced and this result was assigned to the recombination of imidazolyl radicals, regenerating BI at high radical concentration. Due to their important sizes, imidazolyl radicals are low reactive radicals so that dodecanethiol (SH) was incorporated into the photocurable resin in order to generate small free radicals. Using this approach, a significant enhancement of the MMA conversion could be obtained.

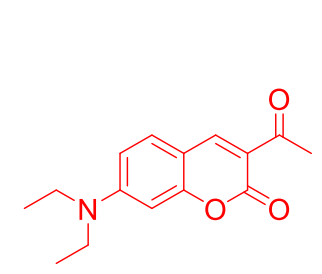

C8

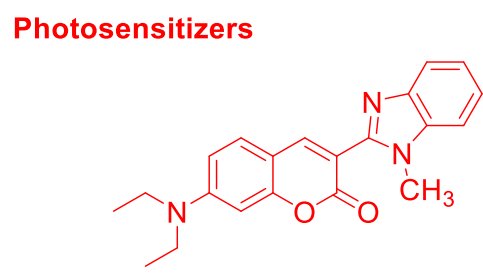

C9
Additives

$\mathrm{C}_{12} \mathrm{H}_{25}-\mathrm{SH}$

$\mathrm{SH}$

Figure 7. Chemical structures of $\mathrm{C} 1, \mathrm{C} 8$ and $\mathrm{C} 9$ and the different additives. 
In 2020, Lalevée and coworkers revisited coumarins as photoinitiators activable under low light intensity and the different polymerization experiments were carried out at $405 \mathrm{~nm}$ which is the wavelength currently under use in 3D printing.[200] Choice of this wavelength is supported by the fact that the $405 \mathrm{~nm}$ LED light sources are the cheapest LED available at present, justifying their incorporation in 3D-printers.[17,201,202] In this work, a series of eight coumarin $\mathrm{C} 10-\mathrm{C} 17$ varying by the substitution pattern were examined in two-component photoinitiating system comprising 4-isopropyl-4'-methyldiphenyliodonium tetrakis(pentafluorophenyl)borate (IOD) as the cationic initiator and performances were compared to that of C18, C19, C4 and C5 that are commercially available (See Figure 8).[112]

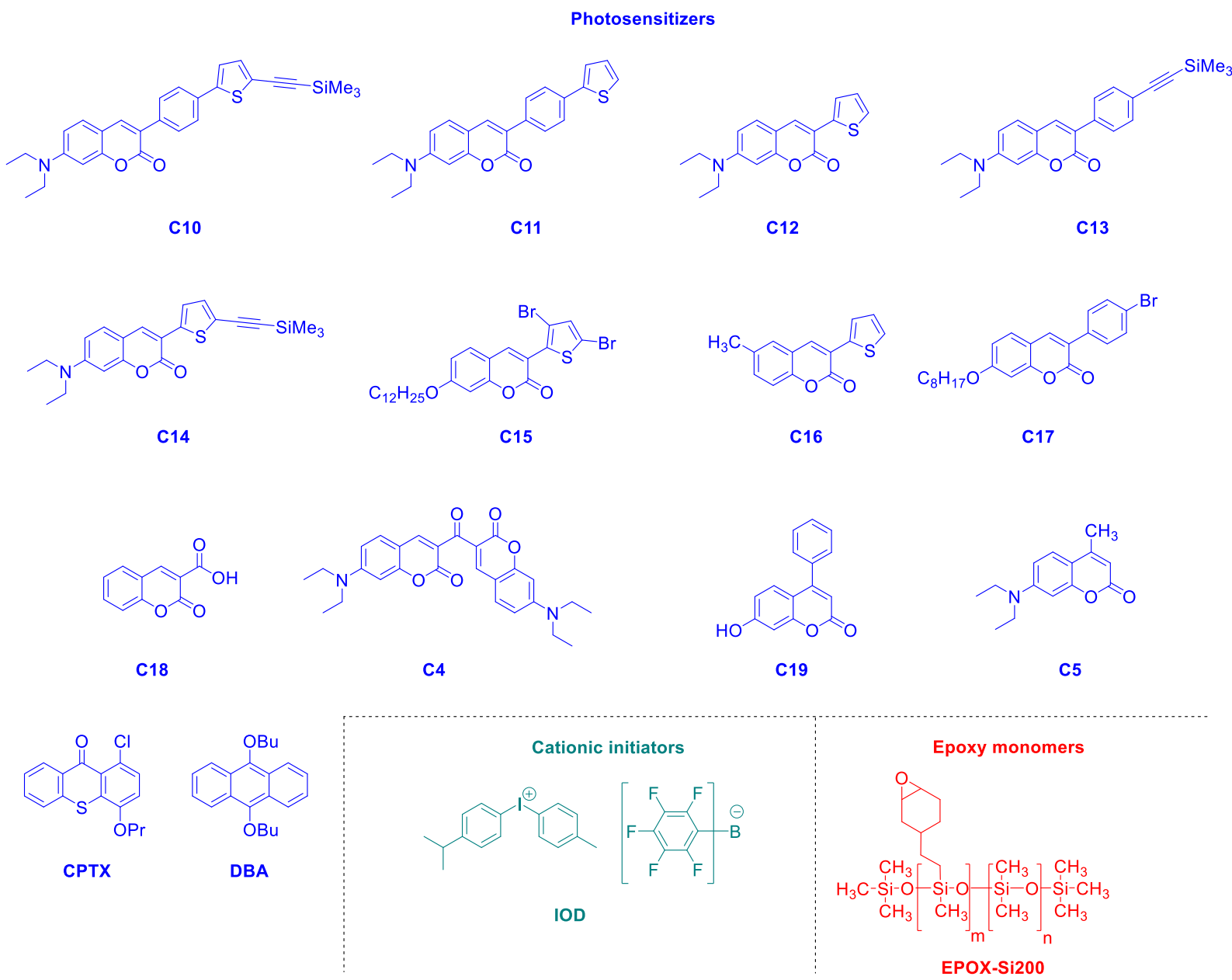

Figure 8. Chemical structures of coumarins $\mathrm{C} 10-\mathrm{C} 19, \mathrm{C} 4$ and $\mathrm{C} 5$, and the different additives and monomer.

Comparisons were also established with 1-chloro-4-propoxythioxanthone (CPTX) and 9,10-dibutoxyanthracene (DBA) that are well-established photoinitiators. Based on previous work of Crivello and coworkers, EPOX-Si200 was selected as the epoxysilicone resin due to the higher polymerization rates that can be obtained with this resin compared to more usual 
epoxy resins, but also due to the interesting mechanical properties of the resulting polymers.[203-206] All dyes showed significant absorptions at $405 \mathrm{~nm}$, as shown in the Table 1 and the Figure 9, except C18 and C19 that showed limited absorption at $405 \mathrm{~nm}$. For all the other dyes, molar extinction coefficients ranging from $260 \mathrm{M}^{-1} \cdot \mathrm{cm}^{-1}$ for $\mathrm{C} 17$ to $47950 \mathrm{M}^{-1} \cdot \mathrm{cm}^{-1}$ for $\mathrm{C} 10$ could be determined. Excellent reactivities and almost similar monomer conversions were determined at $405 \mathrm{~nm}$ using the two-component coumarin/IOD $(0.05 \%$ or $0.1 \% / 1 \% \mathrm{w} / \mathrm{w})$ photoinitiating systems (See Table 2), even if strong variations of the molar extinction coefficients could be determined between dyes. Interestingly, comparisons with benchmark photoinitiators revealed $\mathrm{C} 10, \mathrm{C} 11, \mathrm{C} 12, \mathrm{C} 16$ and $\mathrm{C} 17$ to overcome the two-component CPTX/IOD $(0.1 \% / 1 \% \mathrm{w} / \mathrm{w})$ and DBA/IOD $(0.1 \% / 1 \% \mathrm{w} / \mathrm{w})$, the two systems only reaching 48 and $55 \%$ monomer conversions after $800 \mathrm{~s}$ of irradiation. Indeed, final monomer conversions as high as 57 and $60 \%$ could be obtained with coumarins C16 and C17 in the same conditions (See Table 2). Monomer conversions outperforming that obtained with the benchmark coumarins ( $\mathrm{C} 4$ and $\mathrm{C} 5$ ) were thus determined, demonstrating the pertinence of the approach. A good photobleaching of the generated photopolymers was also detected, with the colour changing from yellow for the initial resin to transparent for the final polymers.

Table 1. Parameters characterizing the light absorption properties of C4, C10-C18 : absorption wavelengths $\lambda_{\max }$, extinction coefficients at $\lambda_{\max }$ and extinction coefficients @405 nm.

\begin{tabular}{|c|c|c|c|}
\hline PI & $\lambda_{\max }(\mathrm{nm})$ & $\lambda_{\max }\left(\mathrm{M}^{-1} \cdot \mathrm{cm}^{-1}\right)$ & $\varepsilon_{\circlearrowleft 405 \mathrm{~nm}}\left(\mathbf{M}^{-1} \cdot \mathrm{cm}^{-1}\right)$ \\
\hline C10 & 411 & 48630 & 47950 \\
\hline C11 & 407 & 42360 & 42270 \\
\hline C12 & 421 & 35200 & 30600 \\
\hline C13 & 408 & 23530 & 23340 \\
\hline C14 & 445 & 34380 & 16880 \\
\hline C15 & 361 & 22970 & 6080 \\
\hline C16 & 357 & 9210 & 530 \\
\hline C17 & 342 & 24760 & 260 \\
\hline C18 & 299 & 11150 & 40 \\
\hline C4 & 457 & 58640 & 17450 \\
\hline C19 & 324 & 11310 & 40 \\
\hline
\end{tabular}



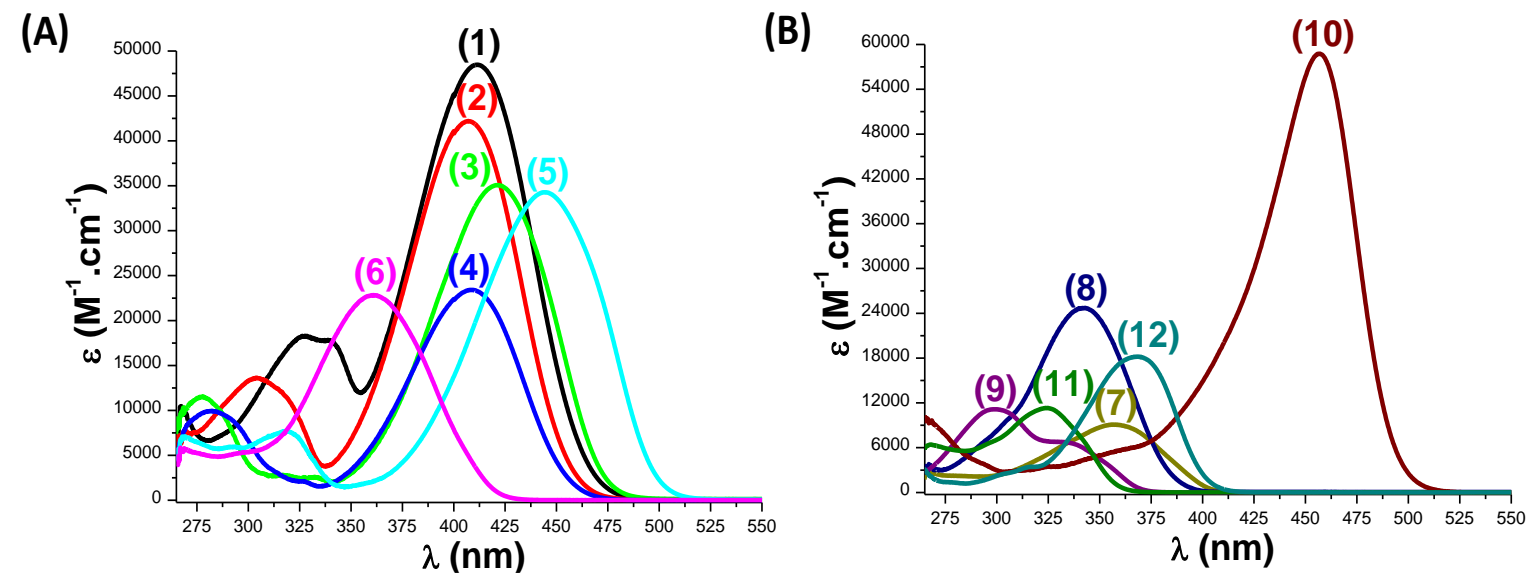

Figure 9. UV-visible absorption spectra of coumarins studied in acetonitrile: (a): (1) C10; (2) C11; (3) C12; (4) C13; (5) C14; (6) C15. (b): (7) C16; (8) C17; (9) C18; (10) C4; (11) C19; (12) C5 respectively. Reprinted with permission from Abdallah et al.[112]

An efficiency trend with the following order: $\mathrm{C} 12>\mathrm{C} 10>\mathrm{C} 11>\mathrm{C} 16>\mathrm{C} 13>\mathrm{C} 17>\mathrm{C} 14>\mathrm{C} 15$ could be determined, perfectly fitting with the light absorption properties at $405 \mathrm{~nm}$. Reactivity of the photoinitiating systems was also strongly related to the formation efficiency of the Bronsted acid $\left(\mathrm{H}^{+}\right)$which constitutes the initiating species in cationic polymerization.[207]

Table 2. Final Reactive Epoxy Function Conversion (FC) for Epoxy-silicones using Different Two-component PISs after $800 \mathrm{~s}$ of Irradiation with the LED @405 nm; thickness $=25 \mu \mathrm{m}$.

\begin{tabular}{|c|c|c|c|c|c|}
\hline C10 & C11 & C12 & C13 & C14 & C15 \\
\hline $57 \%^{\mathrm{a}}$ & $55 \%^{\mathrm{a}}$ & $55 \%^{\mathrm{a}}$ & $53 \%^{\mathrm{a}}$ & $47 \%^{\mathrm{a}}$ & $52 \%^{\mathrm{a}}$ \\
$55 \%^{\mathrm{b}}$ & $55 \%^{\mathrm{b}}$ & $55 \%^{\mathrm{b}}$ & $54 \%^{\mathrm{b}}$ & $44 \%^{\mathrm{b}}$ & $52 \%^{\mathrm{b}}$ \\
\hline $\mathrm{C} 16$ & $\mathbf{C 1 7}$ & $\mathbf{C 1 8}$ & $\mathrm{C} 5$ & $\mathbf{C P T X}$ & DBA \\
\hline $57 \%^{\mathrm{a}}$ & $59 \%^{\mathrm{a}}$ & $47 \%^{\mathrm{a}}$ & $52 \%^{\mathrm{a}}$ & $48 \%{ }^{\mathrm{b}}$ & $55 \%^{\mathrm{b}}$ \\
$57 \%^{\mathrm{b}}$ & $60 \%^{\mathrm{b}}$ & $47 \%^{\mathrm{b}}$ & $55 \%^{\mathrm{b}}$ & & \\
\hline
\end{tabular}

a: Coumarin or Com. Coum/IOD: $(0.05 \% / 1 \%$ w/w) b: Coumarin or Com. Coum or CPTX or DBA/IOD: $(0.1 \% / 1 \% \mathrm{w} / \mathrm{w})$

Finally, to evidence the interest of these structures, 3D printing experiments were carried out. As shown in the Figure 10, 3D patterns exhibiting a remarkable spatial resolution could be obtained with coumarins C11, C12 and C16. 


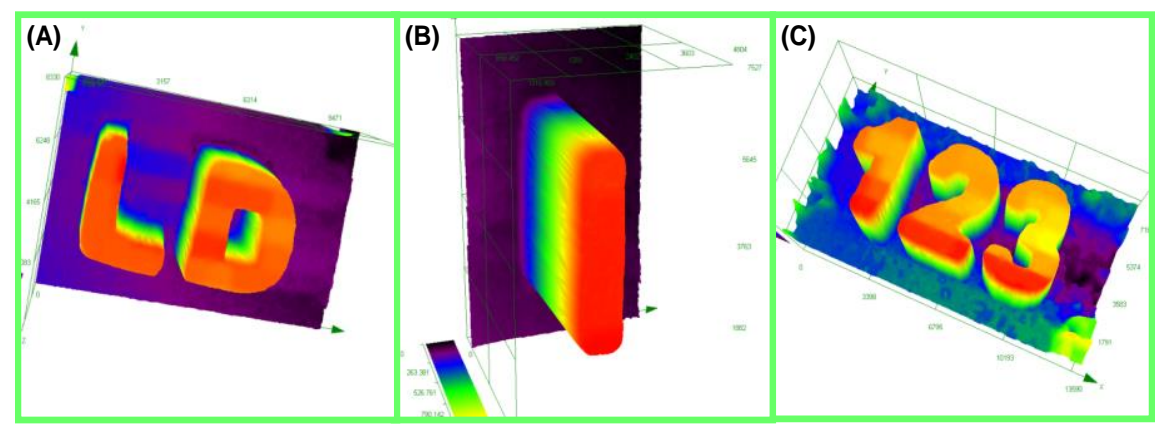

Figure 10. 3D Printing Experiments concerning the $\mathrm{CP}$ of Epoxy-silicones upon irradiation with a Laser Diode (@405 nm): Characterization of the thick 3D generated patterns by numerical optical microscopy: (A) C11/IOD $(0.04 \% / 0.8 \% \mathrm{w} / \mathrm{w})$ (thickness $=1800 \mu \mathrm{m})$; (B) C12/IOD $(0.018 \% / 0.36 \% \mathrm{w} / \mathrm{w})$ (thickness $=1320 \odot \mathrm{m})$ and $(\mathrm{C}) \mathrm{C} 13 / \mathrm{IOD}(0.05 \% / 1 \% \mathrm{w} / \mathrm{w})$ (thickness $=2200 \mu \mathrm{m}$ ); respectively. Reprinted with permission from Abdallah et al.[112]

Following this initial work, Lalevée and coworkers examined the chemical mechanism supporting the polymerization process with a set of thirteen coumarins C20-C32 involved in the cationic polymerization of epoxides but also the free radical polymerization of (meth)acrylates when incorporated in two and three-component photoinitiating systems activable at $405 \mathrm{~nm}$ (See Figure 11).[208]
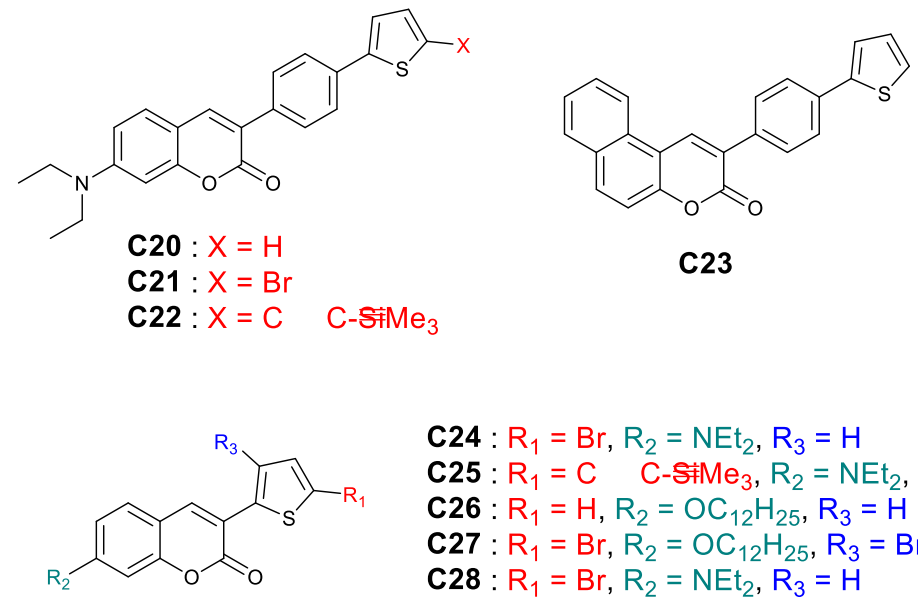

C24: $\mathrm{R}_{1}=\mathrm{Br}, \mathrm{R}_{2}=\mathrm{NEt}_{2}, \mathrm{R}_{3}=\mathrm{H}$

C25: $R_{1}=C \quad C-S M_{3}, R_{2}=N^{2} t_{2}, R_{3}=H$

C26: $\mathrm{R}_{1}=\mathrm{H}, \mathrm{R}_{2}=\mathrm{OC}_{12} \mathrm{H}_{25}, \mathrm{R}_{3}=\mathrm{H}$

C27: $\mathrm{R}_{1}=\mathrm{Br}, \mathrm{R}_{2}=\mathrm{OC}_{12} \mathrm{H}_{25}, \mathrm{R}_{3}=\mathrm{Br}$

C28: $\mathrm{R}_{1}=\mathrm{Br}, \mathrm{R}_{2}=\mathrm{NEt}_{2}, \mathrm{R}_{3}=\mathrm{H}$

C29: $\mathrm{R}_{1}=\mathrm{Br}, \mathrm{R}_{2}=\mathrm{OH}, \mathrm{R}_{3}=\mathrm{H}$

C30: $\mathrm{R}_{1}=\mathrm{Ph}-\mathrm{CHO}, \mathrm{R}_{2}=\mathrm{NEt}_{2}, \mathrm{R}_{3}=\mathrm{H}$

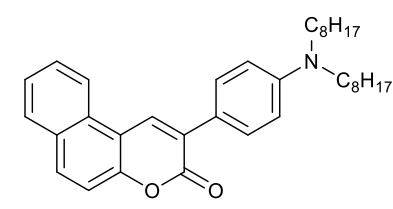

C31

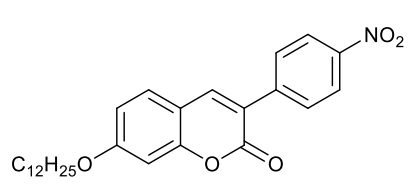

C32

Figure 11. Chemical structures of coumarins C20-C32.

A photocatalytic behavior could be evidenced when incorporated in three-component photoinitiating systems. Here again, a good overlap between the emission spectrum of the LED emitting at $405 \mathrm{~nm}$ and the absorption spectra of the different dyes could be found (See Table 3). 
Table 3. Parameters characterizing the light absorption properties of the investigated coumarins: maximum absorption wavelengths $\lambda_{\max }$, extinction coefficients at $\lambda_{\max }$ and molar extinction coefficients at the emission wavelength of the LED@405 nm.

\begin{tabular}{|c|c|c|c|c|}
\hline PI & $\begin{array}{c}\text { MM } \\
(\mathrm{g} / \mathrm{mol})\end{array}$ & $\begin{array}{l}\lambda_{\max } \\
(\mathrm{nm})\end{array}$ & $\begin{array}{c}\lambda_{\max } \\
\left(\mathbf{M}^{-}\right. \\
\left.{ }^{1} \cdot \mathbf{c m}^{-1}\right)\end{array}$ & $\begin{array}{c}\lambda_{\Theta 405 \mathrm{~nm}} \\
\left(\mathbf{M}^{-}\right. \\
\left.{ }^{1} \mathrm{~cm}^{-1}\right)\end{array}$ \\
\hline C20 & 375 & 407 & 42400 & 42300 \\
\hline C21 & 454 & 408 & 41700 & 41600 \\
\hline $\mathrm{C} 22$ & 472 & 411 & 48600 & 48000 \\
\hline $\mathrm{C} 23$ & 354 & 372 & 26200 & 10200 \\
\hline $\mathrm{C} 24$ & 378 & 432 & 29500 & 20900 \\
\hline C25 & 396 & 445 & 34400 & 16900 \\
\hline C26 & 413 & 367 & 25800 & 8400 \\
\hline C27 & 570 & 361 & 23000 & 6100 \\
\hline C28 & 299 & 421 & 32800 & 28400 \\
\hline C29 & 244 & 355 & 11300 & 700 \\
\hline C30 & 403 & 457 & 48500 & 17300 \\
\hline C31 & 512 & 416 & 21100 & 20200 \\
\hline C32 & 452 & 361 & 25600 & 6200 \\
\hline
\end{tabular}

Interestingly, the different coumarins could be used as photoinitiators in photooxidative and photoreductive processes. When combined with Iod in two-component coumarin/Iod $(0.2 / 1 \% \mathrm{w} / \mathrm{w})$ photoinitiating systems for the free radical polymerization (FRP) of trimethylolpropane triacrylate (TMPTA) in laminate (See Structures in Figure 12), the order

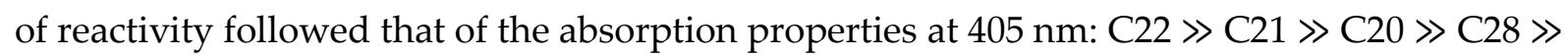
$\mathrm{C} 23 \gg \mathrm{C} 24 \sim \mathrm{C} 25 \gg \mathrm{C} 31 \gg \mathrm{C} 26$. A TMPTA conversion of 48\% could be determined for the $\mathrm{C} 22 / \operatorname{Iod}(0.2 / 1 \% \mathrm{w} / \mathrm{w})$ system after $100 \mathrm{~s}$ of irradiation. The worse conversion was obtained with C26 (27\%) and no polymerization was detected for C27. Under air and in thick films (1.4 $\mathrm{mm}$ ), except for C21, C26 and C31 for which good monomer conversions could be maintained, a severe reduction of the monomer conversions could be observed with the other dyes, resulting from oxygen inhibition (See Table 4). Indeed, in this case, part of the initiation radicals is consumed by oxygen, generated non-reactive radicals and thus considerably reducing the concentration of initiating radicals within the resin. While examining the reactivity of the reductive approach, lower monomer conversions were obtained with the twocomponent coumarin/N-phenylglycine (NPG) $(0.2 \% / 1 \% \mathrm{w} / \mathrm{w})$ systems and even no monomer 
conversions were detected for C24-C29. Surprisingly, a significant enhancement of the monomer conversion was observed with the C32/NPG photoinitiating system, a TMPTA conversion of $39 \%$ being obtained vs. $24 \%$ with the C32/Iod $(0.2 / 1 \% \mathrm{w} / \mathrm{w})$ system. While replacing NPG by ethyl 4-(dimethylamino)benzoate (EDB), only a TMPTA conversion was detected with $\mathrm{C} 32$, furnishing comparable monomer conversions to that obtained with NPG. For all the other dyes, no conversion was detected using EDB, evidencing the importance of the careful selection of the amine for elaborating efficient photoinitiating systems. Higher reactivity of the two-component coumarin/NPG $(0.2 \% / 1 \% \mathrm{w} / \mathrm{w})$ systems compared to that of the two-component coumarin/EDB $(0.2 \% / 1 \% \mathrm{w} / \mathrm{w})$ systems was assigned first to the possibility for NPG to decarboxylate[209-211] and thus to produce initiating radicals and second to avoid an eventual back electron transfer process that certainly occurs with EDB, impeding the formation of initiating radicals.

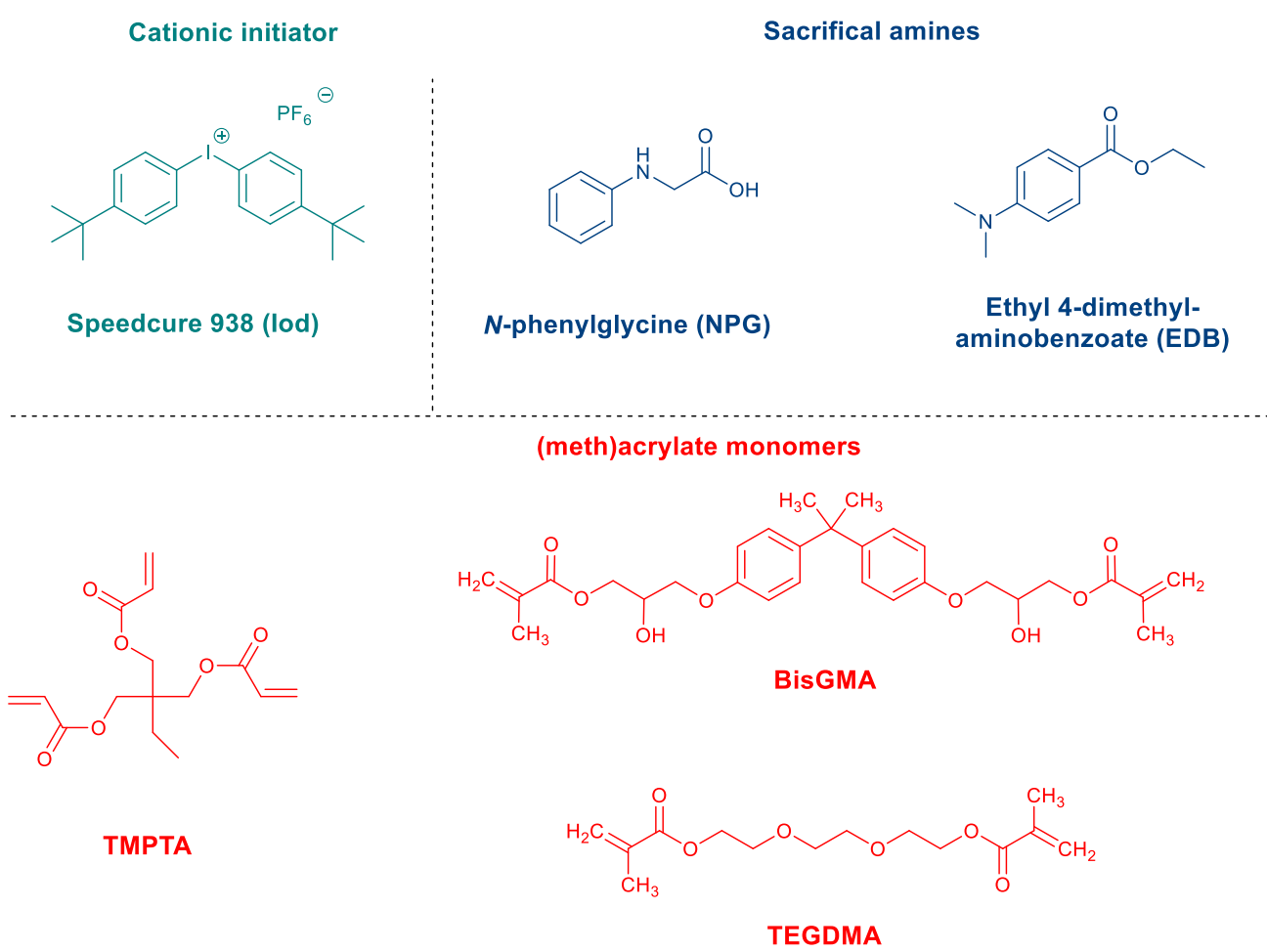

Figure 12. Chemical structures of the different additives and monomers used with C20-C32.

Table 4. Final reactive acrylate function conversion (FC) for TMPTA after $100 \mathrm{~s}$ of irradiation with the LED@405 nm, in the presence of different two and three-component photoinitiating systems based on coumarins compounds.

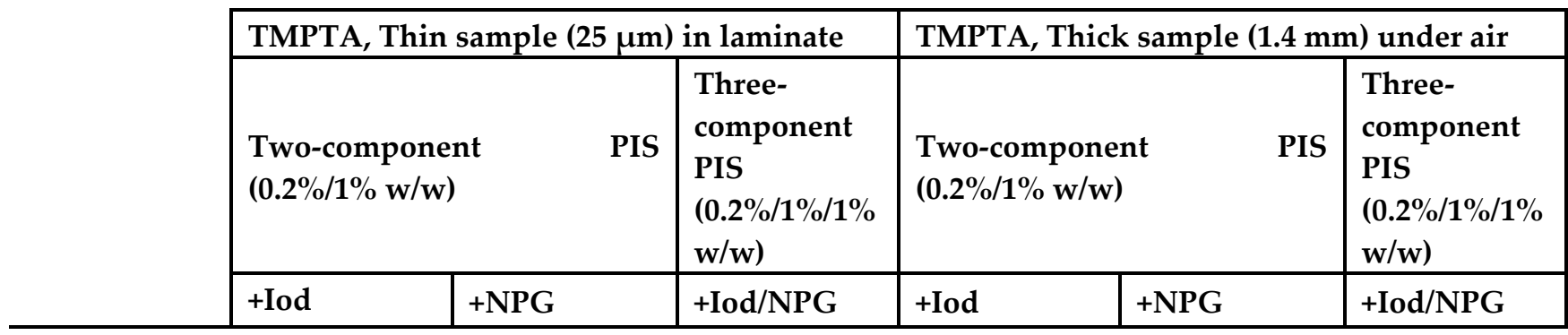




\begin{tabular}{|l|l|l|l|l|l|l|}
\hline C20 & $41 \%$ & $34 \%$ & $59 \%$ & $41 \%$ & n.p. & $83 \%$ \\
\hline C21 & $46 \%$ & $33 \%$ & $59 \%$ & $68 \%$ & $82 \%$ & $83 \%$ \\
\hline C22 & $48 \%$ & $42 \%$ & $59 \%$ & $49 \%$ & $77 \%$ & $73 \%$ \\
\hline C23 & $46 \%$ & $34 \%$ & $59 \%$ & n.p. & $35 \%$ & $82 \%$ \\
\hline C24 & $33 \%$ & n.p. & $53 \%$ & $26 \%$ & n.p. & $85 \%$ \\
\hline C25 & $33 \%$ & n.p. & $51 \%$ & $28 \%$ & n.p. & $31 \%$ \\
\hline C26 & $27 \%$ & n.p. & $49 \%$ & $62 \%$ & n.p. & $82 \%$ \\
\hline C27 & n.p. & n.p. & $26 \%$ & n.p. & n.p. & $81 \%$ \\
\hline C28 & $41 \%$ & n.p. & $53 \%$ & $41 \%$ & n.p. & $83 \%$ \\
\hline C29 & n.p. & n.p. & $44 \%$ & n.p. & n.p. & $82 \%$ \\
\hline C30 & $19 \%$ & $20 \%$ & $44 \%$ & $36 \%$ & $64 \%$ & $94 \%$ \\
\hline C31 & $28 \%$ & $20 \%$ & $51 \%$ & $67 \%$ & n.p. & $82 \%$ \\
\hline C32 & $24 \%$ & $39 \%$ & $49 \%$ & n.p. & $75 \%$ & $83 \%$ \\
\hline
\end{tabular}

Logically, use of the three-component Coumarin/Iod/EDB $(0.2 \% / 1 \% / 1 \% \mathrm{w} / \mathrm{w})$ system could greatly enhance the TMPTA conversions by the concomitant occurrence of both the oxidative and the reductive pathways. An enhancement of the monomer conversion of $22 \%$ could thus be obtained with CoumC7 in thin films. A comparable enhancement could also be detected in thick films, an improvement of the monomer conversion of $20 \%$ being detected with C26. Efficiency of the two and three-component photoinitiating systems were confirmed during the FRP of a monomer blend composed of bisphenol A-glycidyl methacrylate (BisGMA), and triethyleneglycol dimethacrylate (TEGDMA) $(70 / 30 \% \mathrm{w} / \mathrm{w})$, this mixture being classically used in dentistry.[212-215] Owing to the high reactivity of the three-component systems, photocomposites prepared by impregnation of the glass fibers with the resin were obtained upon irradiation with a LED emitting at $395 \mathrm{~nm}$, using a near-UV conveyor (belt speed of $2 \mathrm{~m} / \mathrm{min}$ ). Such photocomposites are characterized by remarkable mechanical properties due to the presence of fibers. These materials are also lightweight and exhibit good chemical and corrosion resistances.[216,217] While polymerizing a resin composed of $50 \%$ glass fibers $/ 50 \%$ resin w/w (TMPTA or BisGMA/TEGDMA blend), very few passes were required to polymerize thick samples of $2 \mathrm{~mm}$. Almost colorless photocomposites were also obtained (See Figure 13). 


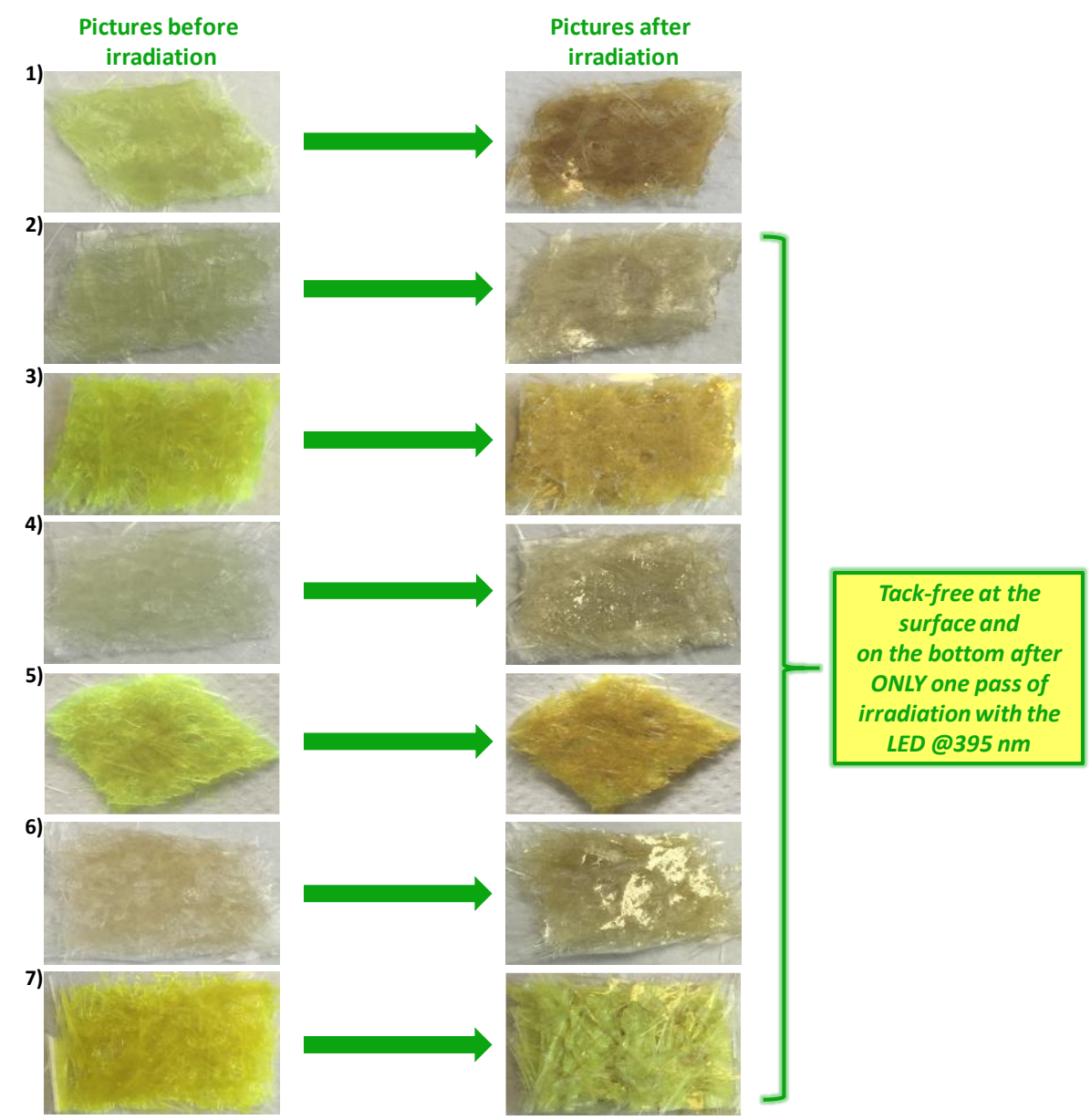

Figure 13. Photocomposites produced upon Near-UV light (LED@395 nm), Belt Speed = 2 $\mathrm{m} / \mathrm{min}$, using the free radical polymerization (FRP) in the presence of $50 \%$ glass fibers $/ 50 \%$ acrylate resin (thickness $=2 \mathrm{~mm}$ for one layer of glass fibers) for different systems in TMPTA: (1) $0.2 \%$ C21 + 1\% Iod; (2) $0.2 \%$ C23 + 1\% Iod + 1\% NPG; (3) $0.2 \%$ C $24+1 \%$ Iod $+1 \%$ NPG; (4) $0.2 \%$ C $26+1 \%$ Iod + 1\% NPG; (5) $0.2 \%$ C $28+1 \%$ Iod + 1\% NPG; (6) $0.2 \%$ C $29+1 \%$ Iod + 1\% NPG; and (7) $0.2 \%$ C $31+1 \%$ Iod $+1 \%$ NPG, respectively. Reprinted with permission from Abdallah et al. [208]

While getting a deeper insight into the photochemical mechanism, steady-state photolysis experiments done with C22 as a model compound revealed C22 to be photostable upon irradiation at $375 \mathrm{~nm}$ in an acetonitrile solution. Conversely, upon addition of the iodonium salt, a rapid decrease of the optical density at the absorption maximum could be detected, with the appearance of a new peak corresponding to a photoproduct (See Figure 14). 

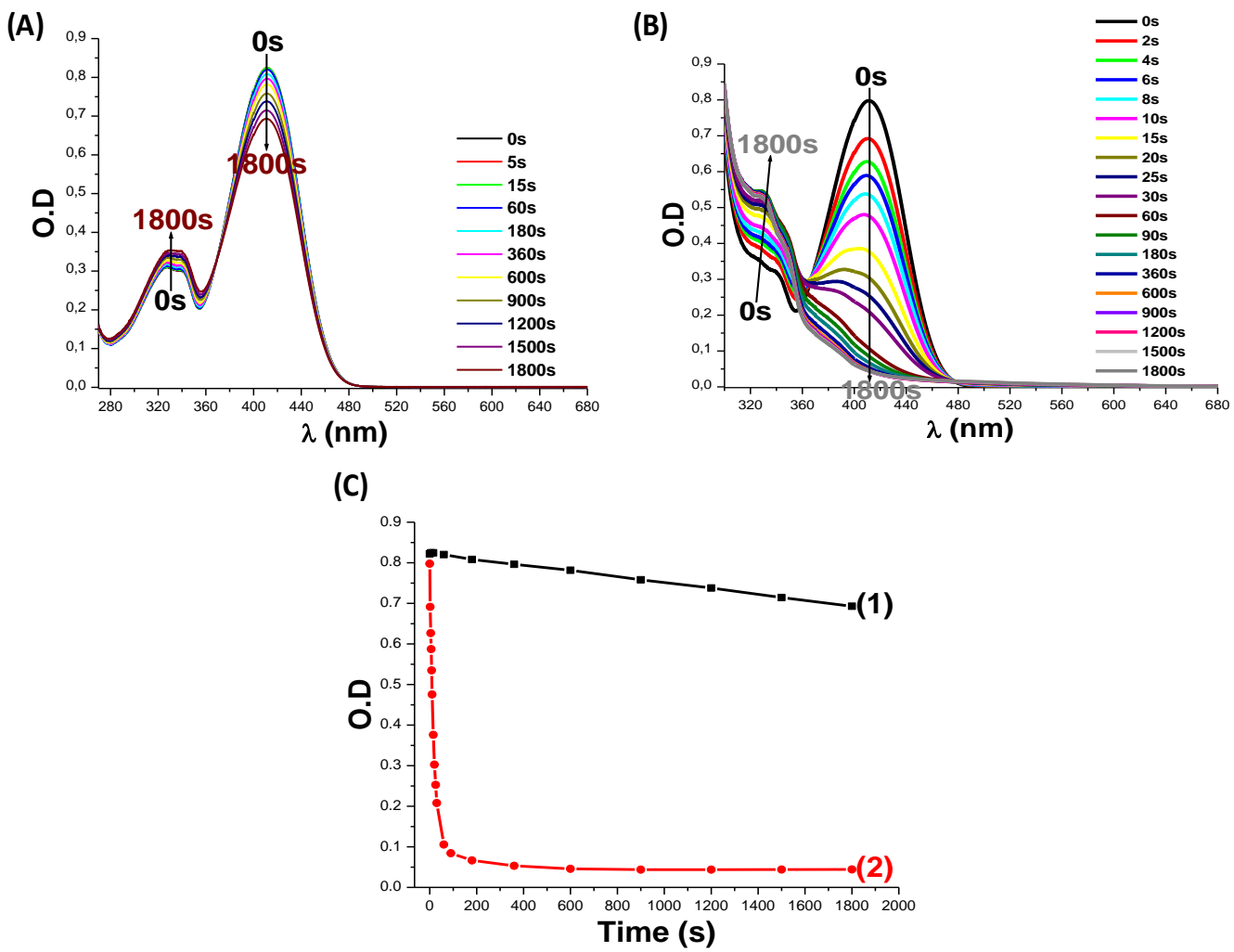

Figure 14. (A) Photolysis of C22 alone; (B) Photolysis of C22 in the presence of the iodonium salt; and (C) Photodegradation of C22 without (1) and with (2) Iodonium salt at different time of irradiation with the LED@375 $\mathrm{nm}$ in acetonitrile. Reprinted with permission from Abdallah et al. [208]

Fluorescence quenching experiments done in acetonitrile also revealed high fluorescence quenching constants for all dyes, consistent with favorable electron-transfer reactions of coumarins with Iod and NPG and the determination of negative free energy

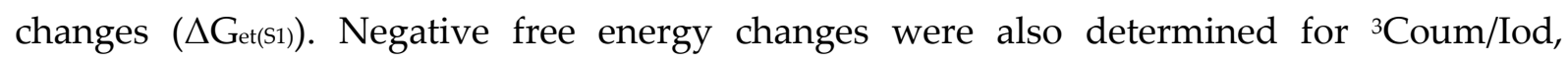
suggesting that, to some extent, the triplet state pathway can also participate to the polymerization process. Therefore, the following mechanism composed of eight reactions ( $r 1-$ r8) could be proposed.

$$
\begin{aligned}
& \text { Coumarin } \rightarrow{ }^{*} \text { Coumarin } \quad(\mathrm{h} v) \\
& { }^{*} \text { Coumarin }+\mathrm{Ar}_{2} \mathrm{I}^{+} \rightarrow \text { Coumarin }^{\bullet+}+\mathrm{Ar}_{2} \mathrm{I}^{\bullet} \rightarrow \text { Coumarin }^{\bullet+}+\mathrm{Ar}^{\bullet}+\mathrm{ArI} \\
& \mathrm{NPG}+\mathrm{Iod} \rightarrow[\mathrm{NPG-Iod}]_{\mathrm{CTC}} \\
& {[\mathrm{NPG}-\mathrm{Iod}]_{\mathrm{CTC}} \rightarrow \rightarrow \mathrm{Ar}^{\bullet} \quad(\mathrm{h} v)} \\
& { }^{*} \text { Coumarin }+\mathrm{NPG} \rightarrow(\mathrm{Coumarin}-\mathrm{H})^{\bullet}+\mathrm{NPG}_{(-\mathrm{H})}{ }^{\bullet} \\
& \mathrm{NPG}_{(-\mathrm{H})}{ }^{\bullet} \rightarrow \mathrm{NPG}_{(-\mathrm{H} ;-\mathrm{CO} 2)}{ }^{\bullet}+\mathrm{CO}_{2} \\
& \mathrm{NPG}_{(-\mathrm{H} ;-\mathrm{CO} 2)}{ }^{\bullet}+\mathrm{Ar}_{2} \mathrm{I}^{+} \rightarrow \mathrm{NPG}_{(-\mathrm{H} ;-\mathrm{CO} 2)}+\mathrm{Ar}^{\bullet}+\mathrm{ArI}
\end{aligned}
$$


Following this initial work, the same authors focused on a series of thirty-one nitrocoumarins in order to determine the impact of the substitution pattern on the photoreactivity of coumarins (See Figure 15).[218] Based on their photoinitiating abilities, three groups of nitrocoumarins could be identified. A scale of reactivity of nitrocoumarins could be established with regards to amines (EDB or NPG) during the FRP of (meta)acrylates. Indeed, contrarily to the previous coumarins that could efficiently react with the iodonium salt in photooxidative processes, nitrocoumarins proved to be poor candidates with the iodonium salt. From the absorption viewpoint, introduction of nitro groups onto coumarins resulted in a blue-shift of their absorption maxima, compared to the previous series in which electrondonating groups were introduced to reinforce the push-pull effects existing in these structures (See Table 5). Indeed, if molar extinction coefficients ranging between 6100 and $48000 \mathrm{M}^{-1} . \mathrm{cm}^{-}$ ${ }^{1}$ were respectively determined at $405 \mathrm{~nm}$ for CoumC 8 and CoumC3, these values were below $800 \mathrm{M}^{-1} \cdot \mathrm{cm}^{-1}$ for most of the 31 nitrocoumarins, except for Coum7, Coum8, Coum10, Coum11 and Coum20 for which molar extinction coefficients greater than $1000 \mathrm{M}^{-1} \cdot \mathrm{cm}^{-1}$ could be calculated at $405 \mathrm{~nm}$. 

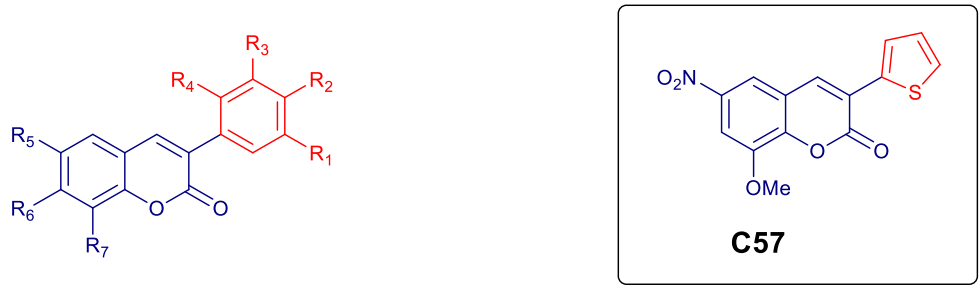

First series : very reactive nitrocoumarin derivatives

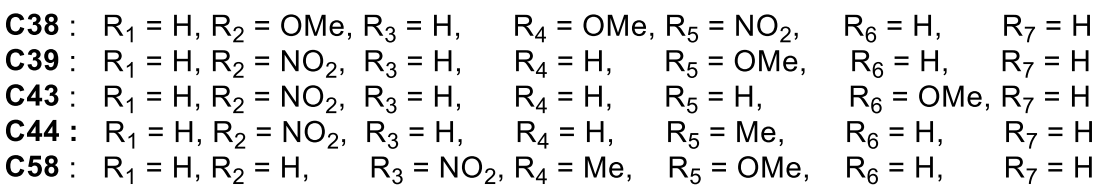

Second series: moderate reactive nitrocoumarin derivatives

\begin{tabular}{|c|c|c|c|c|c|c|c|}
\hline $\begin{array}{l}\text { C33 } \\
\text { C34 } \\
\text { C48 } \\
\text { C52 } \\
\text { C53 } \\
\text { C55 }\end{array}$ & $\begin{array}{l}\mathrm{R}_{1}=\mathrm{H}, \\
\mathrm{R}_{1}=\mathrm{H}, \\
\mathrm{R}_{1}=\mathrm{H}, \\
\mathrm{R}_{1}=\mathrm{H}, \\
\mathrm{R}_{1}=\mathrm{OMe} \\
\mathrm{R}_{1}=\mathrm{H}, \\
\mathrm{R}_{1}=\mathrm{H}, \\
\mathrm{R}_{1}=\mathrm{H},\end{array}$ & $\begin{array}{l}\mathrm{R}_{2}=\mathrm{OMe}, \\
\mathrm{R}_{2}=\mathrm{NO}_{2}, \\
\mathrm{R}_{2}=\mathrm{NO}_{2}, \\
\mathrm{R}_{2}=\mathrm{OMe}, \\
\mathrm{R}_{2}=\mathrm{H}, \\
\mathrm{R}_{2}=\mathrm{H}, \\
\mathrm{R}_{2}=\mathrm{Br}, \\
\mathrm{R}_{2}=\mathrm{H},\end{array}$ & $\begin{array}{l}\mathrm{R}_{3}=\mathrm{H}, \\
\mathrm{R}_{3}=\mathrm{H}, \\
\mathrm{R}_{3}=\mathrm{H}, \\
\mathrm{R}_{3}=\mathrm{OMe}, \\
\mathrm{R}_{3}=\mathrm{H}, \\
\mathrm{R}_{3}=\mathrm{NO}_{2}, \\
\mathrm{R}_{3}=\mathrm{H}, \\
\mathrm{R}_{3}=\mathrm{NO}_{2},\end{array}$ & $\begin{array}{l}\mathrm{R}_{4}=\mathrm{H}, \\
\mathrm{R}_{4}=\mathrm{H}, \\
\mathrm{R}_{4}=\mathrm{H}, \\
\mathrm{R}_{4}=\mathrm{H}, \\
\mathrm{R}_{4}=\mathrm{OMe}, \\
\mathrm{R}_{4}=\mathrm{Me}, \\
\mathrm{R}_{4}=\mathrm{H}, \\
\mathrm{R}_{4}=\mathrm{Me},\end{array}$ & $\begin{array}{l}\mathrm{R}_{5}=\mathrm{NO}_{2}, \\
\mathrm{R}_{5}=\mathrm{NO}_{2}, \\
\mathrm{R}_{5}=\mathrm{H}, \\
\mathrm{R}_{5}=\mathrm{NO}_{2}, \\
\mathrm{R}_{5}=\mathrm{NO}_{2}, \\
\mathrm{R}_{5}=\mathrm{NO}_{2}, \\
\mathrm{R}_{5}=\mathrm{NO}_{2}, \\
\mathrm{R}_{5}=\mathrm{NO}_{2},\end{array}$ & $\begin{array}{l}\mathrm{R}_{6}=\mathrm{H}, \\
\mathrm{R}_{6}=\mathrm{H}, \\
\mathrm{R}_{6}=\mathrm{H}, \\
\mathrm{R}_{6}=\mathrm{H}, \\
\mathrm{R}_{6}=\mathrm{H}, \\
\mathrm{R}_{6}=\mathrm{H}, \\
\mathrm{R}_{6}=\mathrm{H}, \\
\mathrm{R}_{6}=\mathrm{H},\end{array}$ & $\begin{array}{l}\mathrm{R}_{7}=\mathrm{OMe} \\
\mathrm{R}_{7}=\mathrm{OMe} \\
\mathrm{R}_{7}=\mathrm{OMe} \\
\mathrm{R}_{7}=\mathrm{H} \\
\mathrm{R}_{7}=\mathrm{H} \\
\mathrm{R}_{7}=\mathrm{H} \\
\mathrm{R}_{7}=\mathrm{OMe} \\
\mathrm{R}_{7}=\mathrm{OMe}\end{array}$ \\
\hline
\end{tabular}

Third series : low reactive nitrocoumarin derivatives

\begin{tabular}{|c|c|c|c|c|c|c|c|}
\hline $\begin{array}{l}\text { C35: } \\
\text { C36: } \\
\text { C37: } \\
\text { C40: } \\
\text { C41: } \\
\text { C42: } \\
\text { C45: } \\
\text { C46: } \\
\text { C47: } \\
\text { C49: } \\
\text { C50: } \\
\text { C51: } \\
\text { C54: } \\
\text { C56: } \\
\text { C61: } \\
\text { C62: } \\
\text { C63: }\end{array}$ & $\begin{array}{l}\mathrm{R}_{1}=\mathrm{H}, \\
\mathrm{R}_{1}=\mathrm{H}, \\
\mathrm{R}_{1}=\mathrm{H}, \\
\mathrm{R}_{1}=\mathrm{H}, \\
\mathrm{R}_{1}=\mathrm{NO}_{2}, \\
\mathrm{R}_{1}=\mathrm{H}, \\
\mathrm{R}_{1}=\mathrm{H}, \\
\mathrm{R}_{1}=\mathrm{H}, \\
\mathrm{R}_{1}=\mathrm{H}, \\
\mathrm{R}_{1}=\mathrm{H}, \\
\mathrm{R}_{1}=\mathrm{OMe}, \\
\mathrm{R}_{1}=\mathrm{H}, \\
\mathrm{R}_{1}=\mathrm{H}, \\
\mathrm{R}_{1}=\mathrm{H}, \\
\mathrm{R}_{1}=\mathrm{H}, \\
\mathrm{R}_{1}=\mathrm{H}, \\
\mathrm{R}_{1}=\mathrm{H},\end{array}$ & $\begin{array}{l}\mathrm{R}_{2}=\mathrm{NO}_{2}, \\
\mathrm{R}_{2}=\mathrm{NO}_{2}, \\
\mathrm{R}_{2}=\mathrm{NO}_{2}, \\
\mathrm{R}_{2}=\mathrm{NO}_{2}, \\
\mathrm{R}_{2}=\mathrm{OH}, \\
\mathrm{R}_{2}=\mathrm{NO}_{2}, \\
\mathrm{R}_{2}=\mathrm{NO}_{2}, \\
\mathrm{R}_{2}=\mathrm{NO}_{2}, \\
\mathrm{R}_{2}=\mathrm{NO}_{2}, \\
\mathrm{R}_{2}=\mathrm{NO}_{2}, \\
\mathrm{R}_{2}=\mathrm{H}, \\
\mathrm{R}_{2}=\mathrm{H}, \\
\mathrm{R}_{2}=\mathrm{H}, \\
\mathrm{R}_{2}=\mathrm{H}, \\
\mathrm{R}_{2}=\mathrm{H}, \\
\mathrm{R}_{2}=\mathrm{H}, \\
\mathrm{R}_{2}=\mathrm{H},\end{array}$ & $\begin{array}{l}\mathrm{R}_{3}=\mathrm{H}, \\
\mathrm{R}_{3}=\mathrm{H}, \\
\mathrm{R}_{3}=\mathrm{H}, \\
\mathrm{R}_{3}=\mathrm{H}, \\
\mathrm{R}_{3}=\mathrm{NO}_{2}, \\
\mathrm{R}_{3}=\mathrm{OH}, \\
\mathrm{R}_{3}=\mathrm{H}, \\
\mathrm{R}_{3}=\mathrm{H}, \\
\mathrm{R}_{3}=\mathrm{H}, \\
\mathrm{R}_{3}=\mathrm{H}, \\
\mathrm{R}_{3}=\mathrm{H}, \\
\mathrm{R}_{3}=\mathrm{NO}_{2}, \\
\mathrm{R}_{3}=\mathrm{NO}_{2}, \\
\mathrm{R}_{3}=\mathrm{NO}_{2}, \\
\mathrm{R}_{3}=\mathrm{NO}_{2}, \\
\mathrm{R}_{3}=\mathrm{NO}_{2}, \\
\mathrm{R}_{3}=\mathrm{NO}_{2},\end{array}$ & $\begin{array}{l}\mathrm{R}_{4}=\mathrm{NO}_{2}, \\
\mathrm{R}_{4}=\mathrm{NO}_{2}, \\
\mathrm{R}_{4}=\mathrm{NO}_{2}, \\
\mathrm{R}_{4}=\mathrm{NO}_{2}, \\
\mathrm{R}_{4}=\mathrm{H}, \\
\mathrm{R}_{4}=\mathrm{NO}_{2}, \\
\mathrm{R}_{4}=\mathrm{NO}_{2}, \\
\mathrm{R}_{4}=\mathrm{NO}_{2}, \\
\mathrm{R}_{4}=\mathrm{NO}_{2}, \\
\mathrm{R}_{4}=\mathrm{NO}_{2}, \\
\mathrm{R}_{4}=\mathrm{OMe}, \\
\mathrm{R}_{4}=\mathrm{Me}, \\
\mathrm{R}_{4}=\mathrm{Me}, \\
\mathrm{R}_{4}=\mathrm{Me}, \\
\mathrm{R}_{4}=\mathrm{Me}, \\
\mathrm{R}_{4}=\mathrm{Me}, \\
\mathrm{R}_{4}=\mathrm{Me},\end{array}$ & $\begin{array}{l}\mathrm{R}_{5}=\mathrm{H}, \\
\mathrm{R}_{5}=\mathrm{H}, \\
\mathrm{R}_{5}=\mathrm{H}, \\
\mathrm{R}_{5}=\mathrm{H}, \\
\mathrm{R}_{5}=\mathrm{H}, \\
\mathrm{R}_{5}=\mathrm{OMe}, \\
\mathrm{R}_{5}=\mathrm{Me}, \\
\mathrm{R}_{5}=\mathrm{NO}_{2}, \\
\mathrm{R}_{5}=\mathrm{H}, \\
\mathrm{R}_{5}=\mathrm{NO}_{2}, \\
\mathrm{R}_{5}=\mathrm{OMe}, \\
\mathrm{R}_{5}=\mathrm{H}, \\
\mathrm{R}_{5}=\mathrm{H}, \\
\mathrm{R}_{5}=\mathrm{H}, \\
\mathrm{R}_{5}=\mathrm{H}, \\
\mathrm{R}_{5}=\mathrm{H}, \\
\mathrm{R}_{5}=\mathrm{Me},\end{array}$ & $\begin{array}{l}\mathrm{R}_{6}=\mathrm{H}, \\
\mathrm{R}_{6}=\mathrm{OH}, \\
\mathrm{R}_{6}=\mathrm{H}, \\
\mathrm{R}_{6}=\mathrm{OMe}, \\
\mathrm{R}_{6}=\mathrm{H}, \\
\mathrm{R}_{6}=\mathrm{H}, \\
\mathrm{R}_{6}=\mathrm{H}, \\
\mathrm{R}_{6}=\mathrm{H}, \\
\mathrm{R}_{6}=\mathrm{H}, \\
\mathrm{R}_{6}=\mathrm{H}, \\
\mathrm{R}_{6}=\mathrm{H}, \\
\mathrm{R}_{6}=\mathrm{H}, \\
\mathrm{R}_{6}=\mathrm{CH}{ }_{3} \mathrm{COO}, \\
\mathrm{R}_{6}=\mathrm{OMe}, \\
\mathrm{R}_{6}=\mathrm{H}, \\
\mathrm{R}_{6}=\mathrm{H}, \\
\mathrm{R}_{6}=\mathrm{H},\end{array}$ & $\begin{array}{l}\mathrm{R}_{7}=\mathrm{OEt} \\
\mathrm{R}_{7}=\mathrm{H} \\
\mathrm{R}_{7}=\mathrm{H} \\
\mathrm{R}_{7}=\mathrm{H} \\
\mathrm{R}_{7}=\mathrm{OEt} \\
\mathrm{R}_{7}=\mathrm{H} \\
\mathrm{R}_{7}=\mathrm{H} \\
\mathrm{R}_{7}=\mathrm{OMe} \\
\mathrm{R}_{7}=\mathrm{OMe} \\
\mathrm{R}_{7}=\mathrm{H} \\
\mathrm{R}_{7}=\mathrm{OMe} \\
\mathrm{R}_{7}=\mathrm{H} \\
\mathrm{R}_{7}=\mathrm{H} \\
\mathrm{R}_{7}=\mathrm{H} \\
\mathrm{R}_{7}=\mathrm{OMe} \\
\mathrm{R}_{7}=\mathrm{OEt} \\
\mathrm{R}_{7}=\mathrm{H}\end{array}$ \\
\hline
\end{tabular}

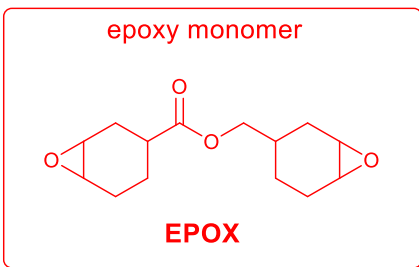

Figure 12. Chemical structures of the 31 nitrocoumarins C38-C63 examined as photoinitiators and the epoxy monomer EPOX. 
Table 5. Parameters characterizing the light absorption properties of all the involved nitrocoumarin derivatives: maximum absorption wavelengths $\left(\lambda_{\max }\right)$, extinction coefficients at $\lambda_{\max }\left(\varepsilon_{\max }\right)$ and extinction coefficients at the emission wavelength of the LED @405 nm ( $\left.\varepsilon_{₫ 405 \mathrm{~nm}}\right)$.

\begin{tabular}{|c|c|c|c|c|}
\hline & PI & $\begin{array}{l}\lambda_{\max } \\
\text { (nm) }\end{array}$ & $\begin{array}{c}\varepsilon_{\max } \\
\left(\mathbf{M}^{-1} \cdot \mathbf{c m}^{-1}\right)\end{array}$ & $\begin{array}{c}\mathcal{E} 405 \mathrm{~nm} \\
\left(\mathrm{M}^{-1} \cdot \mathrm{cm}^{-1}\right)\end{array}$ \\
\hline \multirow{5}{*}{$\begin{array}{l}\text { First Series: } \\
\text { Very reactive } \\
\text { Nitrocoumarins }\end{array}$} & C38 & 340 & 3220 & 460 \\
\hline & C39 & 310 & 15170 & 2400 \\
\hline & C43 & 360 & 17980 & 3650 \\
\hline & C44 & 340 & 11930 & 320 \\
\hline & C58 & 280 & 16410 & 140 \\
\hline \multirow{9}{*}{$\begin{array}{l}\text { Second Series: } \\
\text { Moderate } \\
\text { reactive } \\
\text { Nitrocoumarins }\end{array}$} & C33 & 330 & 15990 & 170 \\
\hline & C34 & 320 & 26910 & 360 \\
\hline & C48 & 330 & 10940 & 350 \\
\hline & C52 & 350 & 14400 & 1710 \\
\hline & C53 & 330 & 4650 & 560 \\
\hline & C55 & 320 & 10100 & 150 \\
\hline & C57 & 350 & 15190 & 770 \\
\hline & C59 & 310 & 25490 & 220 \\
\hline & C60 & 280 & 19150 & 340 \\
\hline \multirow{12}{*}{$\begin{array}{l}\text { Third Series: } \\
\text { low-reactive } \\
\text { Nitrocoumarins }\end{array}$} & C35 & 310 & 11890 & 280 \\
\hline & C36 & 330 & 7940 & 270 \\
\hline & C37 & 330 & 9670 & 280 \\
\hline & C40 & 360 & 8990 & 2600 \\
\hline & C41 & 320 & 19560 & 120 \\
\hline & $\mathrm{C} 42$ & 290 & 10860 & 1650 \\
\hline & C45 & 290 & 13200 & 420 \\
\hline & C46 & 290 & 15020 & 280 \\
\hline & C47 & 310 & 13210 & 390 \\
\hline & C49 & 330 & 1530 & 150 \\
\hline & C50 & 280 & 27320 & 360 \\
\hline & C51 & 280 & 16370 & 90 \\
\hline
\end{tabular}




\begin{tabular}{|c|c|c|c|c|}
\hline $\mathbf{C}$ & C54 & 290 & 15450 & 90 \\
\cline { 2 - 5 } & C56 & 330 & 18660 & 170 \\
\cline { 2 - 5 } & C61 & 300 & 18030 & 310 \\
\cline { 2 - 5 } & C62 & 300 & 770 & 10 \\
\cline { 2 - 5 } & C63 & 280 & 680 & 5 \\
\hline
\end{tabular}

When tested as photoinitiators for the cationic polymerization of $(3,4-$ epoxycyclohexane)methyl 3,4-epoxycyclohexylcarboxylate (EPOX), only C39, C43 and C58 could initiate a polymerization in two-component Coum/Iod $(0.5 \% / 1 \% \mathrm{w} / \mathrm{w})$ photoinitiating systems upon irradiation of thin films with the LED @ $405 \mathrm{~nm}$ under air (See Figure 16 and Table 6). For the other dyes, no polymerization was detected, assigned to a lower reactivity of the generated radical cation (Coum ${ }^{\bullet+}$ ) but also to a lower rate constant of interaction of these coumarins with the iodonium salt.

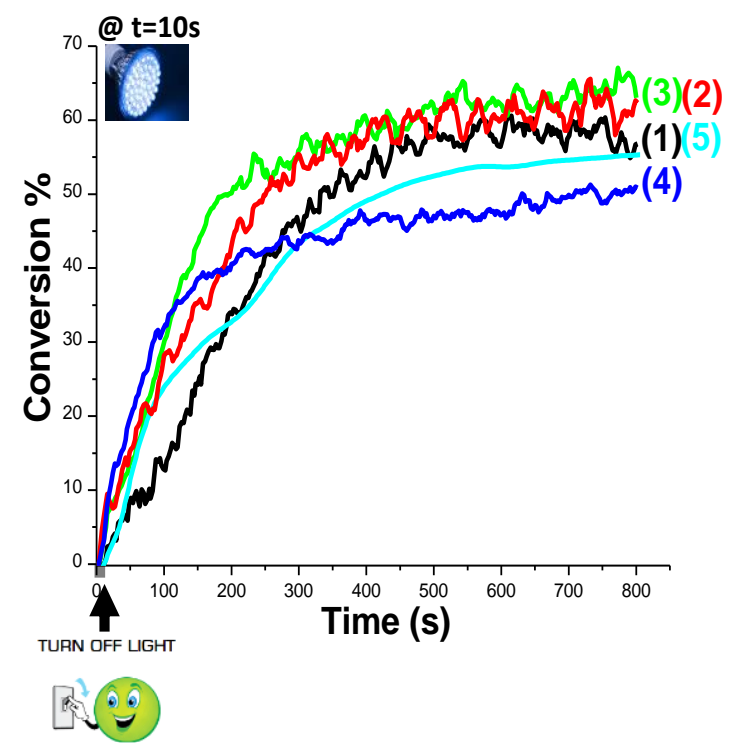

Figure 16. Polymerization profiles (epoxy function conversion vs. irradiation time) for EPOX under air (thickness = $25 \mu \mathrm{m}$ ) upon irradiation with the LED@405 nm, in the presence of different two-component photoinitiating systems: (1): C39/Iod (0.2\%/1\% w/w); (2): C39/Iod (0.5\%/1\% w/w); (3): C43/Iod (0.2\%/1\% w/w) ; (4): C43/Iod (0.5\%/1\% w/w) ; and (5): C58/Iod $(0.5 \% / 1 \% \mathrm{w} / \mathrm{w})$. The irradiation starts for $\mathrm{t}=10 \mathrm{~s}$. Reprinted with permission from Abdallah et al.[218] 
Table 6. Final Reactive Epoxy Function Conversion (FC) for EPOX using Different Twocomponent PISs after 800s of Irradiation with the LED @405 nm.

\begin{tabular}{|c|c|c|}
\hline \multicolumn{3}{|c|}{$\%$ epoxy function conversion $(\mathrm{FC})(\mathrm{at} \mathrm{t}=\mathbf{8 0 0} \mathrm{s})$} \\
\hline \multicolumn{3}{|c|}{ Coum/Iod (thickness $=25 \mu \mathrm{m})$ under air } \\
\hline C39/Iod & C43/Iod & C58/Iod \\
\hline $58 \%^{\mathrm{a}}$ & $64 \%^{\mathrm{a}}$ & $55 \%^{\mathrm{b}}$ \\
$63 \%^{\mathrm{b}}$ & $51 \%^{\mathrm{b}}$ & \\
\hline
\end{tabular}

a: Coum/Iod: (0.2\%/1\% w/w); b: Coum/Iod: $(0.5 \% / 1 \%$ w/w)

When tested as photoinitiators of polymerization for the FRP of TMPTA, three groups of coumarins could be identified, depending on their reactivities. Thus, C38, C39, C43, C44 and C58 proved to be highly reactive in terms of final monomer conversions and rates of polymerization upon irradiation at $405 \mathrm{~nm}$ of thin TMPTA films. In photoreductive processes, C43 clearly outperformed the other dyes, and this superiority was assigned to its higher molar extinction coefficient at $405 \mathrm{~nm}$. Notably a TMPTA conversion of 43 and $46 \%$ were respectively obtained using NPG and EDB as the bases. Conversely, in photooxidative processes using the iodonium salt, C44 proved to be the most reactive dye, providing a TMPTA conversion of 39\% after $100 \mathrm{~s}$ of irradiation (See Table 7). A slightly lower monomer conversion was obtained with C43 (27\%) and no polymerization was obtained with the other dyes. Finally, when tested in three component Coum/Iod/NPG $(0.2 \% / 1 \% / 1 \% \mathrm{w} / \mathrm{w})$ photoinitiating systems, the best conversions were obtained with $\mathrm{C} 43$ and C44, peaking respectively at 54 and 50\% monomer conversions. In thick films and upon irradiation at $405 \mathrm{~nm}$ under air, high monomer conversions could be obtained, irrespective of the photoinitiating systems (using the Coum/Iod, Coum/NPG, Coum/Iod/NPG, or Coum/EDB combinations). Globally, compared to the monomer conversions obtained in thin films and in laminates, an improvement of ca $30 \%$ was typically observed in thick films under air. Interestingly, if no conversion was obtained with the Coum/Iod combinations in thin films, conversely, high monomer conversions could be obtained in thick films, demonstrating that all photoinitiating systems have to be examined both in thin and thick films. A second set of nitrocoumarins, namely C33, C34, C48, C52, C53, C55, C57, C59 and C60 showed lower monomer conversions that that obtained in the same conditions than with the first series. Reduction of the monomer conversions was assigned both to reduced molar extinction coefficients at $405 \mathrm{~nm}$ compared to the previous series but also to coumarins exhibiting a lower solubility in resins, adversely affecting the polymerization efficiency. Significant differences of reactivities were also evidenced in thin films between the two two-component Coum/NPG and Coum/EDB photoinitiating systems, resulting from variations of the electron-transfer quantum yields of coumarins with NPG and EDB. In this case, higher monomer conversions were obtained NPG than with EDB. Here again, no monomer conversion was detected with the Coum/Iod combination, except for C48 for which a monomer conversion of $36 \%$ could be determined. In thick films and as observed for the first 
set of nitrocoumarins, higher monomer conversions were obtained in thick films than in thin films due to reduced oxygen inhibition effects. However, due to inner filter effects, the order of reactivity was different from that observed in thin films and the following order of reactivity could be determined for the Coum/NPG combination: C33 > C57 > C34 > C48 > C53 > C60 > C59 > C55 > C52 and for the Coum/EDB combination: C $33>$ C $34>$ C57 > C53 > C48 > C55 > C52 > C60 > C59. Finally, in this series of 31 coumarins, C35, C36, C37, C40, C41, C42, C45, C46, C47, C49, C50, C51, C54, C56, C61, C62 and C63 showed a low efficiency, irrespective of the photoinitiating systems used. Notably, low monomer conversions were obtained with the three two-component Coum/Iod, Coum/NPG and Coum/EDB photoinitiating systems. Three different points were highlighted by the authors to support their low efficiency : 1) their low molar extinction coefficients at $405 \mathrm{~nm}$ for C51, C54, C62 and C63; 2) the low solubility of several coumarins such as C50, C51, C54, C56, C61 and C63. Notably, their low solubilities is supported by the NMR analyses which have been done in DMSO- $\mathrm{d}_{6}$ for these different dyes due to their low solubility in deuterated chloroform $\left.\left(\mathrm{CDCl}_{3}\right) ; 3\right)$ their low initiation yields that are not sufficient to overcome the oxygen inhibition. While preparing photocomposites with glass fibers in the same conditions than that used for the C33-C45 series, only one pass of LED conveyor was required to fully cure both the surface and the bottom of 2-mm thick samples, contrarily to several passes for the C33-C45 series. However, if three distinct families of nitrocoumarins could be identified, no structure/performance relationship could be established with regards of their reactivities, each family being composed of dyes significantly differing in terms of substitution.

Table 7. Final reactive acrylate function conversion (FC) for TMPTA in the presence of different two $(0.2 \% / 1 \% \mathrm{w} / \mathrm{w})$ and three-component $(0.2 \% / 1 \% / 1 \% \mathrm{w} / \mathrm{w})$ PISs (first and second series of nitrocoumarins) after $100 \mathrm{~s}$ of irradiation with the LED @405 nm.

\begin{tabular}{|c|c|c|c|c|c|c|c|c|c|}
\hline & & \multicolumn{4}{|c|}{ Thin sample $(25 \mu \mathrm{m})$ in laminate } & \multicolumn{4}{|c|}{ Thick sample $(1.4 \mathrm{~mm})$ under air } \\
\hline & & \multicolumn{3}{|c|}{ Two-component PIS } & \multirow{2}{*}{$\begin{array}{c}\text { Three } \\
\text { component } \\
\text { PIS }\end{array}$} & \multicolumn{3}{|c|}{ Two-component PIS } & \multirow{2}{*}{$\begin{array}{c}\begin{array}{c}\text { Three } \\
\text { component } \\
\text { PIS }\end{array} \\
\text { +lod/NPG }\end{array}$} \\
\hline & & + lod & +NPG & +EDB & & + lod & +NPG & +EDB & \\
\hline \multirow{5}{*}{$\begin{array}{l}\text { First Series: } \\
\text { Very reactive } \\
\text { Nitrocoumarins }\end{array}$} & C38 & n.p. & $36 \%$ & $39 \%$ & $45 \%$ & $59 \%$ & $72 \%$ & $73 \%$ & $85 \%$ \\
\hline & C39 & n.p. & $34 \%$ & $31 \%$ & $46 \%$ & $50 \%$ & $72 \%$ & $73 \%$ & $87 \%$ \\
\hline & C43 & $27 \%$ & $43 \%$ & $46 \%$ & $54 \%$ & $64 \%$ & $72 \%$ & $72 \%$ & $84 \%$ \\
\hline & C44 & $39 \%$ & $42 \%$ & $41 \%$ & $50 \%$ & $72 \%$ & $72 \%$ & $75 \%$ & $84 \%$ \\
\hline & C58 & n.p. & $33 \%$ & $34 \%$ & $40 \%$ & n.p. & $67 \%$ & $58 \%$ & $79 \%$ \\
\hline Second Series: & C33 & n.p. & $32 \%$ & $31 \%$ & $44 \%$ & n.p. & $72 \%$ & $73 \%$ & $82 \%$ \\
\hline
\end{tabular}




\begin{tabular}{|c|c|c|c|c|c|c|c|c|c|}
\hline \multirow{8}{*}{$\begin{array}{c}\text { Moderately } \\
\text { reactive } \\
\text { Nitrocoumarins }\end{array}$} & C34 & n.p. & $42 \%$ & $33 \%$ & $41 \%$ & $22 \%$ & $64 \%$ & $63 \%$ & $80 \%$ \\
\hline & C48 & $36 \%$ & $38 \%$ & $33 \%$ & $47 \%$ & $59 \%$ & $70 \%$ & $66 \%$ & $82 \%$ \\
\hline & C52 & n.p. & $29 \%$ & $22 \%$ & $36 \%$ & n.p. & $64 \%$ & $66 \%$ & $81 \%$ \\
\hline & C53 & n.p. & $42 \%$ & $42 \%$ & $47 \%$ & n.p. & $60 \%$ & $59 \%$ & $84 \%$ \\
\hline & C55 & n.p. & $18 \%$ & $26 \%$ & $33 \%$ & n.p. & $54 \%$ & $53 \%$ & $74 \%$ \\
\hline & C57 & n.p. & $32 \%$ & $30 \%$ & $45 \%$ & $38 \%$ & $71 \%$ & $69 \%$ & $83 \%$ \\
\hline & C59 & n.p. & $19 \%$ & $22 \%$ & $35 \%$ & n.p. & $63 \%$ & $59 \%$ & $81 \%$ \\
\hline & C60 & n.p. & $25 \%$ & $24 \%$ & $39 \%$ & n.p. & $57 \%$ & $50 \%$ & $77 \%$ \\
\hline
\end{tabular}

n.p.: no polymerization

If no clear trend could be established by comparing nitrocoumarins of various substitution, superiority of nitrocoumarins over methoxybenzene-based coumarins and ethoxycoumarins, thiophene-based coumarins or alkyne-based coumarins during the FRP of TMPTA could be demonstrated by comparing the reactivity of a series 19 structures (See Figure 17).[219]

First family Nitrocoumarins

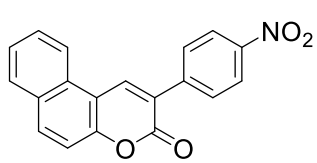

C64

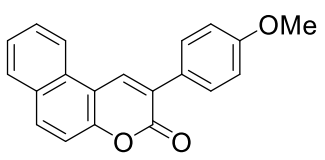

C72

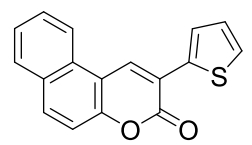

C78

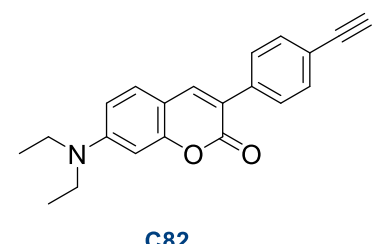

$\mathrm{C} 82$<smiles>[2H]c1cc2cc(-c3ccc(I)cc3)c(=O)oc2c([2H])c1C</smiles>

C65-C69

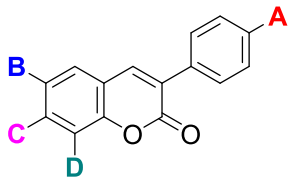

C70,C71,C73-C75

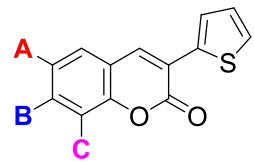

$\mathrm{C} 76, \mathrm{C} 77, \mathrm{C} 79-\mathrm{C} 82$

C65: $\mathrm{A}=\mathrm{NO}_{2}, \mathrm{~B}=\mathrm{H}, \mathrm{C}=\mathrm{H}, \mathrm{D}=\mathrm{OE}$ C66: $A=\mathrm{NO}_{2}, \mathrm{~B}=\mathrm{H}, \mathrm{C}=\mathrm{OH}, \mathrm{D}=\mathrm{H}$ C67: $A=\mathrm{NO}_{2}, \mathrm{~B}=\mathrm{NO}_{2}, \mathrm{C}=\mathrm{H}, \mathrm{D}=\mathrm{H}$ C68: $A=\mathrm{NO}_{2}, B=\mathrm{H}, \mathrm{C}=\mathrm{H}, \mathrm{D}=\mathrm{H}$ C69: $A=\mathrm{Br}, \mathrm{B}=\mathrm{NO}_{2}, \mathrm{C}=\mathrm{H}, \mathrm{D}=\mathrm{H}$

C70 : $A=O M e, B=H, C=H, D=O E t$ C71: $A=O M e, B=H, C=H, D=H$ C73: $A=O M e, B=N_{2}, C=H, D=H$ C74: $A=O M e, B=H, C=O H, D=H$ C75: $A=B r, B=H, C=H, D=O E t$

C76: $A=H, B=H, C=O E t$ C77: $A=\mathrm{CH}_{3}, \mathrm{~B}=\mathrm{H}, \mathrm{C}=\mathrm{H}$ C79: $A=H, B=H, C=H$ C80: $A=H, B=O H, C=H$ C81: $A=\mathrm{NO}_{2}, \mathrm{~B}=\mathrm{H}, \mathrm{C}=\mathrm{H}$

Figure 17. Chemical structures of C64-C82.

Once again, at $405 \mathrm{~nm}$, molar extinction coefficients of 64-82 were low, ranging between $135 \mathrm{M}^{-1} \cdot \mathrm{cm}^{-1}$ for $\mathrm{C} 74$ to 7710 and $9750 \mathrm{M}^{-1} \cdot \mathrm{cm}^{-1}$ for C78 and C64 respectively (See Table 8). 
Table 8. Parameters highlighting the light absorption properties of the coumarins: maximum absorption wavelengths $\lambda_{\max }$, extinction coefficients for $\lambda_{\max }$ and extinction coefficients at 405 $\mathrm{nm}$.

\begin{tabular}{|c|c|c|c|c|}
\hline & PI & $\begin{array}{l}\lambda_{\max } \\
(\mathbf{n m})\end{array}$ & $\begin{array}{c}\varepsilon_{\max } \\
\left(\mathrm{M}^{-1} \cdot \mathrm{cm}^{-1}\right)\end{array}$ & $\begin{array}{c}\mathcal{E}^{\Theta 405 \mathrm{~nm}} \\
\left(\mathrm{M}^{-1} \cdot \mathrm{cm}^{-1}\right)\end{array}$ \\
\hline \multirow{6}{*}{$\begin{array}{l}\text { First Family: } \\
\text { Nitrocoumarins }\end{array}$} & C64 & 376 & 17820 & 9750 \\
\hline & C65 & 329 & 13110 & 230 \\
\hline & C66 & 339 & 11760 & 330 \\
\hline & C67 & 325 & 13940 & 320 \\
\hline & C68 & 336 & 16410 & 300 \\
\hline & C69 & 317 & 10950 & 145 \\
\hline \multirow{6}{*}{$\begin{array}{l}\text { Second Family: } \\
\text { Methoxybenzene- } \\
\text { based coumarins } \\
\text { and } \\
\text { Ethoxycoumarin }\end{array}$} & C70 & 327 & 11620 & 190 \\
\hline & C71 & 333 & 10280 & 160 \\
\hline & C72 & 366 & 10110 & 1920 \\
\hline & C73 & 338 & 8790 & 200 \\
\hline & C74 & 335 & 7130 & 135 \\
\hline & C75 & 313 & 13760 & 260 \\
\hline \multirow{6}{*}{$\begin{array}{l}\text { Third Family: } \\
\text { Thiophene-based } \\
\text { coumarins }\end{array}$} & C76 & 350 & 8430 & 330 \\
\hline & C77 & 357 & 9210 & 530 \\
\hline & C78 & 386 & 10280 & 7710 \\
\hline & C79 & 353 & 8995 & 345 \\
\hline & $\mathrm{C} 80$ & 356 & 8695 & 560 \\
\hline & C81 & 356 & 15210 & 940 \\
\hline $\begin{array}{l}\text { Fourth Family: } \\
\text { Alkyne-based } \\
\text { coumarin }\end{array}$ & C82 & 409 & 2560 & 2530 \\
\hline
\end{tabular}

Thus, during the cationic polymerization of EPOX, only six coumarins could initiate a polymerization process, namely C64, C72, C77, C78, C79 and C80. Most of these dyes comprise the thiophene motif. Markedly, the order of reactivity of coumarins was different from that of their molar extinction coefficients at $405 \mathrm{~nm}$. Thus, as shown in the Table 9, a decreasing reactivity could be determined from C77 $>$ C64 >> C82 >> C80 >>C78 > C72 > C79 whereas the molar extinction coefficients followed another trend: C64 >> C78 >> C82 >> C72 >> C80 
> C77 >> C79. Photochemical reactivity of coumarins with the iodonium salt but also their abilities to form radical cations $\left(\mathrm{Coum}^{\bullet+}\right)$ explain these differences. Notably, thiophene-based coumarins can facilely form a radical cation due to the presence of the electroactive thiophene moiety which is well-known to oxidize at low oxidation potential.[220 223]

Table 9. Final reactive epoxy function conversion (FC) for EPOX, in the presence of different two-component photoinitiating systems after 800s of irradiation with the LED @405 nm.

\begin{tabular}{|c|c|c|c|c|c|c|}
\hline \multicolumn{7}{|c|}{ Coum/Iod (0.2\%/1\% w/w); (thickness = 25 $\mu \mathrm{m})$ under air } \\
\hline C82/Iod & C77/Iod & C78/Iod & C79/Iod & C80/Iod & C72/Iod & C64/ Iod \\
\hline $50 \%$ & $54 \%$ & $32 \%$ & $23 \%$ & $38 \%$ & $30 \%$ & $58 \%$ \\
\hline
\end{tabular}

Conversely, during the FRP of TMPTA, nitrocoumarins C64-C69 clearly outperformed the other coumarins using the Coumarin/Iod, Coumarin/NPG, Coumarin/Iod/NPG or Coumarin/EDB couples. In this series of nitrocoumarins, C65 showed the best photoinitiating ability in thin films, peaking at 43,40 and $41 \%$ conversions with the two-component Coumarin/Iod, Coumarin/NPG and Coumarin/EDB combinations after $100 \mathrm{~s}$ of irradiation at $405 \mathrm{~nm}$. In fact, C65 proved to be as efficient in photo-oxidative processes than in photoreduction and this superiority was confirmed during the polymerization of thick films. Using the three-component Coumarin/Iod/NPG $(0.2 \% / 1 \% / 1 \% \mathrm{w} / \mathrm{w})$ photoinitiating system, a final TMPTA conversion as high as $83 \%$ could be obtained. Noticeably, in two-component photoinitiating systems, use of NPG instead of EDB greatly improved the monomer conversion. While testing the methoxybenzene-based coumarins and ethoxycoumarins, the thiophene-based coumarins or the alkyne-based coumarins, no monomer conversions were observed with the different two-component photoinitiating systems. Only the threecomponent Coumarin/Iod/NPG $(0.2 \% / 1 \% / 1 \% \mathrm{w} / \mathrm{w})$ photoinitiating system could initiate a polymerization. Compared to the nitrocoumarins series, if lower monomer conversions were obtained in thin films, lowered by ca $10 \%$, conversely, in thick films, the four aforementioned series could compete with the nitrocoumarin-based photoinitiating systems (See Table 10). 
Table 10. Final reactive acrylate function conversion (FC) for TMPTA, in the presence of different two $(0.2 \% / 1 \% \mathrm{w} / \mathrm{w})$ and three-component $(0.2 \% / 1 \% / 1 \% \mathrm{w} / \mathrm{w})$ photoinitiating systems after $100 \mathrm{~s}$ of irradiation with LED@405 nm.

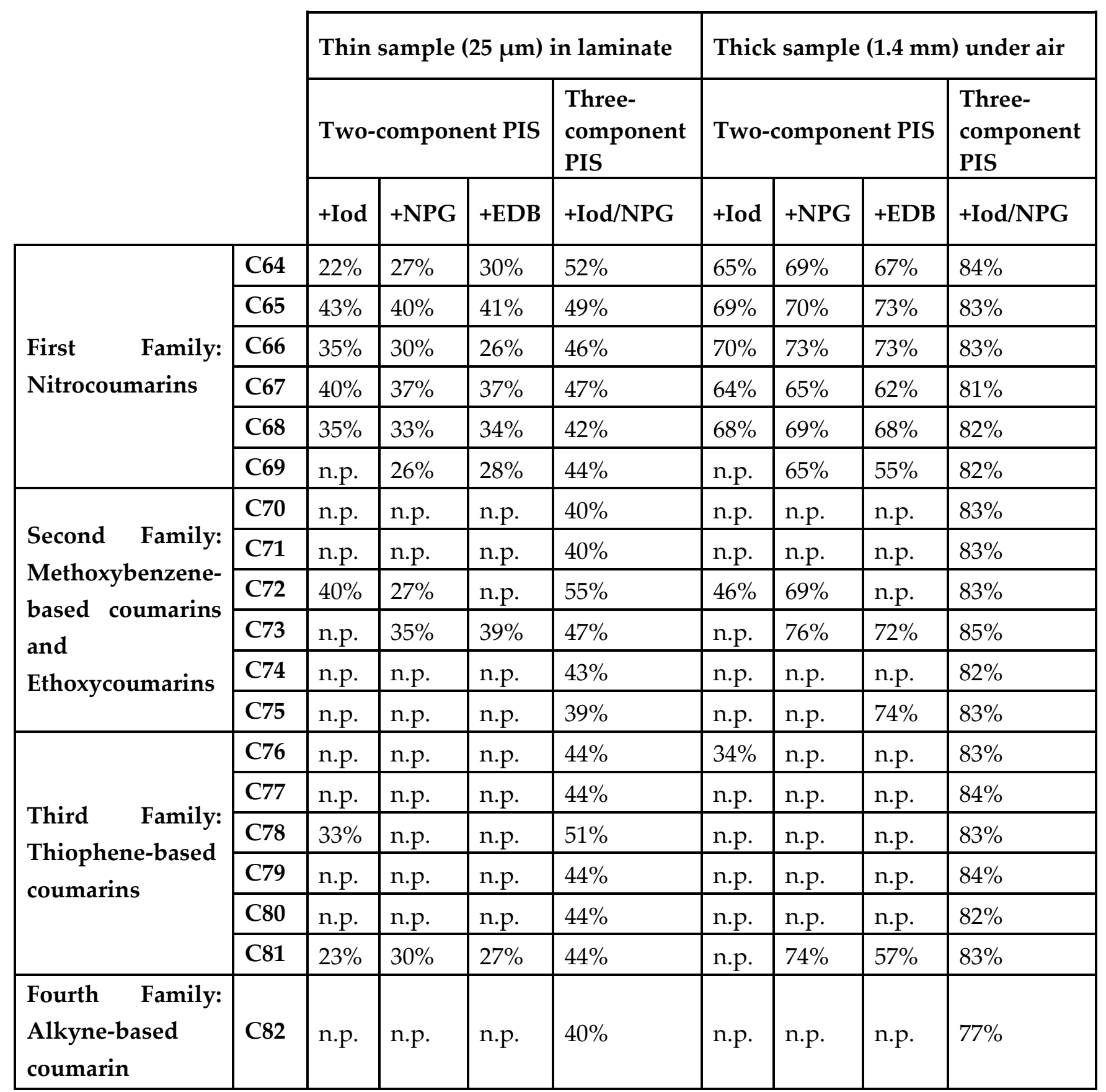

n.p.: no polymerization

Investigation of the photoinitiating ability of coumarins was not limited to monofunctional coumarins and one example of difunctional coumarin C85 was tested and the results compared with that obtained with C83 and C84 (See Figure 18).[116] Interest of C85 relies in its high molecular weight, addressing the migratability issue of photoinitiators within the resulting polymers.[224,225] From the absorption viewpoint, C83-C85 exhibited similar absorption maxima, C85 being the combination of C83 and C84 that only differs with the 
terminal end-groups. For the three coumarins, an absorption maximum located at $444 \mathrm{~nm}$ was determined (See Figure 19 and Table 11).

Photosensitizers
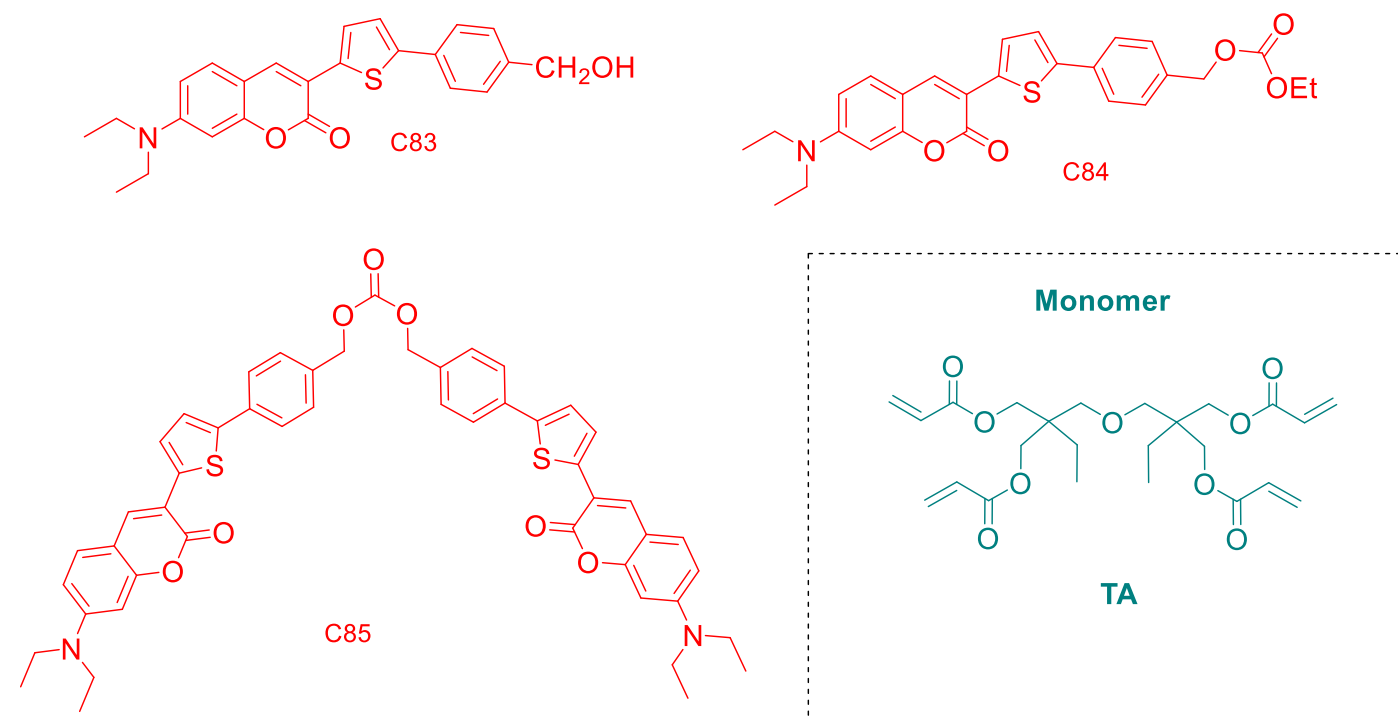

Figure 18. Chemical structures of C83-C85.

However, if the approach is appealing, C85 could not initiate the FRP of di(trimethylolpropane) tetraacrylate (TA) in thick films using the two-component C85/Iod $(0.05 \% / 1 \% \mathrm{w} / \mathrm{w})$. Conversely, final monomer conversions of 83 and $71 \%$ could be obtained after $400 \mathrm{~s}$ of irradiation at $405 \mathrm{~nm}$ with C83 and C84 in the same conditions. While using the iodonium concentration to $1 \% \mathrm{w}$, a TA conversion of $32 \%$ could however be obtained with C85. While using three-component photoinitiating systems, an improvement of the monomer conversion was obtained while using NPG instead of EDB and this trend is consistent with that observed with the previous series of coumarins (See Table 12). Indeed, with this amine, a decarboxylation reaction can occur on the amine, generating highly reactive radicals.

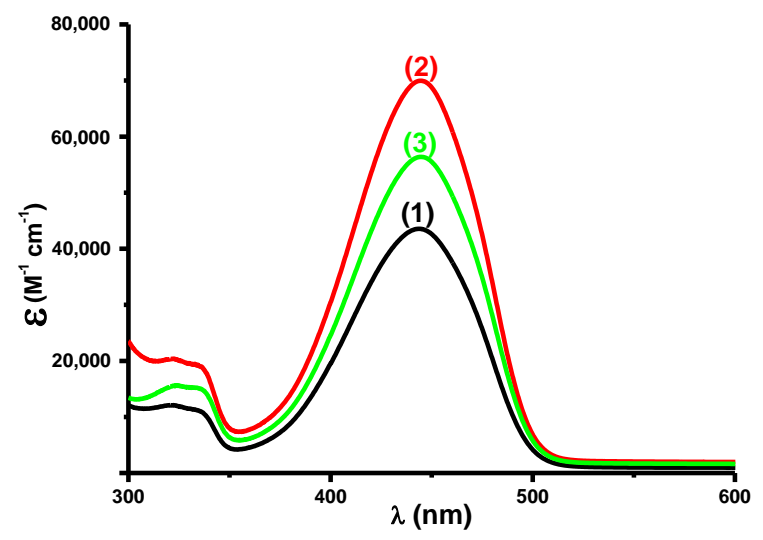

Figure 19. UV-visible absorption spectra in chloroform: (1) C83, (2) C84 and (3) C85.

Reprinted with permission from Rahal et al. [116] 
Table 11. Light absorption properties of coumarin compounds at $405 \mathrm{~nm}$ and $\lambda_{\max }$.

\begin{tabular}{cccc}
\hline- & $\lambda_{\max }(\mathbf{n m})$ & $\boldsymbol{\varepsilon}_{\max }\left(\mathbf{M}^{-\mathbf{1}} \cdot \mathbf{c m}^{-\mathbf{1}}\right)$ & $\left.\boldsymbol{\varepsilon} @ 405 \mathrm{~nm}_{\left(\mathbf{M}^{-1} \cdot \mathbf{c m}\right.}^{-1}\right)$ \\
\hline C83 & 444 & 43,500 & 23,000 \\
C84 & 444 & 69,900 & 35,900 \\
C85 & 445 & 56,400 & 28,900 \\
\hline
\end{tabular}

Table 12. Final conversions of the acrylate function for TA using different PIS (400 s of irradiation, LED @ 405 nm, sample thickness=1.4 mm).

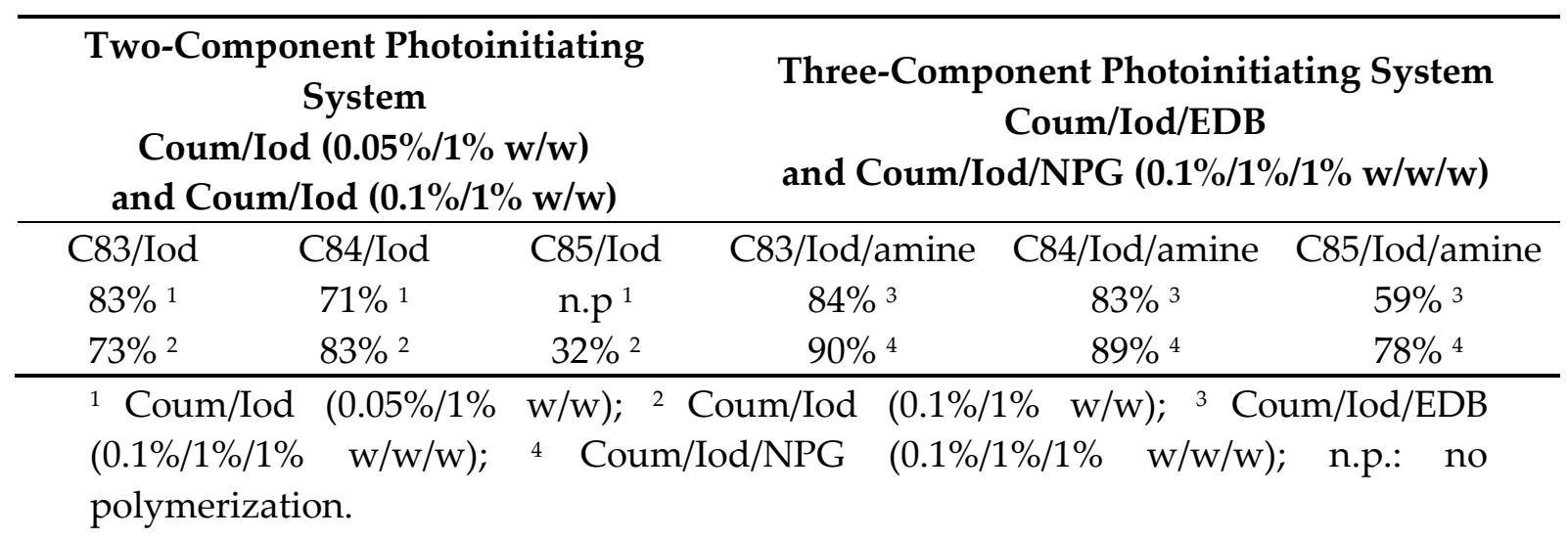

In thick films, C83 remained the best photoinitiator in three-component photoinitiating systems, and a final monomer conversion of $90 \%$ was obtained with the three-component C83/Iod/NPG $(0.1 \% / 1 \% / 1 \% \mathrm{w} / \mathrm{w} / \mathrm{w})$ system. Here again, a significant decrease of the final monomer conversion was obtained with C85 in the same conditions, decreasing to $78 \%$. Interestingly, increase of the coumarin concentration could improve the monomer conversions in the case of $\mathrm{C} 84$ and $\mathrm{C} 85$, attesting from a greater generation of radicals. Conversely, in the case of C83, a reduction of the monomer conversion was observed upon increase of the coumarin concentration, resulting from inner filter effects with this coumarin.

The crucial role of additives on the polymerization efficiency was recently demonstrated with the introduction of borates within the photocurable resins.[113] Based on the literature, it has been noted that borane $\mathrm{A}\left(\mathrm{B}\left(\mathrm{C}_{6} \mathrm{~F}_{5}\right)_{3}\right)$ can complex ketones and therefore can change their absorption or emission properties and then their photochemical reactivities.[226-229] Notably, without light activation, the cationic polymerization of $p$-methoxystyrene was reported in the presence of borane A and water. Owing to the complexation of borane A with water, acidity of the reaction media could be greatly improved, enabling the polymerization of $p$ methoxystyrene to occur.[230] Considering that boranes can complex ketones, the complexation of coumarins with boranes was thus investigated, and influence on the polymerization efficiency examined during the cationic polymerization of epoxy silicones. Two borane derivatives were tested, namely tetrakis(pentafluorophenyl)borane (borane A $\left.\mathrm{B}\left(\mathrm{C}_{6} \mathrm{~F}_{5}\right)_{3}\right)$ and tetrakis(3,5-bis(trifluoromethyl)phenyl)borate (borate $\left.\mathrm{B} \mathrm{B}\left(\mathrm{C}_{6}\left(\mathrm{CF}_{3}\right)_{5}\right)_{3}\right)$ (See Figure 20). 

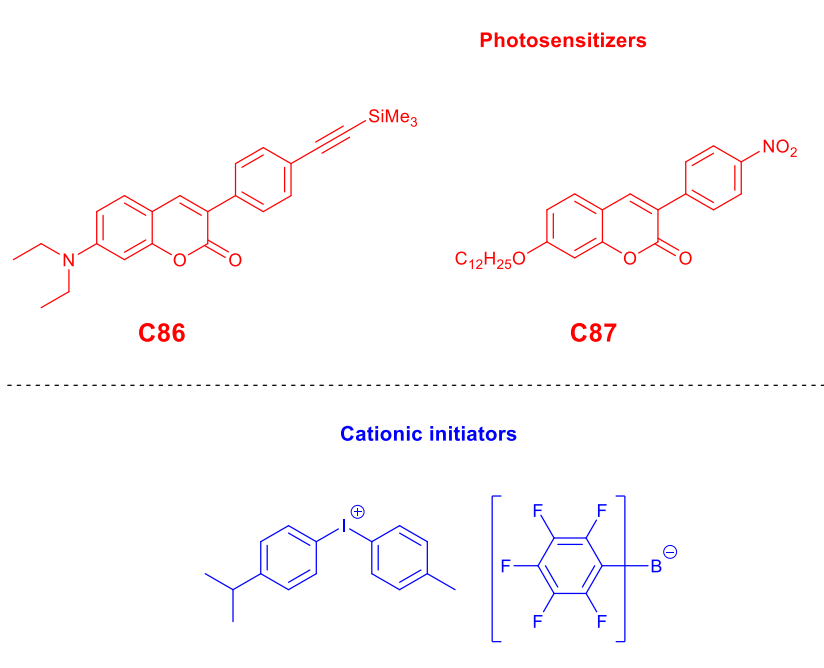

SpeedCure 939

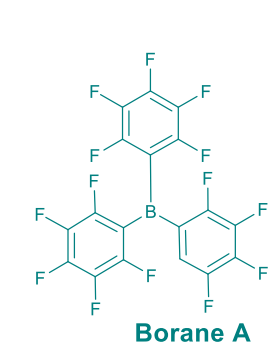

Additives

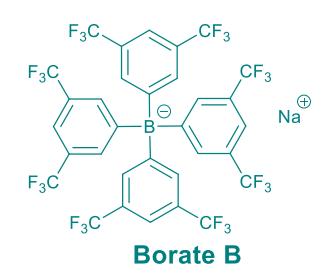

Figure 20. Chemical structures of borane A and borate B.

Interestingly, if a strong influence on the fluorescence properties of coumarins could be evidenced with C86 and C87, almost no influence on the absorption properties of the two coumarins could be detected. Thus, if the emission maximum in toluene was centered at 440 $\mathrm{nm}$ in toluene, a redshift to 485 and $493 \mathrm{~nm}$ could be detected upon addition of borane $\mathrm{A}$ and borate $\mathrm{B}$ respectively. This redshift was assigned to the formation of complexes between Coum-B and borane A or Coum-B and the sodium cation of borate B. As the most interesting feature, the polymerization process could continue even when the light was switched off, and this phenomenon known as dark polymerization could be evidenced with EPOX and epoxycyclohexylethyl)methylsiloxane-dimethylsiloxane copolymer (epoxy-silicone). Precisely, comparisons of the two-component C86/SC939 $(0.05 \% / 1 \% \mathrm{w} / \mathrm{w})$ photoinitiating systems and the three-component C86/SC939/Borane (or Borate) $(0.05 \% / 1 \% / 0.5 \%$ or $1 \%$ or $2 \%$ $\mathrm{w} / \mathrm{w}$ ) photoinitiating systems revealed an improvement of the polymerization profiles for the three-component photoinitiating systems. Thus, if similar final monomer conversions could be obtained in the two cases, a faster polymerization process occurred in the presence of borane A or borate B (See Figure 21). After $75 \mathrm{~s}$ of irradiation at $405 \mathrm{~nm}$, a final monomer conversion of $40 \%$ could be obtained with the three-component C86/SC939/Borane A $(0.05 \% / 1 \% / 0.5 \% \mathrm{w} / \mathrm{w})$ during the $\mathrm{CP}$ of epoxy-silicone contrarily to $21 \%$ for the twocomponent C86/SC939 (0.05\%/1\% w/w) system. A similar behavior could be determined with Borate B. Thus, 41\% monomer conversion was obtained with C86/SC939/Borate $\mathrm{B}(0.05 \% / 1 \% / 0.5 \% \mathrm{w} / \mathrm{w})$ after $75 \mathrm{~s}$ of irradiation contrarily to $21 \%$ with C86/SC $939(0.05 \% / 1 \%$ $\mathrm{w} / \mathrm{w})$. Improvement of the monomer conversion was assigned to the complexation of the radical cation, modifying its reactivity. Comparison of the contributions of borane $\mathrm{A}$ and borate $\mathrm{B}$ revealed slightly improved monomer conversions with borate $\mathrm{B}$, related to an enhanced solubility of borate $B$ in the resins. Interestingly, addition of $1 \%$ water in the threecomponent photoinitiating systems did not modify the final monomer conversions. As previously observed, comparisons of the final monomer conversions obtained with C86 and C87 revealed the nitrocoumarin C87 to outperform C86 (See Figure 21). 

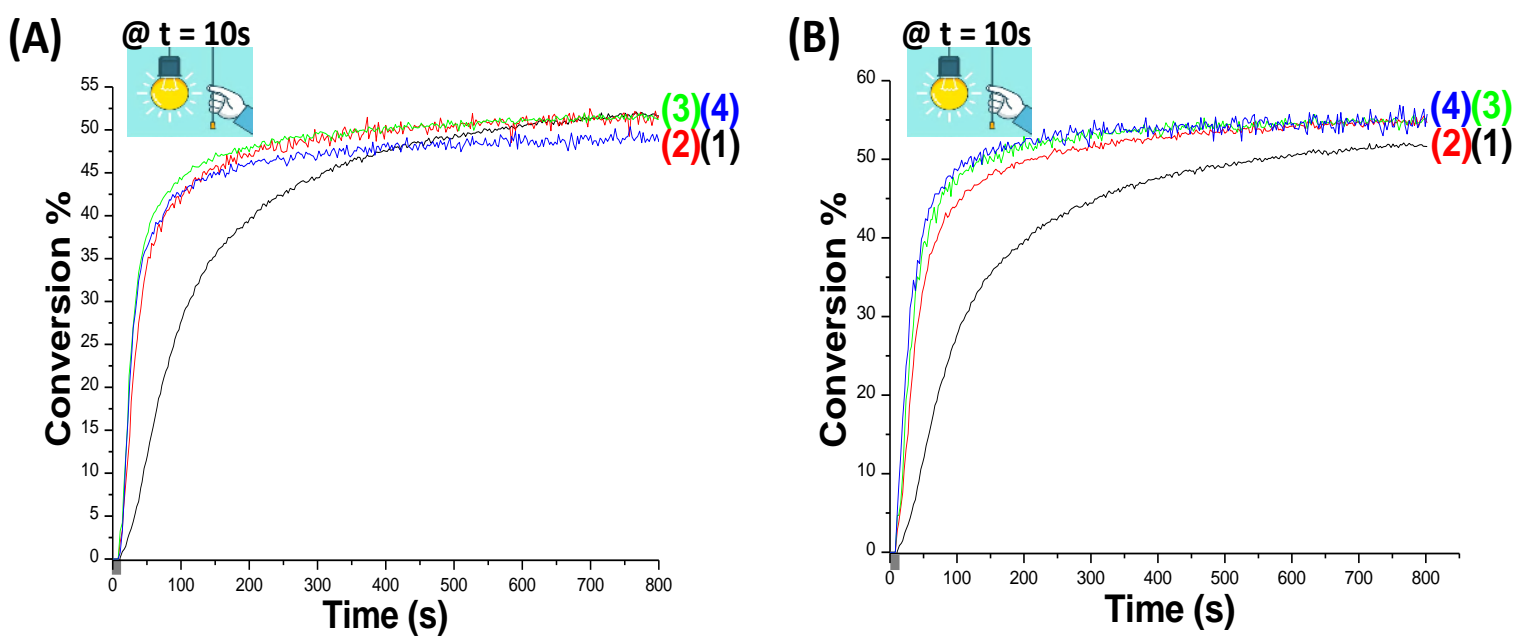

Figure 21. Polymerization profiles (epoxy function conversion vs. irradiation time) for thin epoxy-silicone films (thickness $=25 \mu \mathrm{m}$ ) under air, upon irradiation with the LED@405 nm, using different two and three-component photoinitiating systems: (A): Without and With Borane: (1) C86/SC939 (0.05\%/1\% w/w); (2) C86/SC939/Borane A $(0.05 \% / 1 \% / 0.5 \% \mathrm{w} / \mathrm{w})$; (3) C86/SC939/Borane A (0.05\%/1\%/1\% w/w); and (4) C86/SC939/Borane A $(0.05 \% / 1 \% / 2 \% \mathrm{w} / \mathrm{w})$, and (B): Without and With Borate: (1) C86/SC939 (0.05\%/1\% w/w); (2) C86/SC939/Borate B (0.05\%/1\%/0.5\% w/w); (3) C86/SC939/Borate B (0.05\%/1\%/1\% w/w); and (4) C86/SC939/Borate $\mathrm{B}(0.05 \% / 1 \% / 2 \% \mathrm{w} / \mathrm{w})$. The irradiation starts at $\mathrm{t}=10 \mathrm{~s}$. Reprinted with permission from Abdallah et al. [113]

While examining the dark polymerization of the three-component photoinitiating system based on C86, excellent monomer conversion was obtained, even when the light was switched off after $30 \mathrm{~s}$ of irradiation. However, a lower final monomer conversion was obtained with the three-component C86/SC939/Borane A $(0.05 \% / 1 \% / 2 \%$ w/w) system, compared to that determined after $800 \mathrm{~s}$ of irradiation ( $44 \%$ vs. $50 \%$ ). The same hold true for the three-component C86/SC939/Borate B (0.05\%/1\%/2\% w/w) system: 53\% conversion when the light is switched off after $30 \mathrm{~s}$ vs. $56 \%$ when the light is switched off after $800 \mathrm{~s}$ (See Figure 22).
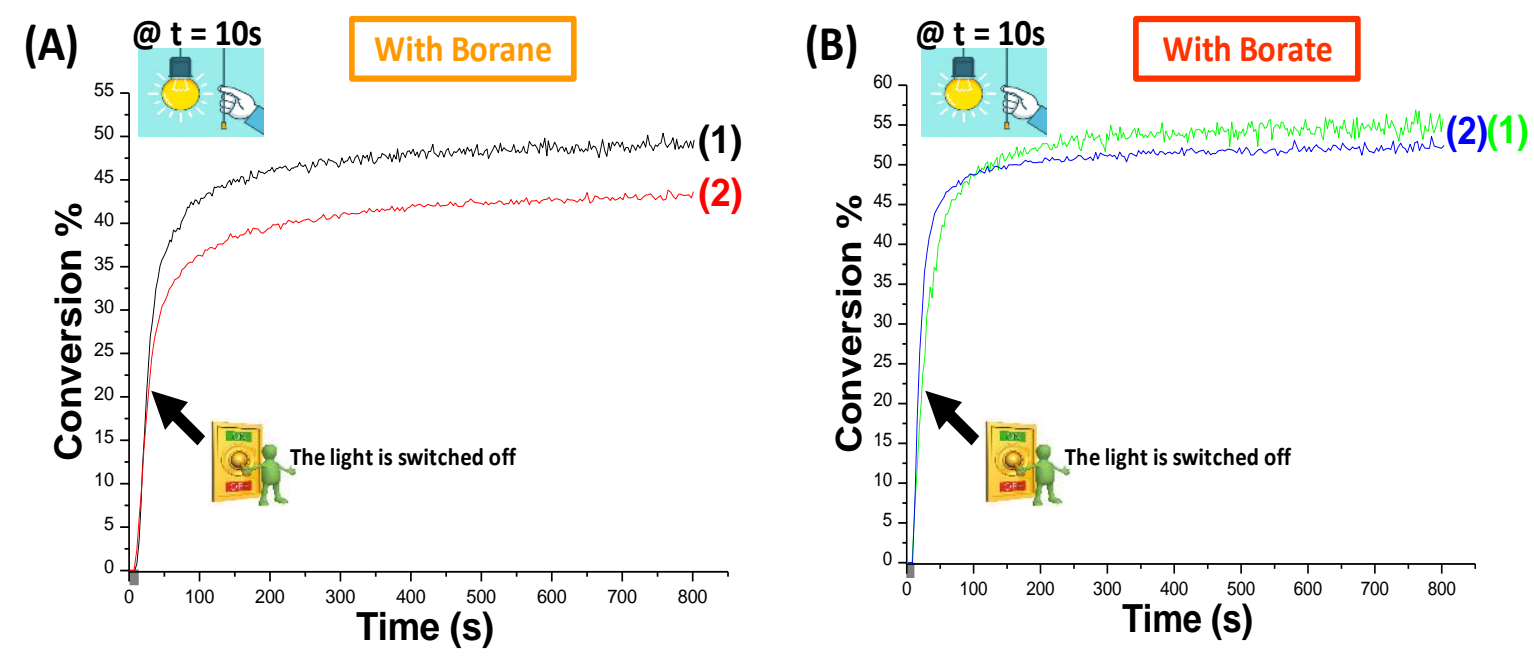
Figure 22. Polymerization profiles (epoxy function conversion vs. irradiation time) for thin epoxy-silicone films (thickness $=25 \mu \mathrm{m}$ ) under air, upon irradiation with the LED@405 nm, using different three-component photoinitiating systems: (A): (1) C86/SC939/Borane A $(0.05 \% / 1 \% / 2 \% \mathrm{w} / \mathrm{w})$ (when the light was continuously on for $800 \mathrm{~s}$ ); (2) C86/SC939/Borane A $(0.05 \% / 1 \% / 2 \% \mathrm{w} / \mathrm{w})$ (when the irradiation was turned off at $\mathrm{t}=30 \mathrm{~s})$. (B): (1) C86/SC939/Borate $\mathrm{B}(0.05 \% / 1 \% / 2 \% \mathrm{w} / \mathrm{w})$ (when the light was continuously on for $800 \mathrm{~s}$ ); (2) C86/SC939/Borate B $(0.05 \% / 1 \% / 2 \% \mathrm{w} / \mathrm{w})$ (when the irradiation was turned off at $\mathrm{t}=30 \mathrm{~s})$. The irradiation starts at $\mathrm{t}$ $=10 \mathrm{~s}$. Reprinted with permission from Abdallah et al. [113]

Based on the polymerization results, a global photochemical mechanism could be proposed, relying on equations r9-r12.

Coumarin $\rightarrow{ }^{*}$ Coumarin $(\mathrm{h} v)$

${ }^{*}$ Coumarin $+\mathrm{Ar}_{2} \mathrm{I}^{+} \rightarrow$ Coumarin ${ }^{\bullet+}+\mathrm{Ar}_{2} \mathrm{I}^{\bullet}$

$\mathrm{Ar}_{2} \mathrm{I} \bullet \rightarrow \mathrm{Ar} \bullet+\mathrm{ArI}$

Coumarin $+\mathrm{B} \rightarrow[\text { Coumarin-B] }]_{\text {Complex }}$

$[\text { Coumarin-B }]_{\text {Complex }}+\mathrm{Ar}_{2} \mathrm{I}^{+} \rightarrow[\text { Coumarin-B }]^{\bullet+}+\mathrm{Ar} \bullet+$ ArI

In the case of the three-component Coum/Iod/Borane (or Borate) systems, [Coumarin-B] $]^{\bullet+}$ could be considered as the initiating species whereas in the presence of water, $\mathrm{H}_{3} \mathrm{O}^{+}-{ }_{--}-[\mathrm{BOH}]^{-}$ could be considered as the initiating species.

\subsection{Carboxylic acid and formyl-derived coumarins as visible light photoinitiators of polymerization.}

Coumarins belong to a family of compounds exhibiting a wide range of structures. Considering that the reactivity of photoinitiators can be greatly influenced by the peripheral groups and their positions with regards to the coumarin scaffold, formyl or carboxylic acidderived coumarins were tested as visible light photoinitiators of polymerization (See Figure 23).[119] Notably, various groups (hydroxy, diethylamino, methoxy, nitro, aryl groups) were introduced at the 3- and 7-positions of the coumarin core. 


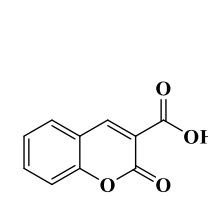

C88

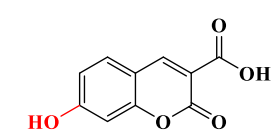

C89<smiles>CCc1ccc2ccc(=O)oc2c1</smiles>

C90

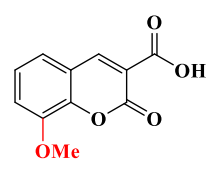

C91

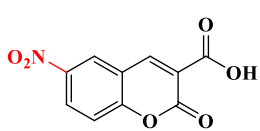

C92

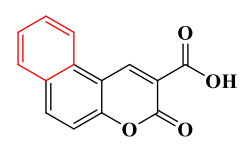

C93

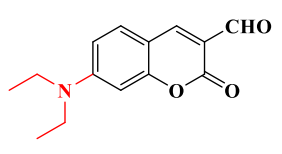

C94
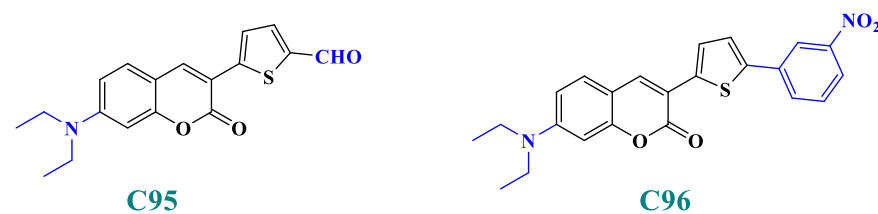

Monomers
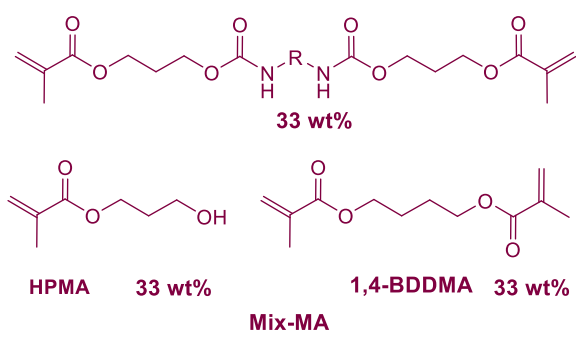

Figure 23. Chemical structures of carboxylic acid and formyl-derived coumarins C88-C96.

In this work, different trends could be evidenced. First, substitution at the 3-position of coumarins by electron-withdrawing groups such as formyl groups (See coumarins C94, C95) could improve the reactivity of coumarins and the final monomer conversions. Second, introduction of a strong electron-donating group at the 7-position (diethylamino or naphthalene groups) could reinforce the electronic delocalization and improve the reactivity of the different systems comprising C90, C94 or C95 as the photosensitizers. Finally, the best situation was found for C94 and C95 bearing simultaneously a formyl and a diethylamino substituent at the 3 and 7-positions. From the absorption viewpoint, the most red-shifted absorptions were logically found for C94 (442 nm) and C95 (458 nm) bearing both an electrondonating and an electron accepting group attached at both ends. For comparison, an almost similar absorption maximum was found for C96 substituted with a nitro group (445 nm) (See Figure 24 and Table 13). For these three dyes, high molar extinction coefficients could be determined at $405 \mathrm{~nm}$, making these chromophores good candidates for photoinitiation at this wavelength. Comparison of the final monomer conversions obtained with the two-component Coum/Iod (or NPG) $(0.1 \% / 1 \% \mathrm{w} / \mathrm{w})$ and the three-component Coum/Iod/NPG $(0.1 \% / 1 \% / 1 \%$ $\mathrm{w} / \mathrm{w} / \mathrm{w})$ photoinitiating systems during the polymerization of thick films revealed the monomer conversions to be lower with the two-component photoinitiating systems. Thus, during the FRP of mix-MA at $405 \mathrm{~nm}$ and in the case of C96, a final monomer conversion of $24 \%$ could only be obtained with the two-component system whereas it could increase up to 
$76 \%$ for the three-component system after $400 \mathrm{~s}$ of irradiation. More significant results were obtained with C88, no monomer conversion being obtained with the two-component system whereas it could increase up to $76 \%$ for the three-component system.

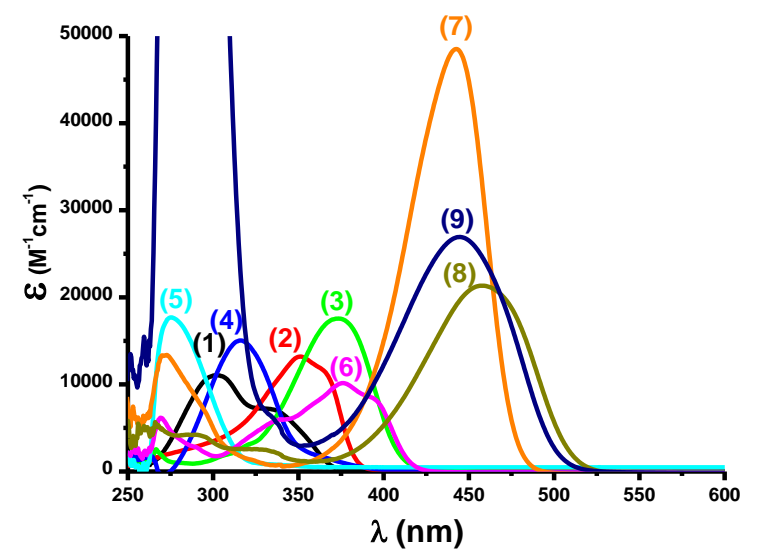

Figure 24. UV-visible absorption spectra of the investigated compounds based on Coumarin derivatives in ACN: (1) C88, (2) C89, (3) C90, (4) C91, (5) C92, (6) C93, (7) C94, (8) C95 and (9) C96. Reprinted with permission from Rahal et al.[119]

Table 13. Light absorption properties of Coumarins at $405 \mathrm{~nm}$ and at $\lambda_{\max }$; Singlet state energy (Es1) determined from the crossing point of absorption and fluorescence spectra.

\begin{tabular}{lccc}
\hline & $\begin{array}{c}\lambda_{\max } \\
(\mathrm{nm})\end{array}$ & $\begin{array}{c}\varepsilon_{\max } \\
\left(\mathrm{M}^{-1} \mathrm{~cm}^{-1}\right)\end{array}$ & $\begin{array}{c}\varepsilon 405 \mathrm{~nm} \\
\left(\mathrm{M}^{-1} \mathrm{~cm}^{-1}\right)\end{array}$ \\
\hline C88 & 302 & 11000 & 40 \\
C89 & 351 & 13000 & 80 \\
C90 & 374 & 18000 & 3500 \\
C91 & 322 & 14000 & 100 \\
C92 & 275 & 18000 & 60 \\
C93 & 376 & 10000 & 4800 \\
C94 & 442 & 48000 & 19000 \\
C95 & 458 & 21000 & 6500 \\
C95 & 445 & 27000 & 1400 \\
\hline
\end{tabular}

While comparing the efficiency of the two two-component Coum/Iod $(0.1 \% / 1 \% \mathrm{w} / \mathrm{w})$ and Coum/NPG $(0.1 \% / 1 \% \mathrm{w} / \mathrm{w})$ photoinitiating systems during the FRP of Mix-MA, C89, C91, C92, C93 and C94 proved to be more efficient in photoreductive processes whereas the opposite situation was found for C90 and C95 (See Table 14). In the case of TMPTA or TA, most of the coumarins proved to be efficient in both photoreductive and photooxidative processes, except C88, C89 and C92 that were efficient only in photoreductive processes.

Table 14. Final reactive functions conversion (FC\%) for different monomers and different PISs upon visible light irradiation using a LED@405nm (400 s of irradiation and thickness = $1.4 \mathrm{~mm}$ ). 


\begin{tabular}{|c|c|c|c|c|c|c|}
\hline & \multicolumn{3}{|c|}{$\begin{array}{l}\text { Two-component PISs } \\
\text { Coum/Additives }(0.1 \% / 1 \% \text { w/w })\end{array}$} & \multicolumn{3}{|c|}{$\begin{array}{l}\text { Three-component PISs } \\
\text { Coum/Iod/NPG } \\
(\mathbf{0 . 1} \% / \mathbf{1} \% / \mathbf{1} \% \text { w/w/w) }\end{array}$} \\
\hline & TMPTA & TA & Mix-MA & TMPTA & TA & Mix-MA \\
\hline \multirow{2}{*}{ C88 } & n.p. $\mathrm{p}^{\mathrm{a}}$ & n.p $\mathrm{p}^{\mathrm{a}}$ & n.p $p^{a}$ & $80 \%$ & $85 \%$ & $76 \%$ \\
\hline & $61 \% \mathrm{o}^{\mathrm{b}}$ & $30 \%{ }^{b}$ & n. $\mathrm{p}^{\mathrm{b}}$ & & & \\
\hline \multirow{2}{*}{ C89 } & n.p $\mathrm{p}^{\mathrm{a}}$ & $\mathrm{n} \cdot \mathrm{p}^{\mathrm{a}}$ & n. $\mathrm{p}^{\mathrm{a}}$ & $78 \%$ & $88 \%$ & $76 \%$ \\
\hline & $78 \%$ b & $81 \%$ b & $67 \% \mathrm{o}^{\mathrm{b}}$ & & & \\
\hline \multirow[t]{2}{*}{ C90 } & $60 \%{ }^{a}$ & $80 \%{ }^{a}$ & $70 \%{ }^{a}$ & $80 \%$ & $88 \%$ & $80 \%$ \\
\hline & $42 \%{ }^{b}$ & $56 \%$ b & $28 \% \mathrm{o}^{\mathrm{b}}$ & & & \\
\hline \multirow[t]{2}{*}{ C91 } & $33 \%{ }^{a}$ & $74 \%{ }^{a}$ & n. $\mathrm{p}^{\mathrm{a}}$ & $86 \%$ & $92 \%$ & $79 \%$ \\
\hline & $83 \%{ }^{b}$ & $90 \%{ }^{b}$ & $75 \% \mathrm{o}^{\mathrm{b}}$ & & & \\
\hline \multirow[t]{2}{*}{ C92 } & $\mathrm{n} \cdot \mathrm{p}^{\mathrm{a}}$ & $\mathrm{n} \cdot \mathrm{p}^{\mathrm{a}}$ & $\mathrm{n} \cdot \mathrm{p}^{\mathrm{a}}$ & $73 \%$ & $75 \%$ & $64 \%$ \\
\hline & $36 \%$ & $25 \%$ b & $30 \%$ & & & \\
\hline \multirow{2}{*}{ C93 } & $60 \%{ }^{a}$ & $86 \%{ }^{a}$ & $13 \%{ }^{a}$ & $80 \%$ & $88 \%$ & $64 \%$ \\
\hline & $81 \%$ & $88 \% \mathrm{o}^{\mathrm{b}}$ & $63 \% \mathrm{o}^{\mathrm{b}}$ & & & \\
\hline \multirow[t]{2}{*}{ C94 } & $70 \%{ }^{a}$ & $80 \%{ }^{a}$ & $35 \% \%^{a}$ & $50 \%$ & $40 \%$ & $46 \%$ \\
\hline & $75 \%{ }^{b}$ & $82 \%^{\mathrm{b}}$ & $55 \%$ b & & & \\
\hline \multirow[t]{2}{*}{ C95 } & $65 \%{ }^{a}$ & $84 \%{ }^{a}$ & $62 \%{ }^{a}$ & $81 \%$ & $87 \%$ & $75 \%$ \\
\hline & $53 \% \mathrm{o}^{\mathrm{b}}$ & $59 \%{ }^{b}$ & $29 \% \mathrm{o}^{\mathrm{b}}$ & & & \\
\hline \multirow[t]{2}{*}{ C96 } & $58 \% \%^{a}$ & $78 \%{ }^{a}$ & $24 \%{ }^{a}$ & $70 \%$ & $75 \%$ & $76 \%$ \\
\hline & $60 \% \mathrm{o}^{\mathrm{b}}$ & $31 \% \mathrm{o}^{\mathrm{b}}$ & $18 \%{ }^{b}$ & & & \\
\hline
\end{tabular}

a Coum/Iod $(0.1 \% / 1 \% \mathrm{w} / \mathrm{w}) ;{ }^{\mathrm{b}}$ Coum/NPG $(0.1 \% / 1 \% \mathrm{w} / \mathrm{w})$.

Finally, considering the high reactivity of C90, C91 and C95 in thick films, 3D-patterns were prepared by direct laser write experiments using different PISs based on Coum/Iod/TMA $(0.05 \% / 0.5 \% / 0.235 \% \mathrm{w} / \mathrm{w} / \mathrm{w})$ in TA or TMPTA. Comparison with the 3D patterns obtained with diphenyl(2,4,6-trimethylbenzoyl)phosphine oxide (TPO) which a type I photoinitiator revealed the possibility to get $3 \mathrm{D}$ patterns of similar quality, but by using $0.5 \% \mathrm{w} / \mathrm{w}$ contrarily to only $0.05 \%$ for the different coumarins. It thus evidences all the interest of the carboxylic acid and formyl-derived coumarins in photopolymerization.

\subsection{Ketocoumarins as visible light photoinitiators of polymerization.}

Among coumarins, ketocoumarins have been extensively studied for their photophysical properties. Indeed, ketocoumarins are characterized by an efficient singlet to triplet intersystem crossing, small singlet to triplet energy gaps and high molar extinction coefficients, long-living triplet excited state lifetimes so that these molecules constitute an important class of triplet sensitizers.[190,231-233] Ketocoumarins have been used as soon as 1983 for the design of photocurable resins based on pentaerythritol tetraacrylate (PETA) and pentaerythritol tetramethacrylate (PETMA) (See Figure 25).[234] In this pioneering works, C4, C97-C102 could constitute efficient photosensitizers when combined with the proper co- 
initiators. Thus, 3-benzoyl-7-methoxycoumarin C97 was an excellent initiator when associated to ethyl $p$-dimethylaminobenzoate. Conversely, low monomer conversions were obtained with trialkylamines. The same holds true with acetic acid derivatives. If low monomer conversions were obtained with C100-C102 and C4, high monomer conversions could be determined with C97-C99. Finally, while using pyridinium salts as co-initiators, only C100C102 and C4 proved to be suitable photosensitizers.

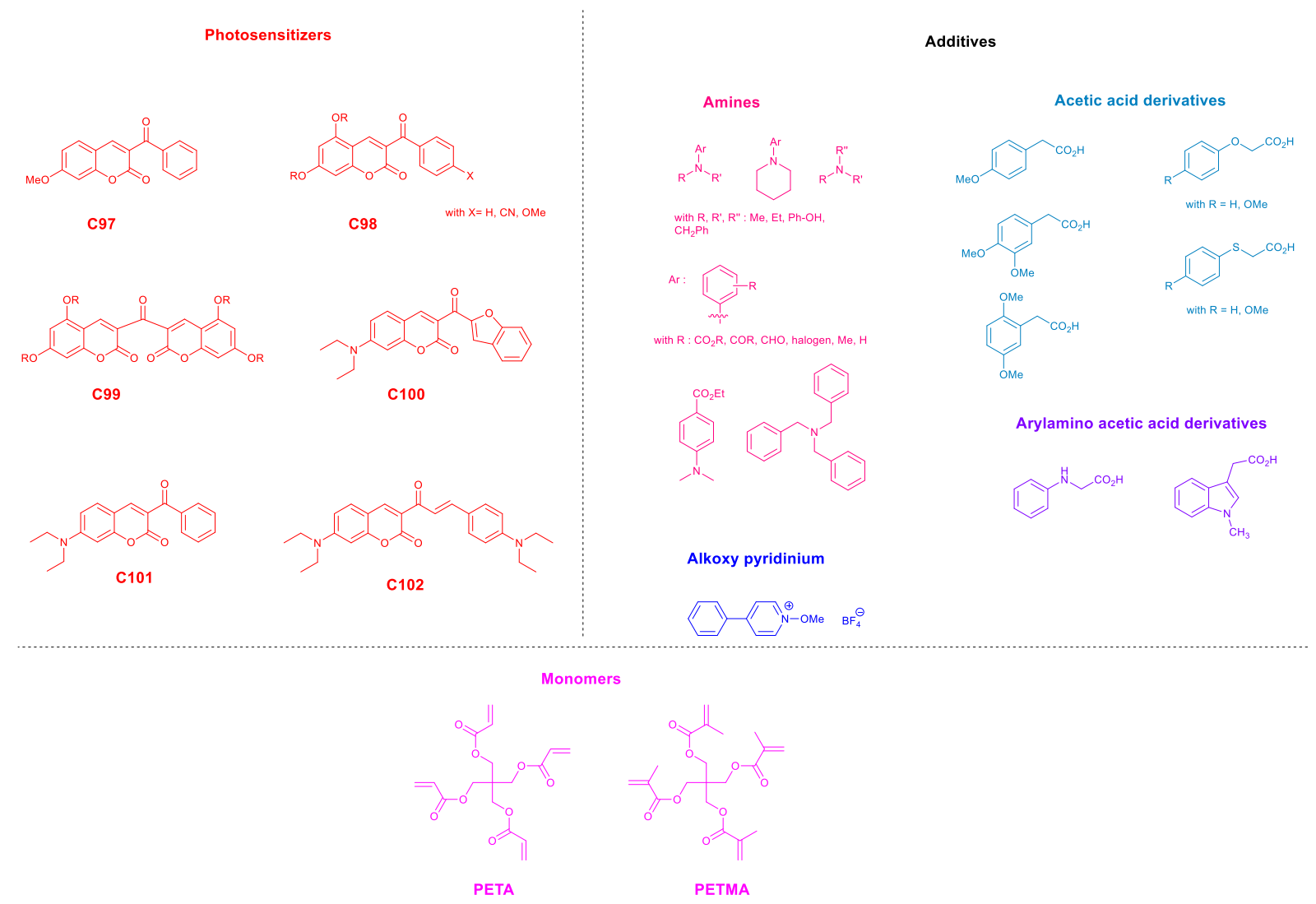

Figure 25. Various coumarins (C4, C97-C102) and co-initiators investigated as soon as 1983 for the FRP of acrylates.

These different results were rationalized in terms of mechanism, and it was determined that the mechanism was strongly related to the co-initiators used. Thus, in the case of amines, amines being good electron donors, a mechanism based on an electron transfer followed by a proton transfer was determined. Conversely, formation of charge transfer complexes between acetic acids derivatives and coumarins facilitates proton transfer towards coumarins. By electron transfer, carboxylate radicals can form and decarboxylation yields secondary radicals $\mathrm{R}-\mathrm{CH}_{2} \bullet$ capable to initiate polymerizations. Finally, a mechanism based on electron transfer in first step was determined when alkoxy-pyridinium salts were used as co-initiators. As a result of this, a fragmentation of the reduced pyridinium salts can occur, producing a pyridine derivative and the initiating alkoxy radicals. Interestingly, efficiency of the photopolymerization process was reinforced by using electron-rich coumarins bearing dialkylamino substituents. More recently, the combination of ketocoumarins with 1,3,5triazine and various aliphatic thiols were reported. The resulting multicomponent 
photoinitiating systems based on C4 and C103 could efficiently initiate the FRP of acrylates such as ethoxylated bisphenol A diacrylate (SR349) or Ebecryl 605 (See Figure 26).[235,236]

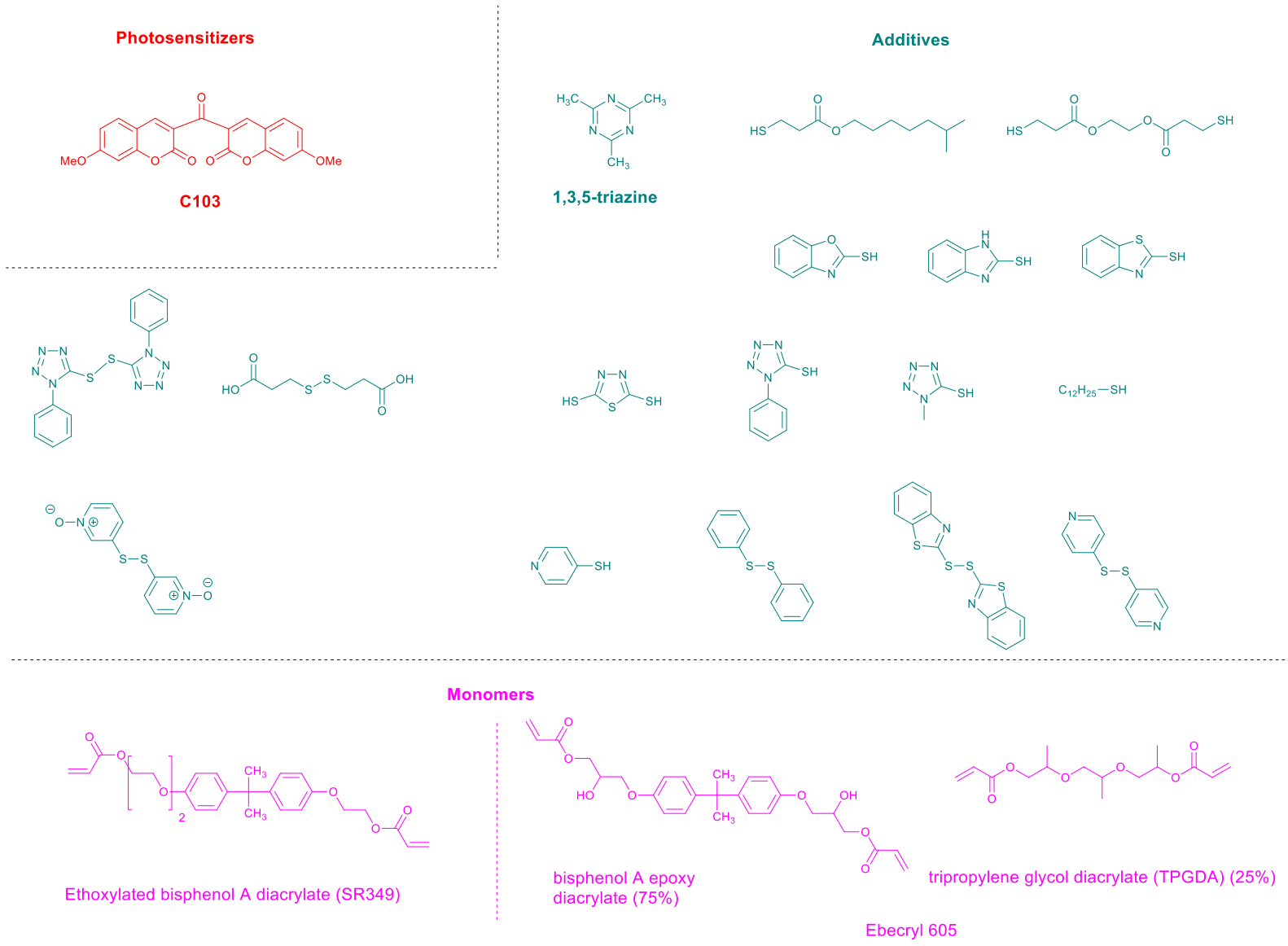

Figure 26.

In 2020, alkoxy and dialkylamino ketocoumarins were revisited by Lalevée and coworkers and a series of six coumarins were tested as photoinitiators for the CP of epoxides and the FRP of TMPTA or the CP of EPOX upon irradiation with a LED@405 nm (See Figure 27).[111]<smiles>CCNc1ccc2cc(-c3ccc([N+](=O)[O-])cc3)c(=O)oc2c1</smiles><smiles>CCCCNc1ccc2cc(C(=O)c3ccc(F)cc3)c(=O)oc2c1</smiles><smiles>COc1ccc2cc(C(=O)c3ccccc3)c(=O)oc2c1</smiles>

C97<smiles>CCCCNc1ccc2cc(C(=O)c3ccc(OC)cc3)c(=O)oc2c1</smiles>

C108<smiles>COc1ccc(C(=O)c2cc3ccccc3oc2=O)cc1</smiles>

C109

C110

Figure 27. A series of six alkyloxy and dialkylamino-substituted ketocoumarins C97, C101, C105-C110 examined as visible light photoinitiators of polymerization. 
Investigation of the substituent effect revealed the presence of the diethylamino group to drastically impact the CP of EPOX. Thus, the following order of reactivity could be determined using the two-component coumarin/Iod (Speedcure 938) $(0.2 \% / 1 \% \mathrm{w} / \mathrm{w}$ ) photoinitiating systems : C101 > C108 > C107 > C110 > C97 > > C109. Notably, higher final monomer conversions were obtained for diethylamino groups attached to the coumarin core. Conversely, a significant decrease of the monomer conversion was obtained for methoxysubstituted coumarins (See Table 15). A direct correlation between molar extinction coefficients and final monomer conversions was also established. However, reactivity of the coumarin radical cations, the ability to facilely release Bronsted acids has also to be considered.

Table 15. Final reactive epoxy function conversion (FC) for EPOX using different twocomponent photoinitiating systems after 800s of irradiation with the LED @405 nm.

\begin{tabular}{|c|c|c|c|c|c|}
\hline \multicolumn{6}{|c|}{ coumarin/Iod (0.2\%/1\% w/w) (thickness = 25 $\mu \mathrm{m})$ under air } \\
\hline C101/Iod & C107/Iod & C97/Iod & C108/Iod & C109/Iod & C110/Iod \\
\hline $45 \%$ & $31 \%$ & $50 \%$ & $38 \%$ & n.p. & $59 \%$ \\
\hline
\end{tabular}

n.p.: no polymerization

Influence of the molar extinction coefficients on the photoinitiating ability was confirmed during the FRP of TMPTA in thin and thick films. While using the two-component $\mathrm{PI} / \mathrm{Iod}(0.2 \% / 1 \% \mathrm{w} / \mathrm{w})$ systems, best conversions were obtained with C101 and C108, exhibiting the highest extinction coefficients at $405 \mathrm{~nm}: \varepsilon_{(@ 405 \mathrm{~nm})}=31730 \mathrm{M}^{-1} \cdot \mathrm{cm}^{-1}$ for $\mathrm{C} 101$ and $\varepsilon(@ 405 \mathrm{~nm})=$ $32420 \mathrm{M}^{-1} \cdot \mathrm{cm}^{-1}$ for $\mathrm{C} 108$. An almost similar order of reactivity was determined : $\mathrm{C} 101>\mathrm{C} 108>$ C107 > C97 > > C109, C110. Excellent polymerization profiles could also be obtained while using coumarins in photo-reductive processes with NPG. However, if the reactivity of coumarins was directly related to the absorption ability in photooxidative processes with Speedcure938, different order of reactivity was found for thin and thick films, assigned to inner filter effects adversely affecting the reactivity of the photoreductive photoinitiating systems. Lower final monomer conversions were obtained with the two-component PI/EDB $(0.2 \% / 1 \%$ $\mathrm{w} / \mathrm{w})$ systems, assigned to less favorable electron transfer with EDB compared to NPG.

Influence of the substitution pattern was also examined with another series of ketocoumarins bearing methyl ester groups.[118] In this series, best TA conversions were obtained with the electron-rich C118-C120 peaking respectively at 81,70 and $61 \%$ upon irradiation at $405 \mathrm{~nm}$ for $400 \mathrm{~s}$ and by using two-component coumarin/Iod $(0.4 \% / 1 \% \mathrm{w} / \mathrm{w})$ systems. Here again, lower monomer conversions were obtained with the methoxysubstituted coumarins and coumarins bearing electron-withdrawing groups such as nitro groups. In photoreductive systems based on NPG, monomer conversions of 86,83 and $87 \%$ were respectively obtained with C118, C119 and C120. If C118, C119 and C120 could furnish 
high monomer conversions irrespective of the photoinitiating systems, interestingly, C113, C114, C115 and C116 were only effective in photoreductive processes (See Table 16). As anticipated, use of three-component photoinitiating systems enabling to concomitantly induce the photooxidative and photoreductive processes resulted in a drastic improvement of the TA conversion. Thus, an enhancement of the monomer conversion of ca. $30 \%$ could be obtained with the less efficient coumarins such as C111, C112 and C117.<smiles>COC(=O)c1cc2ccccc2oc1=O</smiles>

C111<smiles>COC(=O)c1cc2cccc(OC)c2oc1=O</smiles>

C115<smiles>COC(=O)c1cc2cc(C)ccc2oc1=O</smiles>

C112<smiles>CCOc1cccc2cc(C(=O)OC)c(=O)oc12</smiles>

C116<smiles>COC(=O)c1cc2ccc(O)cc2oc1=O</smiles>

C113<smiles>COC(=O)c1cc2cc([N+](=O)[O-])ccc2oc1=O</smiles>

C117<smiles>COC(=O)c1cc2cc3c4c(cccc4c2oc1=O)C(=O)N([13CH3])C3=O</smiles>

C120<smiles>COC(=O)c1cc2ccc(OC)cc2oc1=O</smiles>

C114<smiles>COC(=O)c1cc2c(ccc3ccccc32)oc1=O</smiles>

C118<smiles>CCN(CC)c1ccc2cc(C(=O)OC)c(=O)oc2c1</smiles>

C119

Figure 28. Chemical structures of C111-C120.

Table 16. Final reactive function conversions (FC\%) for different monomers and different PISs upon visible light irradiation using a LED @405nm (400 s of irradiation and thickness $=1.4 \mathrm{~mm}$ ).

\begin{tabular}{|c|c|c|c|}
\hline \multirow{2}{*}{} & \multicolumn{2}{|c|}{$\begin{array}{c}\text { Two component photoinitiating } \\
\text { systems }\end{array}$} & $\begin{array}{c}\text { Three component photoinitiating } \\
\text { systems }\end{array}$ \\
\cline { 2 - 4 } & \multicolumn{2}{|c|}{ TA } & $\begin{array}{c}\text { TA } \\
\text { Iod/NPG } \\
\mathbf{( 1 \% / 1 \% ~ w / w ) ~}\end{array}$ \\
\hline C111 & n.p & $\mathbf{1 \% N P G}$ & $81 \%$ \\
\hline C112 & n.p & $52 \%$ & $76 \%$ \\
\hline C113 & n.p & $34 \%$ & $83 \%$ \\
\hline C114 & n.p & $71 \%$ & $87 \%$ \\
\hline C115 & $12 \%$ & $70 \%$ & $87 \%$ \\
\hline C116 & $13 \%$ & $75 \%$ & $87 \%$ \\
\hline C117 & $10 \%$ & $74 \%$ & $52 \%$ \\
\hline C118 & $81 \%$ & $19 \%$ & $91 \%$ \\
\hline C119 & $70 \%$ & $86 \%$ & $84 \%$ \\
\hline C120 & $65 \%$ & $83 \%$ & $89 \%$ \\
\hline
\end{tabular}

${ }^{1}$ n.p. : no polymerization 


\subsection{Coumarins substituted with iodonium salts}

In the previous works, coumarins have often been combined with iodonium salts to elaborate photoinitiating systems. More generally, efficient polymerizations can be obtained if coumarins are combined with onium salts.[181,237] With aim at simplifying the composition of the photocurable resins, the substitution of coumarins with iodonium salts was examined. As a result of this combination, the different molecules could operate as one-component photoinitiators, the photosensitizer being connected to the co-initiator. The first examples of iodonium-substituted coumarins were reported in 2015.[122] In this work, photoinitiating ability of C121 and C122 were compared to that of a ferrocenium salt DC1200 (See Figure 29). As interesting feature, $\mathrm{C} 121$ and $\mathrm{C} 122$ differ by the counteranions i.e. $\mathrm{PF}_{6}$ or $\mathrm{SbF}_{6}$. Indeed, nucleophilicity of anions can drastically impact the polymerization process. In the case of highly nucleophilic anions, the cationic chain reaction can be prematurely terminated so that the less nucleophilic hexafluoroantimonate anion was tested for comparison with the more nucleophilic hexafluorophosphate anion.[238-240] From the absorption viewpoint, C121 and C122 exhibited a low absorption in the visible range, not extending beyond $400 \mathrm{~nm}$ (See Figure 30). Noticeably, absorption of the ferrocenium salt DC1200 (salt-[(1,2,3,4,4a,8a-g)naphthalene](1,2,3,4,5-g)-2,4-cyclopentadien-1-yl]-iron(11) hexafluorophosphate is even weaker at $400 \mathrm{~nm}$, even if ferrocenium salts are historical cationic photoinitiators.[45] Besides, a sufficient overlap between the absorption of the different coumarins and the emission spectra of the LED emitting at $405 \mathrm{~nm}$ could be found to initiate polymerization processes. Comparison of the polymerization efficiency during the cationic polymerization of EPOX revealed C122 to outperform C121, as a result of the lower nucleophilicity of the anion $(69 \%$ vs. $50 \%$ conversion after $800 \mathrm{~s}$ of irradiation at $405 \mathrm{~nm}$ ).

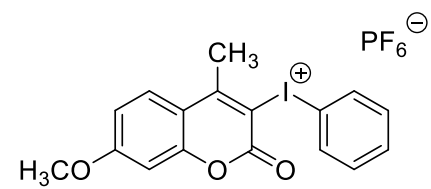

C121

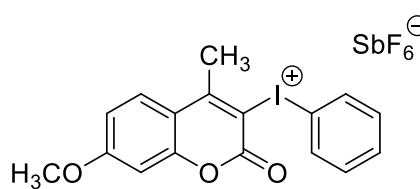

C122

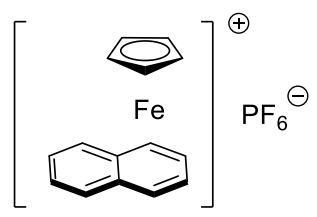

DC1200

Figure 29. Chemical structures of $\mathrm{C} 121$ and $\mathrm{C} 122$, the different monomers and additives. 


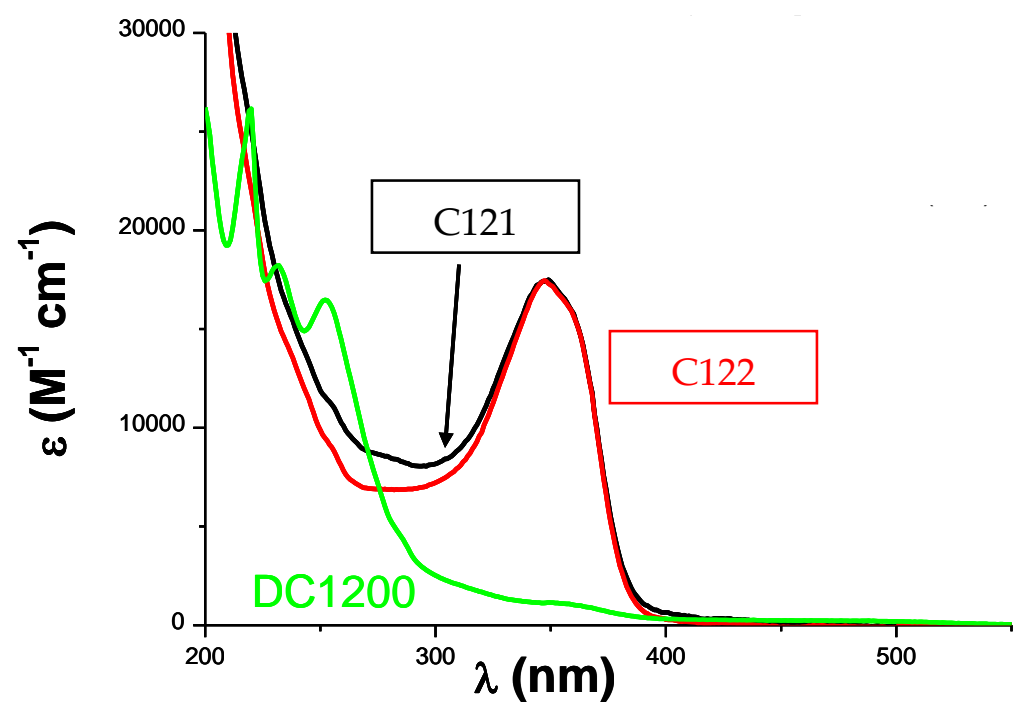

Figure 30. Comparison of the light absorption properties of the three salts i.e. C121, C122 and DC1200. Reprinted with permission from Mokbel et al. [122]

Interestingly, an efficient dark polymerization process could be evidenced with $\mathrm{C} 122$ even after a short irradiation period (200 s) whereas no dark polymerization was detected for P3C-P (See Figure 31). Thus, an increase of $18 \%$ of the final monomer conversion was evidenced with C122 whereas this conversion only increased of 5\% with C121 after $1800 \mathrm{~s}$ in the dark.

Interest of these hybrid coumarin/iodonium structures in practical applications was demonstrated by polymerizing dental resins consisting in a monomer blend composed of bisphenol A glycerolate dimethacrylate (Bis-GMA), triethyleneglycol dimethacrylate (TEGDMA) and 2-Hydroxyethyl methacrylate (HEMA) (50 wt $\% / 25 \mathrm{wt} \% / 25 \mathrm{wt} \%$ ) with P3CSb2 (See Figure 32).[241] Interestingly, use of C123 as a third component for the wellestablished camphorquinone (CQ)/EDB two-component system [242-244] enabled to drastically reduce the sensitivity of the photoinitiating system to the residual presence of solvents such as ethanol in resins. Indeed, if the combination CQ/amine is popular in dentistry, this binary system exhibits several drawbacks. Notably, CQ can cause a significant yellowing of the dental resins due to its intense coloration.[245] Similarly, amines can oxidize over time, resulting in a yellowing of the dental composites.[246] The binary CQ/amine systems are also well-known to be sensitive to the presence of residual solvents in monomers.[247] Parallel to this, efficiency of the polymerization process can also be drastically impacted by the acidity of monomers. Indeed, in this last case, during storage of the resin, an acid/base reaction between the amine and the monomer can occur, reducing the amine concentration. $[248,249]$ 


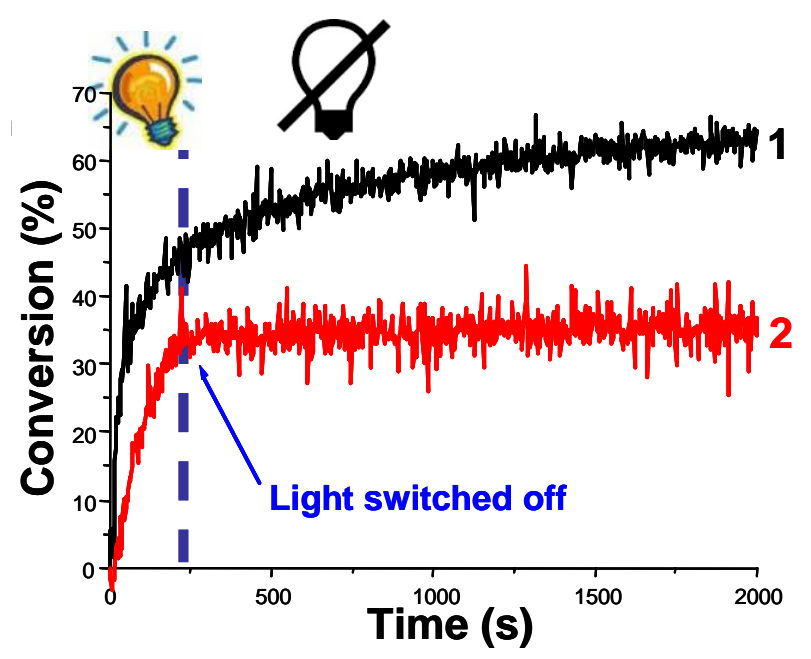

Figure 31. Photopolymerization profiles of EPOX under air: (A) under LED @405nm exposure (1) C122 (1\%wt), (2) C121 (1\%wt). Reprinted with permission from Mokbel et al.

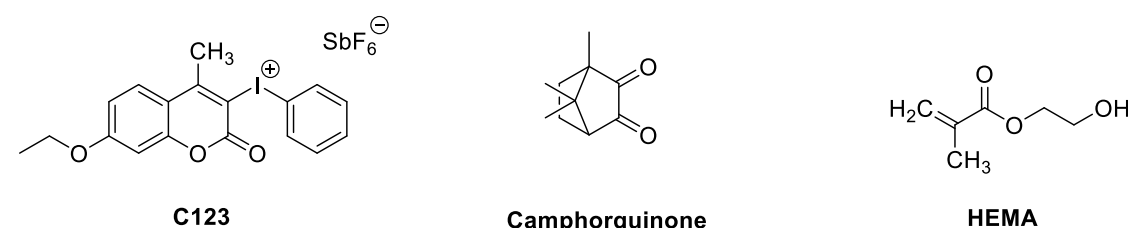<smiles>C=C(C)C(=O)OCCOCCOCCOC(=O)C(=C)C</smiles><smiles>C=C(C)C(=O)OCC(CC(=O)OP(=O)(O)O)OP(=O)(O)O</smiles>

Figure 32. Chemical structures of $\mathrm{C} 123$ and monomers.

If the benefits of $\mathrm{C} 123$ in the polymerization of monomers containing residual solvents was demonstrated, conversely, similar monomer conversions were obtained upon introduction of acidic monomer such as 1,3-glycerol dimethacrylate phosphate (GDMA-P) in the BisGMA/TEGDMA/HEMA blend. Even at low GDMA-P content (lower than 10\%), the final monomer conversions obtained with the three-component $\mathrm{CQ} / \mathrm{EDB} / \mathrm{C} 123$ system were comparable to that of the two-component CQ/EDB system. At 40\% GDMA-P content, a similar inhibitory effect was even found for the two systems, and no polymerization could be detected with the two systems, upon irradiation at $405 \mathrm{~nm}$. Investigation of the fragmentation mechanism of the iodonium-substituted coumarins by theoretical calculations revealed the bond dissociation of the iodonium salt to occur on the phenyl side due to a lower bond energy. As shown in the Figure 33, due to the asymmetric substitution of the iodonium salt, two 
different bond dissociation energy (BDE) could be determined, being respectively of 45.66 and $61.37 \mathrm{kcal} / \mathrm{mol}$, favorable to a fragmentation of the phenyl side. These results were confirmed by EPR experiments, the PBN adduct of the phenyl radical being detected (See Figure 34).

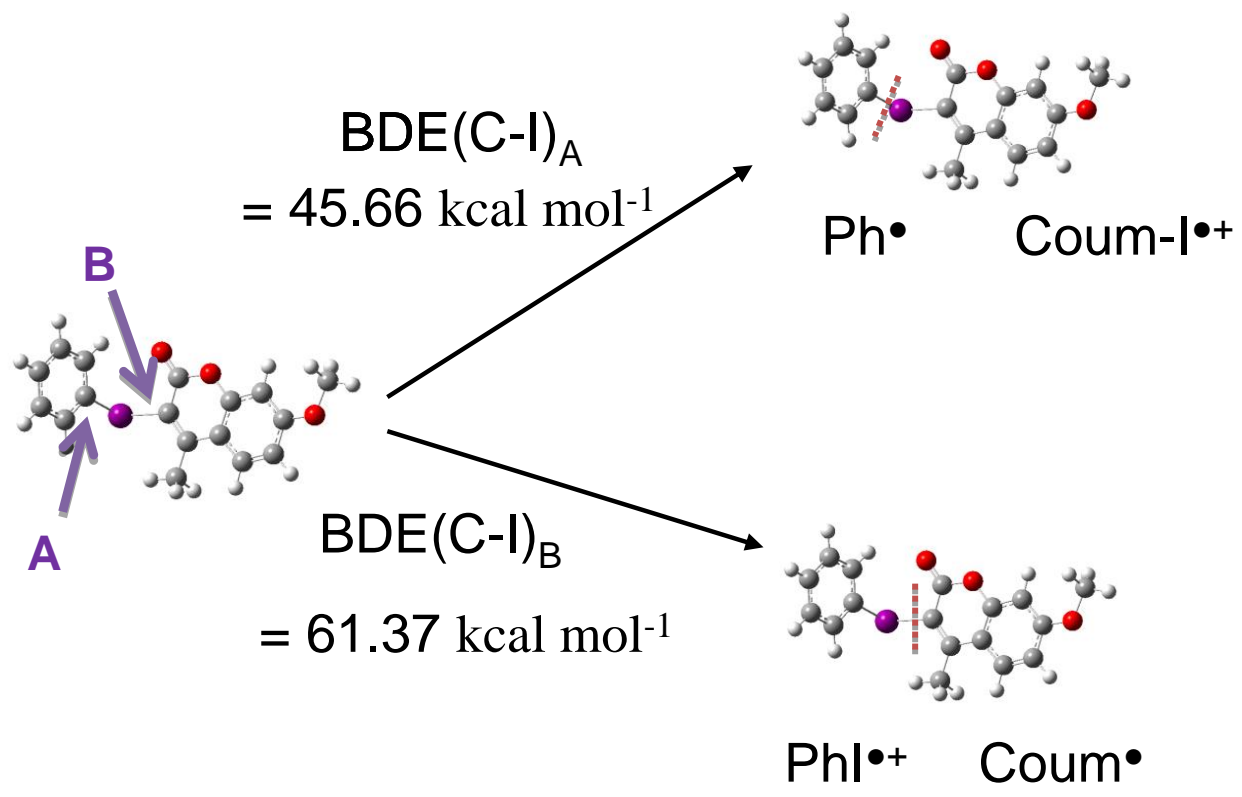

Figure 33. The two possible fragmentation mechanism of the iodonium salt salts calculated at uB3LYP/LANL2DZ level. Reprinted with permission from Mokbel et al. [122]
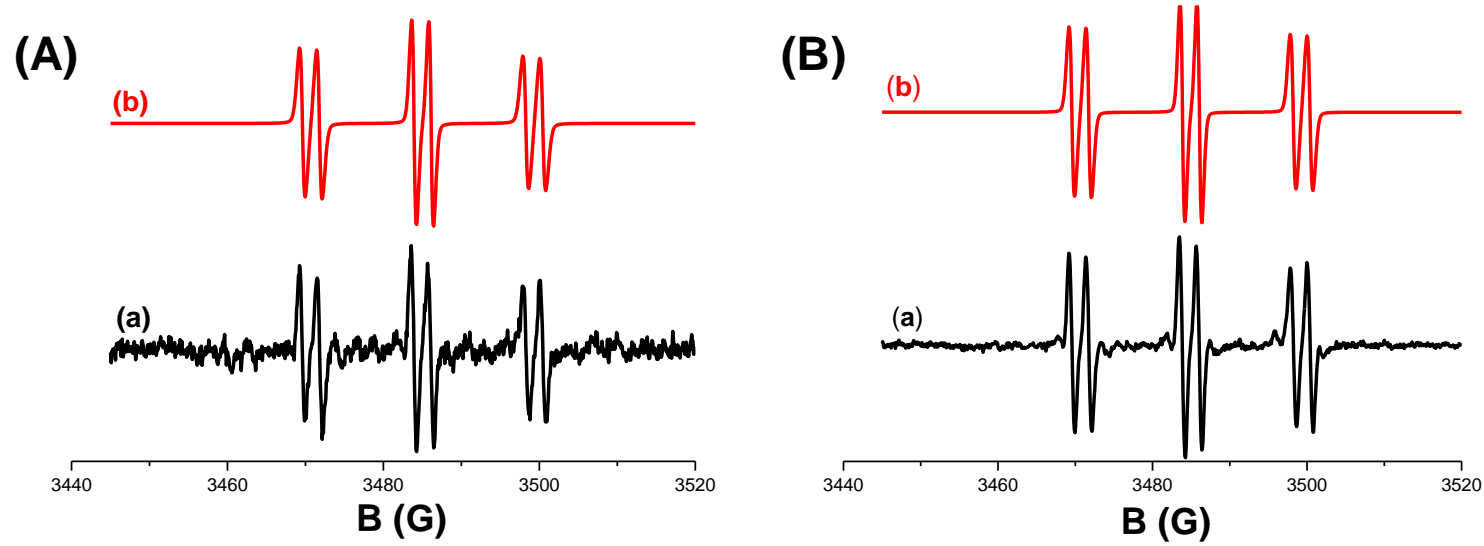

Figure 34. ESR-Spin Trapping spectra of the radical generated in (A) C122 upon LED@385 nm exposure; (B) C121 upon LED@385 nm exposure in tert-butylbenzene under nitrogen. experimental (a) and simulated (b) spectra. Phenyl-N-tert-butylnitrone (PBN) was used as the spin trap. Reprinted with permission from Mokbel et al. [122]

\subsection{Water-soluble coumarins}

Polymerization in water constitutes an appealing approach by avoiding the use of organic solvents during polymerization. It also allows the design of biocompatible 
materials.[250-252] However, at present, availability of water-soluble photoinitiators remains limited. In this field, introduction of functional groups such as sulfonic acid or sulfonate groups can greatly contribute to improve the solubility of organic dyes in water. This approach was notably developed with coumarins. By the presence of two sulfonate groups onto C125, its solubility in water was considerably increased compared to that of its parent structure C124 (See Figure 35).[253] From the absorption viewpoint, a slight blue shift of the absorption maxima could be detected for C125, peaking at $405 \mathrm{~nm}$ vs $421 \mathrm{~nm}$ for C124. Besides this blueshift, the two dyes were appropriate for irradiation done at $405 \mathrm{~nm}$.

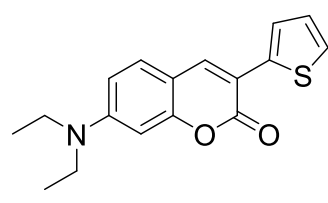

C124

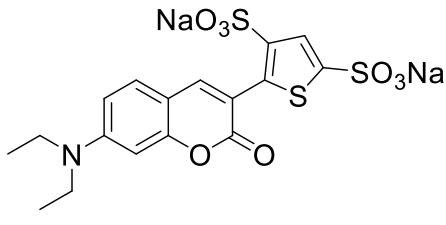

C125

Figure 35. Chemical structures of C124 and C125.

Examination of the photoinitiating ability of $\mathrm{C} 124$ and $\mathrm{C} 125$ during the cationic polymerization of EPOX in two-component systems Coumarin/Iod $(0.2 \% / 1 \% \mathrm{w} / \mathrm{w})$ revealed C124 to outperform C125. Indeed, if an EPOX conversion of $80 \%$ could be determined after $800 \mathrm{~s}$ of irradiation at $405 \mathrm{~nm}$ under air with $\mathrm{C} 124$, this value was reduced to only $10 \%$ with C125. A similar trend was evidenced during the FRP of TMPTA in thin films. As shown in the Table 17 and by using two-component Coumarin/Iod $(0.2 \% / 1 \% \mathrm{w} / \mathrm{w})$ photoinitiating systems, a final TMPTA conversion of $40 \%$ could be obtained with C124 whereas no polymerization occurred with $\mathrm{C} 125$. The lack of reactivity of C125 was ascribed to the low initiating radical yield of this coumarin, consistent with the results obtained during the $\mathrm{CP}$ of EPOX. A different trend was found in thick films since a TMPTA conversion of $58 \%$ could be obtained with $\mathrm{C} 125$, outperforming C124 (45\% conversion). A photoredox behavior could be demonstrated with the three-component coumarin/Iod/NPG $(0.2 \% / 1 \% / 1 \% \mathrm{w} / \mathrm{w})$ photoinitiating systems upon exposure of the resins to a LED emitting at $405 \mathrm{~nm}$. Upon addition of NPG, an increase of the performance could be evidenced, the final monomer conversion peaking at $56 \%$ with the threecomponent C124/Iod/NPG $(0.2 \% / 1 \% / 1 \% \mathrm{w} / \mathrm{w})$ compared to $40 \%$ for the two-component system. A higher enhancement could be even obtained in thick films, the monomer conversion reaching $80 \%$ after $100 \mathrm{~s}$. Similar improvement of the monomer conversions were obtained with $\mathrm{C} 125$ in thin and thick films. In fact, the best monomer conversion was obtained with C125 during the FRP of TMPTA thick films using the tertiary combination, reaching 93\%. Counter-performance of $\mathrm{C} 124$ in thick films was assigned to the strong color change of the resin, from light green to deep green, inducing an inner filter effect. On the opposite, such a color change was not detected with $\mathrm{C} 125$, resulting in an improved monomer conversion. In fact, good bleaching properties could even be evidenced with C125, enabling to produce almost colorless coatings. Finally, comparison of the coumarin/Iod and coumarin/NPG (or 
EDB) systems revealed C124 and C125 to be poor candidates in photoreduction process, no monomer conversions being obtained when combined with an amine.

Table 17. Acrylate Function Conversion (FC) for TMPTA Using Different Photoinitiating Systems after 100s of Irradiation with LED @405 nm (A = C124; B = C125).

\begin{tabular}{|c|c|c|c|c|c|c|c|c|}
\hline \multicolumn{2}{|c|}{$\%$ acrylate function conversion (FC) for TMPTA (at $t=100$ s); thin sample (25 *.tm) in } \\
laminate
\end{tabular}

n.p. : no polymerization.

Interestingly, if C125 was rather insoluble in organic resins such as TMPTA, an opposite situation was found in water. Polymerization of hydrogels based on HEMA $(50 \%$ in water) upon irradiation at $405 \mathrm{~nm}$ with the two component C125/MDEA $(0.2 \% / 1 \% \mathrm{w} / \mathrm{w})$ photoinitiating systems (where MDEA stands for $N$-methyldiethanolamine) furnished hydrogels containing $78 \%$ of water.

\subsection{Coumarin-substituted iridium complexes}

Iridium complexes have been extensively studied as visible light photoinitiators of polymerization activable under low light intensity.[59-64] In 2012, the combination of coumarins and iridium complexes was examined.[254] Iridium complexes are characterized by a strong absorption in the visible range, long living excited state lifetimes so that iridium complexes were extensively used in photoredox catalysis but also in the polymerization area.[255-258] To evidence the benefits of the substitution of iridium complexes with coumarins (C127 and C128), a comparison with an iridium complex not substituted with coumarins C126 was established (See Figure 36).[259] 


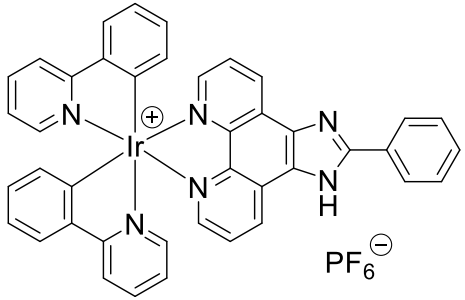

C126

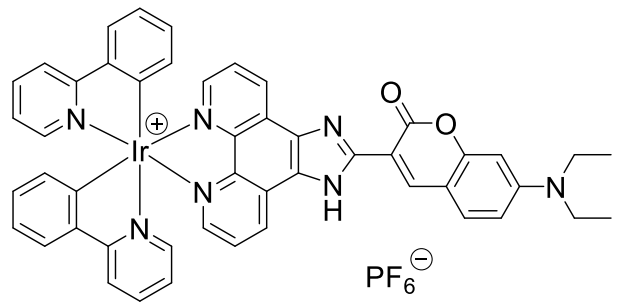

C127

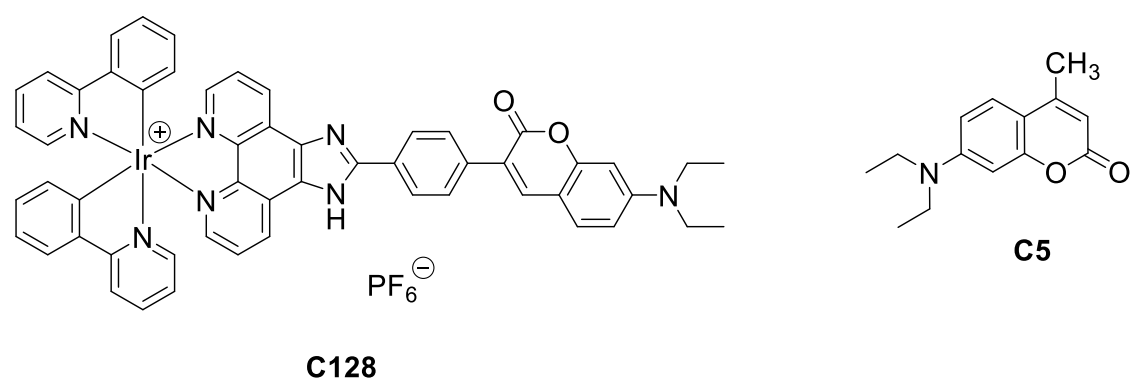

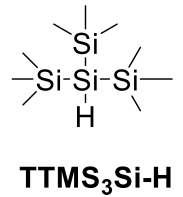<smiles>[O-]c1ccccc1</smiles>

$\mathbf{P h}_{\mathbf{2}} \mathbf{I}^{\oplus}$

Figure 36. Chemical structures of coumarin-based iridium complexes $\mathrm{C} 126-\mathrm{C} 128$ and additives.

From the absorption viewpoint, introduction of the coumarin fragment onto C127 and C128 enabled the two complexes to strongly absorb in the visible range and absorption maxima located at 466 and $418 \mathrm{~nm}$ respectively (See Figure 37). As a result of these redshifted absorptions, C127 and C128 could efficiently initiate the CP of EPOX by using threecomponent iridium/(TMS) ${ }_{3} \mathrm{Si}-\mathrm{H} / \mathrm{Ph}_{2} \mathrm{I}^{+} \quad(0.2 \% / 3 \% / 2 \% \mathrm{w} / \mathrm{w})$ photoinitiating systems upon irradiation at $462 \mathrm{~nm}$ and $514 \mathrm{~nm}$ whereas no monomer conversion was detected with $\mathrm{C} 126$ at these two wavelengths due to the lack of absorption. Thus, an EPOX conversion of $70 \%$ could be obtained after $10 \mathrm{~min}$ of irradiation at $462 \mathrm{~nm}$ by using the three-component C127/(TMS) $3 \mathrm{Si}$ $\mathrm{H} / \mathrm{Ph}_{2} \mathrm{I}^{+}(0.2 \% / 3 \% / 2 \% \mathrm{w} / \mathrm{w})$ photoinitiating systems. 


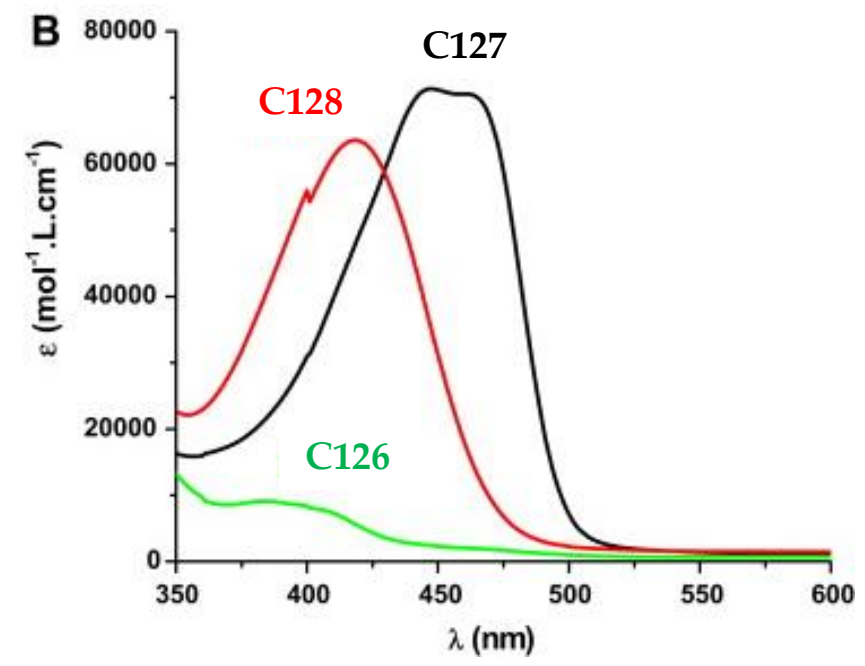

Figure 37. UV-visible absorption spectra of C126-C128 in acetonitrile. Reprinted with permission from Tehfe et al. [254]

A significant improvement of the monomer conversion was obtained while using the three-component system compared to the two-component $\mathrm{C} 127 / \mathrm{Ph}_{2} \mathrm{I}^{+}(0.2 \% / 2 \% \mathrm{w} / \mathrm{w})$ system. Thus, upon irradiation at $462 \mathrm{~nm}$, the EPOX conversion increased from 25\% for the twocomponent system up to $38 \%$ with the three-component photoinitiating system. Comparison with the reference system 7-diethylamino-4-methylcoumarin (C5)/(TMS) ${ }_{3} \mathrm{Si}-\mathrm{H} / \mathrm{Ph}_{2} \mathrm{I}^{+}$revealed the three-component systems based on C127 and C128 to outperform that based on C5. Thus, if a monomer conversion of 68 and 30\% could be obtained with $\mathrm{C} 127$ and C128, this value reduced to only $10 \%$ with C5 upon irradiation at $462 \mathrm{~nm}$. Worse results were obtained with the unsubstituted iridium complex $\mathrm{C} 126$, the final monomer conversion being below $5 \%$ (See Figure 38).

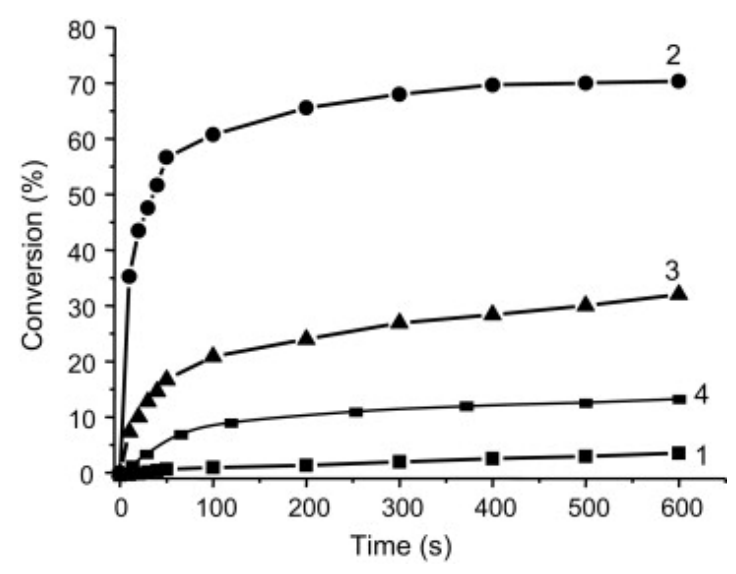

Figure 38. Comparison of the polymerization profiles of EPOX upon irradiation at $462 \mathrm{~nm}$ using three-component photoinitiating systems $(0.2 \% / 3 \% / 2 \% \quad \mathrm{w} / \mathrm{w})$ under air. (1) C126/(TMS) ${ }_{3} \mathrm{Si}-\mathrm{H} / \mathrm{Ph}_{2} \mathrm{I}^{+}$; (2) C127/(TMS) ${ }_{3} \mathrm{Si}-\mathrm{H} / \mathrm{Ph}_{2} \mathrm{I}^{+}$; (3) C128/(TMS) $3 \mathrm{Si}-\mathrm{H} / \mathrm{Ph}_{2} \mathrm{I}^{+}$and (4) $\mathrm{C} 5 /(\mathrm{TMS}){ }_{3} \mathrm{Si}-\mathrm{H} / \mathrm{Ph}_{2} \mathrm{I}^{+}$. Reprinted with permission from Tehfe et al. [254]

By combining photolysis experiments, cyclic voltammetry and electron spin resonance spin-trapping (EPR) experiments, mechanism could be elucidated. As shown in the Figure 39, 
upon photoexcitation of the iridium-based photosensitizer, a photoinduced electron transfer can occur, induced the decomposition of the iodonium salt and the formation of aryl radicals $\mathrm{Ph} \bullet$, supported by ESR-ST experiments. The oxidized iridium catalysts can thus initiate the CP of epoxides. Parallel to this, aryl radicals $\mathrm{Ph} \bullet$ can be converted as silyl radicals TTMS $3 \mathrm{Si}^{\bullet}$ by hydrogen abstraction on tris(trimethylsilyl)silane. These radicals can be easily oxidized by the oxidized photosensitizer $\mathrm{PC}^{+}$, leading to the formation of initiating silylium cations $\mathrm{TTMS}_{3} \mathrm{Si}^{+}$ and regenerating the photosensitizer PC in its initial oxidation state. Based on previous results, silylium cations are highly reactive species capable to efficiently initiate the $\mathrm{CP}$ of epoxides.[260-263] As a result of this regeneration, iridium complexes can be introduced in catalytic amount, typically $0.2 \%$ in resins. Considering that $\mathrm{PC}^{+}$and $\mathrm{TTMS}_{3} \mathrm{Si}^{+}$can both contribute to the cationic polymerization of epoxides, it thus explains the enhancement of monomer conversions detected with the three-component systems compared to the twocomponent ones.

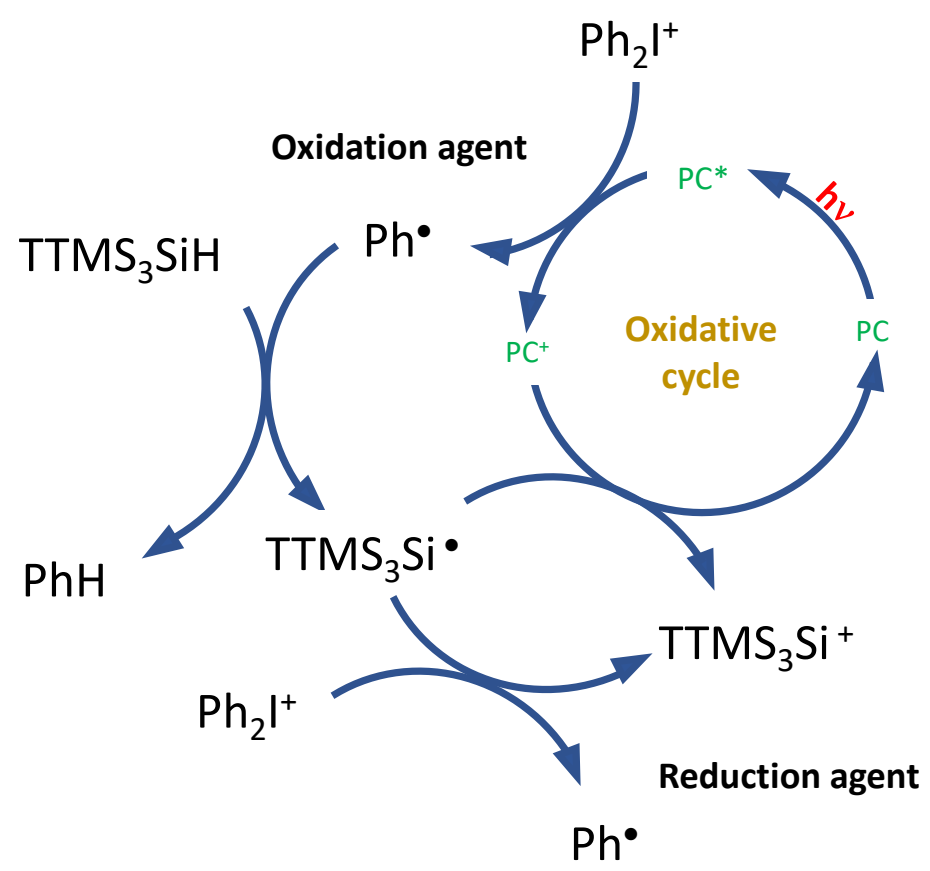

Figure 39. Mechanism proposed to support the remarkable photoinitiating ability of the three-component photoinitiating systems based on coumarin-substituted iridium complexes.

\subsection{Coumarin-based oxime esters}

In the different examples presented above, coumarins have been used as type II photoinitiators. In this situation, coumarins are used as photosensitizers capable to induce the photo-assisted decomposition of iodonium salts. More generally, photocatalytic systems can be obtained upon introduction of a sacrificial amine in charge to reduce the oxidized coumarin. With aim at simplifying the composition of the photocurable resins, the covalent linkage of iodonium salts to coumarin was examined, enabling to get mono-component systems. The 
same result in terms of simplification of the photocurable resins can be obtained with Type I photoinitiators. Coumarins have been used as chromophores for numerous oximes esters. Notably, a series of four coumarins fused with a carbazole moiety C129-C132 [191] and another related structure i.e. C134 [192] were notably developed for two-photon polymerization (See Figure 40). Similarly, coumarins bearing extended electron-donating groups (C133, C135, C136) were also developed for two-photon polymerization.[193]

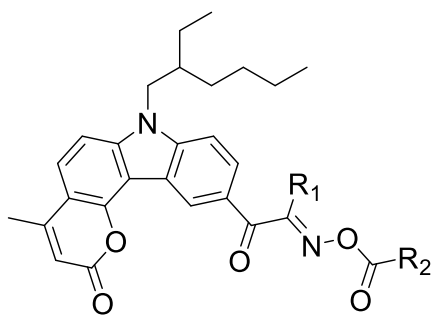

$$
\begin{aligned}
& \text { C129: } \mathrm{R}_{1}=\mathrm{Et}, \mathrm{R}_{2}=\mathrm{Me} \\
& \text { C130: } \mathrm{R}_{1}=i-\mathrm{Pr}, \mathrm{R}_{2}=\mathrm{Me} \\
& \text { C131 }: \mathrm{R}_{1}=\mathrm{Et}, \mathrm{R}_{2}=\mathrm{Ph}
\end{aligned}
$$$$
\text { C132: } \mathrm{R}_{1}=i-\mathrm{Pr}, \mathrm{R}_{2}=\mathrm{Ph}
$$

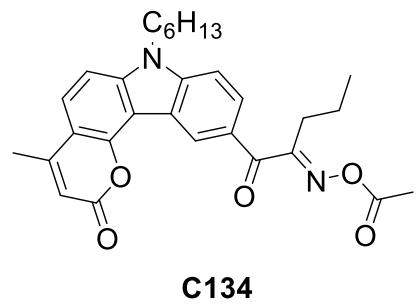<smiles>CCCCO/N=C\c1cc(=O)oc2cc(C#Cc3ccc(N(C)C)cc3)ccc12</smiles>

C133<smiles>[R]C(=O)ON=C(C)c1cc2ccc(C#Cc3ccc(N(C)C)cc3)cc2oc1=O</smiles>

Figure 40. Examples of coumarins C129-C136 developed for two-photon polymerization.

Cleavage of oxime esters can only be obtained if a sufficient energy is transferred from the photosensitizer towards the oxime group. At present, most of the oxime esters are UV sensitive, requiring a noxious irradiation wavelength to be used. In 2019, an interesting approach was developed, based on the functionalization of up-conversion nanoparticles by a coumarin substituted with an oxime ester (C137) (See Figure 41).[264] To chemically modify the surface of up-conversion nanoparticles, a thiol-ene click reaction was carried out.

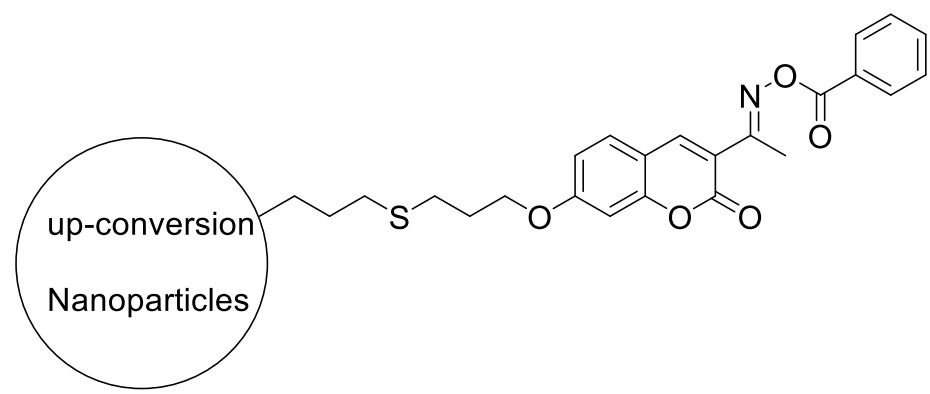

Figure 41. Chemical structures of up-conversion nanoparticles functionalized with coumarin-based oxime esters C137.

Using this approach, a nonharmful near-infrared light could be used. Interestingly, functionalization of the up-conversion nanoparticles with oxime esters enabled to get locally 
a high concentration of oxime esters and to optimize the Forster energy transfer from particles towards the oximes. As a result of this, mobile free radicals could be efficiently produced. Upon photoexcitation of up-conversion nanoparticles at $980 \mathrm{~nm}$ with a laser, three different emissions could be obtained at 451, 474 and $345 \mathrm{~nm}$. A weaker emission at $291 \mathrm{~nm}$ was also detected. Considering that the maximum absorption of coumarins is located at $335 \mathrm{~nm}$, a good overlap between the emitted light and the absorption of coumarins could be obtained. Comparison of the photodecomposition kinetics of coumarin oxime esters when covalently linked to up-conversion nanoparticles or mixed with the particles revealed the photodecomposition rates to be one order of magnitude higher for coumarins covalently linked to the particles. Versatility of these nanoparticles was demonstrated with the free radical photopolymerization of methyl methacrylate (MMA), the controlled/living polymerization of MMA via a photo RAFT polymerization process. In these different experiments, polymers exhibiting a narrow molecular weight distribution could be obtained. Finally, the possibility to initiate a thiol-ene polymerization was also demonstrated.

In 2022, a series of eleven coumarin-based oxime esters C138-C148 was synthesized and influence of the substitution of the oxime esters on the photoinitiating ability was examined (See Figure 42).[265] Interestingly, aliphatic and aromatic groups were used to produce oxime esters. Markedly, a crosslinkable group, namely an acryloyl group, was also used (See C139). To evidence the influence of the difference of reactivity of the generated radicals, coumarins were functionalized so that their absorption spectra perfectly superimpose (See Figure 43). Thus, a variation as low as $10 \mathrm{~nm}$ could be determined between the different coumarins. Hence, if absorption maxima located at $431 \mathrm{~nm}$ were determined for C139 and C141, the most red-shifted absorption was found for C147 at $441 \mathrm{~nm}$ due to the presence of the strong electron-withdrawing nitro group. Conversely, significant differences of molar extinction coefficients could be determined between the different oxime esters, attributable of the difference of molar weights. Indeed, if an acetyl group has been used to prepare C141, naphthoyl groups have respectively been used in C142 and C143. Upon irradiation of oxime esters at $405 \mathrm{~nm}$ with a LED, excellent TMPTA conversions were obtained with all oxime esters, except for $\mathrm{C} 145$ bearing an electron-donating methoxy group attached to the aryl group. As anticipated, a low monomer conversion was obtained with $\mathrm{C} 138$, this coumarin not bearing an oxime ester group. Interestingly, final monomer conversions obtained with the different coumarins were not related to their molar extinction coefficients, demonstrating that the efficiency of the cleavage reaction and the decarboxylation reaction as well as the reactivity of the generated radicals were different parameters affecting the final monomer conversions. Indeed, the reactive species is the radical produced by decarboxylation, as shown in equation r13.

$$
\mathrm{R}_{1} \mathrm{R}_{2} \mathrm{C}=\mathrm{N}-\mathrm{O}-\mathrm{C}(=\mathrm{O}) \mathrm{R}^{\prime}(\mathrm{h} v) \rightarrow \mathrm{R}_{1} \mathrm{R}_{2} \mathrm{C}=\mathrm{N}^{\bullet}+{ }^{\bullet} \mathrm{O}-\mathrm{C}(=\mathrm{O}) \mathrm{R}^{\prime} \rightarrow \mathrm{R}_{1} \mathrm{R}_{2} \mathrm{C}=\mathrm{N}^{\bullet}+\mathrm{CO}_{2}+{ }^{\bullet} \mathrm{R}^{\prime}
$$

Theoretical calculations revealed the cleavage reaction to occur from the singlet excited state of the molecules and not from their triplet states, due to an unfavorable free energy 
change. For all oxime esters, bond dissociation energy (BDE) around $42-50 \mathrm{kcal} / \mathrm{mol}$ were determined (See Table 18). The highest final monomer conversions were obtained for C141 (72\% TMPTA conversion) and C147 (73\% conversion), bearing a nitro group. However, photolysis experiments revealed the decarboxylation reaction to be faster for C141 than for the other oxime esters, consistent with results previously reported in the literature.[191,266-275] Indeed, the decarboxylation reaction is well-known to be faster for aliphatic groups than for aromatic groups due to the electronic delocalization of the odd electron.
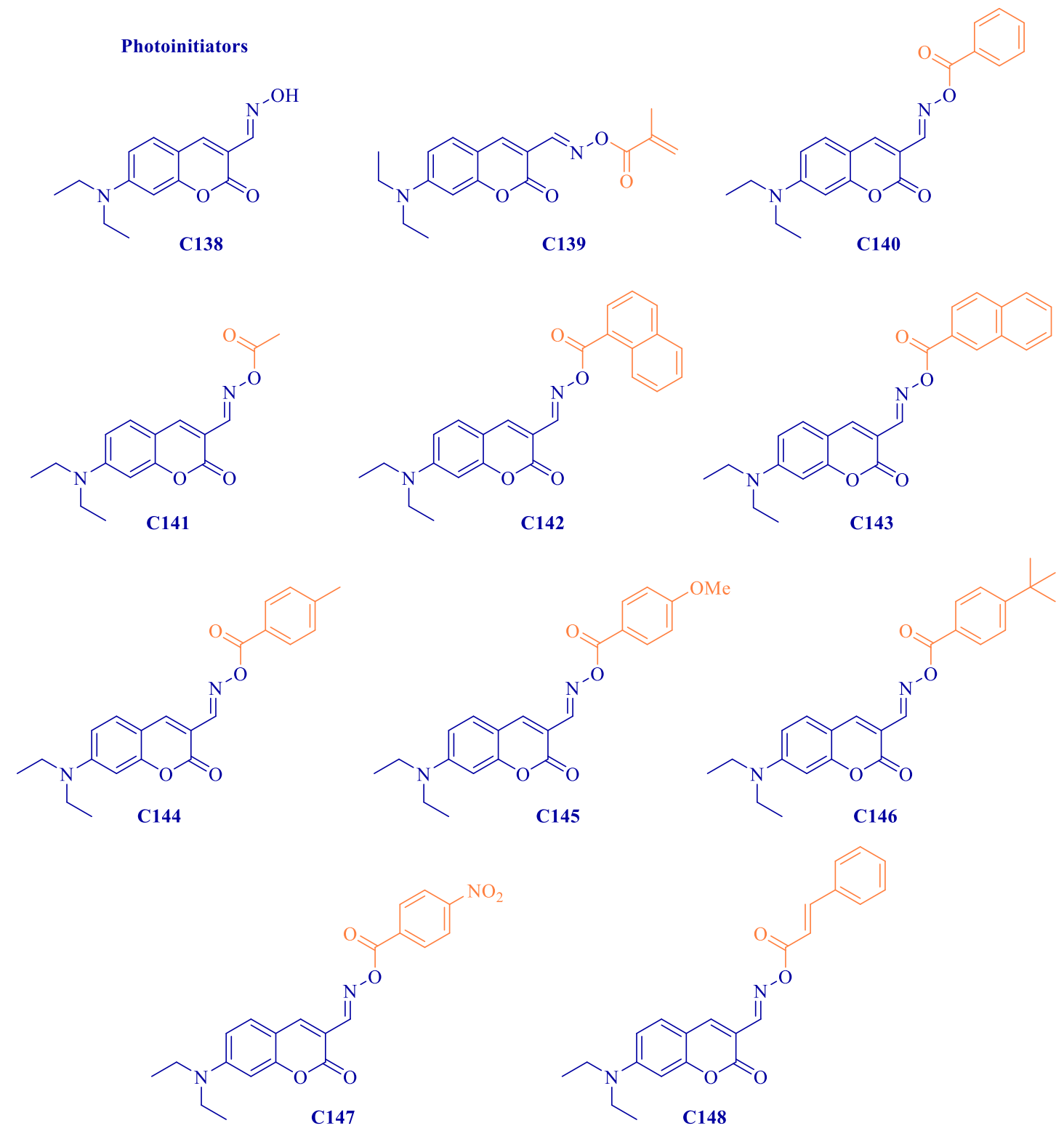

Figure 42. Chemical structures of coumarins-based oxime esters C138-C148. 


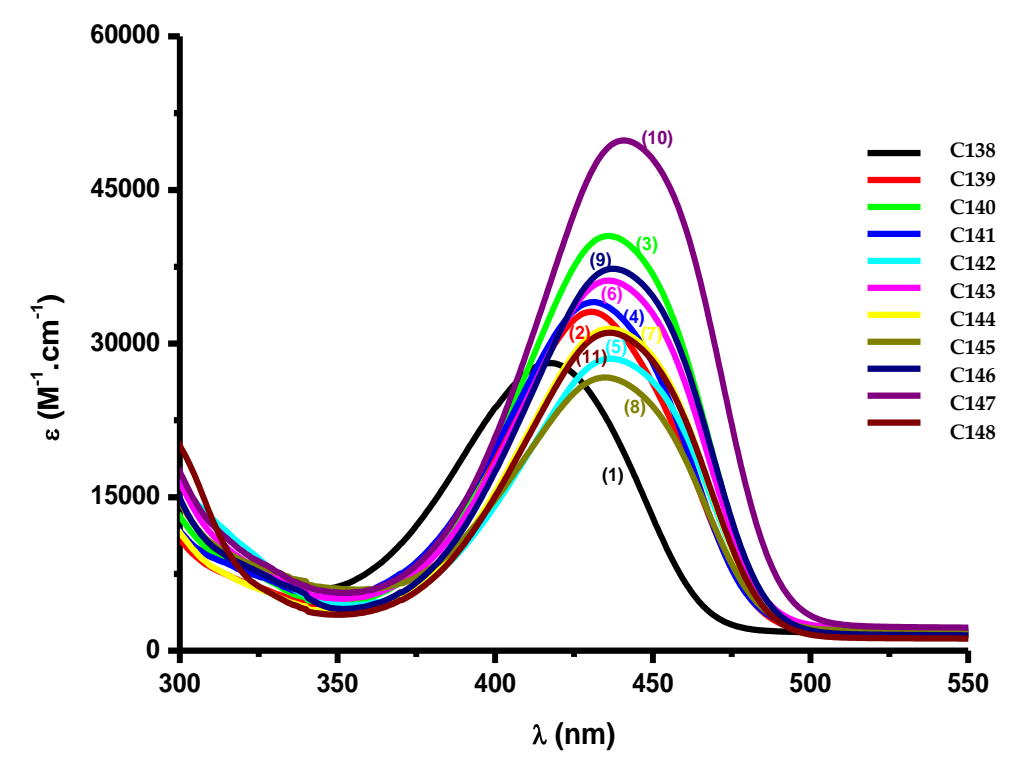

Figure 43. UV-visible absorption spectra of C138-C148 in acetonitrile. Reprinted with permission from Hammoud et al. [265]

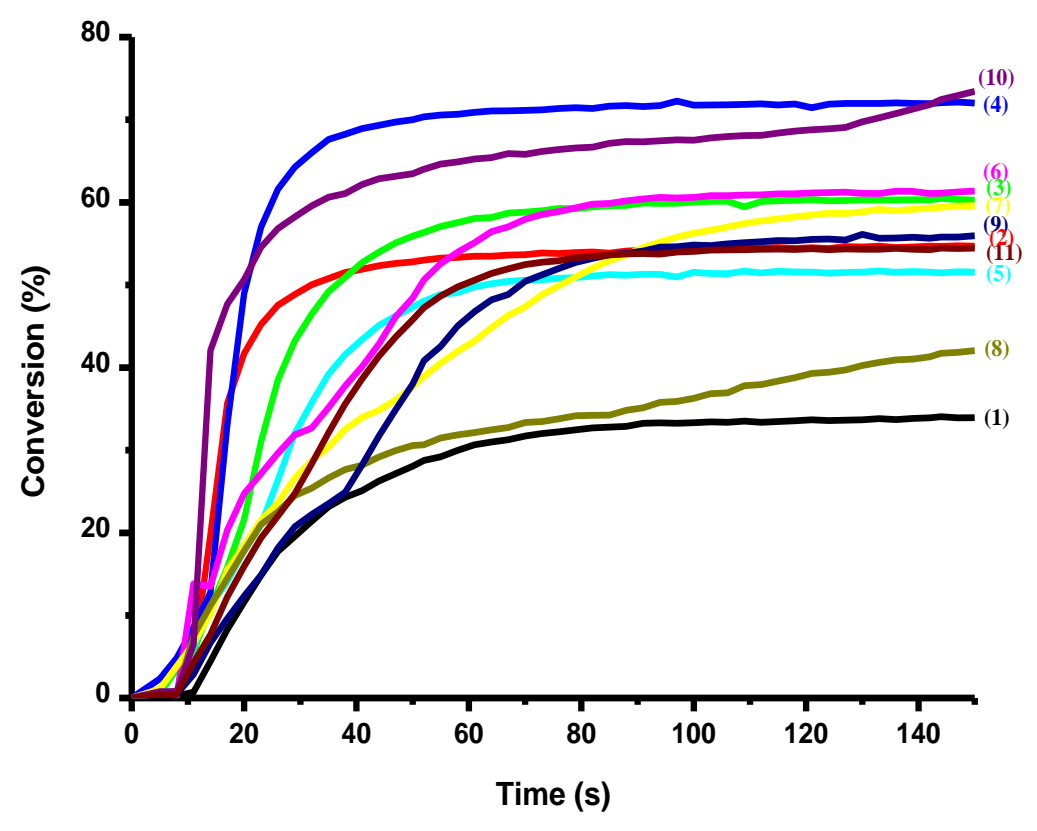

Figure 44. Photopolymerization profiles of TMPTA (acrylate function conversion vs. irradiation time) in laminate (thickness $=25 \mu \mathrm{m}$ ) upon exposure to a LED at $405 \mathrm{~nm}$ in the presence of: (1) C138 (0.5\% w); (2) C139 (0.5\% w); (3) C140 (0.5\% w); (4) C141 (0.5\% w); (5) C142 (0.5\% w); (6) C143 (0.5\% w); (7) C144 (0.5\% w); (8) C145 (0.5\% w); (9) C146 (0.5\% w); (10) C147 (0.5\% w); and (11) C148 (0.5\% w); respectively. The irradiation starts after $\mathrm{t}=10 \mathrm{~s}$.

Reprinted with permission from Hammoud et al. [265] 
Table 18. Parameters characterizing the investigated OXEs. Some parameters characterizing the proposed oxime-esters were calculated by molecular modelling: the Bond Dissociation Energy BDE (N-O), the triplet state energy $\mathrm{E}_{\mathrm{T} 1}$, the enthalpy $\Delta \mathrm{H}_{\text {cleavageT1 }}$ for cleavage process

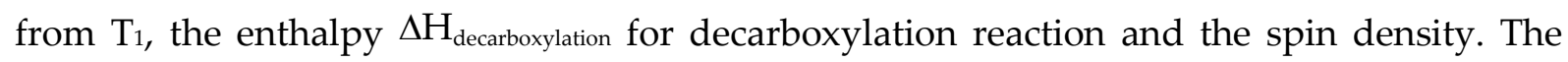
singlet excited state energy Es1, the enthalpy $\Delta \mathrm{H}_{\text {cleavages1 }}$ for cleavage process from $\mathrm{S}_{1}$, and the fluorescence lifetime of the OXEs were measured experimentally.

\begin{tabular}{|c|c|c|c|c|c|c|c|c|}
\hline PI & $\begin{array}{c}\text { BDE } \\
(\mathrm{N}-\mathrm{O}) \\
\left.\text { (kcal.mol }{ }^{-1}\right)\end{array}$ & $\begin{array}{c}\mathrm{E}_{\mathrm{S1}} \\
\text { (kcal.mol } \\
{ }^{1} \text { ) }\end{array}$ & 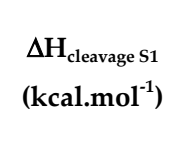 & $\begin{array}{l}*_{0} \\
(\mathrm{~S} 1) \\
(\mathrm{ns})\end{array}$ & $\begin{array}{c}\mathrm{E}_{\mathrm{T1}} \\
\text { (kcal.mol } \\
{ }^{1} \text { ) }\end{array}$ & $\begin{array}{c}\Delta \mathbf{H}_{\text {cleavage T1 }} \\
\left(\text { kcal.mol }^{-1}\right)\end{array}$ & $\begin{array}{c}\Delta \mathrm{H}_{\text {decarboxylation }} \\
\left({\mathrm{kccal} . \mathrm{mol}^{-1}}^{-1}\right)\end{array}$ & $\begin{array}{c}\text { Spin } \\
\text { density } \\
\left(\mathbf{R}^{*}\right)\end{array}$ \\
\hline C138 & 64.56 & 61.8 & 2.76 & 3.36 & 42.70 & 21.86 & - & - \\
\hline C139 & 42.31 & 59.72 & -17.41 & 1.92 & 47.49 & -5.18 & 0.52 & 0.999 \\
\hline C140 & 48.42 & 59.26 & -10.84 & 1.65 & 44.67 & 3.75 & 5.92 & 0.989 \\
\hline C141 & 48.87 & 60.42 & -11.55 & 1.89 & 44.83 & 4.04 & -4.94 & 1.156 \\
\hline C142 & 45.54 & 59.49 & -13.95 & 1.64 & 44.74 & 0.8 & 4.36 & 0.999 \\
\hline C143 & 48.34 & 59.26 & -10.92 & 1.61 & 44.60 & 3.74 & 6.24 & 0.995 \\
\hline C144 & 48.14 & 59.03 & -10.89 & 1.65 & 44.61 & 3.53 & 6.92 & 0.990 \\
\hline C145 & 47.85 & 58.57 & -10.72 & 1.79 & 44.51 & 3.34 & 8.77 & 0.996 \\
\hline C146 & 48.13 & 59.49 & -11.36 & 1.58 & 44.61 & 3.52 & 6.97 & 0.989 \\
\hline C147 & 50.58 & - & - & - & 44.78 & 5.8 & 3.14 & 0.998 \\
\hline C148 & 49.09 & 59.72 & -10.63 & 0.989 & 44.42 & 4.67 & 7.64 & 1.076 \\
\hline
\end{tabular}

Interestingly, all oxime-esters could behave as thermal initiators and decomposition temperatures ranging from $166^{\circ} \mathrm{C}$ for $\mathrm{C} 144$ to $198^{\circ} \mathrm{C}$ for $\mathrm{C} 147$ could be determined. The dual photochemical and thermal initiating ability was thus demonstrated for all oxime esters (See Table 19). Considering that oxime-esters strongly absorb in the visible range, their use as Type II photoinitiators in combination with an iodonium salt was examined. Excellent polymerization profiles could be determined during the FRP of TMPTA (See Figure 45 and Table 20). Steady state photolysis experiments done with and without iodonium salt revealed the photolysis of oxime-esters to be much faster in the presence of iodonium salt. It was thus concluded that the electron transfer from the coumarin chromophore towards the iodonium salt was much favorable that the direct $\mathrm{N}-\mathrm{O}$ cleavage. 
Table 19. Maximal polymerization temperatures for TMPTA using OXE $(1 \% \mathrm{w})$ as thermal initiators under $\mathrm{N}_{2}$.

\begin{tabular}{|c|c|c|c|c|c|c|c|c|c|c|}
\hline PI & C139 & C140 & C141 & C142 & C143 & C144 & C145 & C146 & C147 & C148 \\
\hline $\begin{array}{l}\mathrm{T}_{\max } \\
\left({ }^{\circ} \mathrm{C}\right)\end{array}$ & 209 & 215 & 181 & 205 & 208 & 207 & 212 & 212 & 215 & 210 \\
\hline $\begin{array}{l}\text { Tonse } \\
t\left({ }^{\circ} \mathrm{C}\right)\end{array}$ & 170 & 186 & 155 & 171 & 169 & 166 & 180 & 186 & 198 & 173 \\
\hline
\end{tabular}

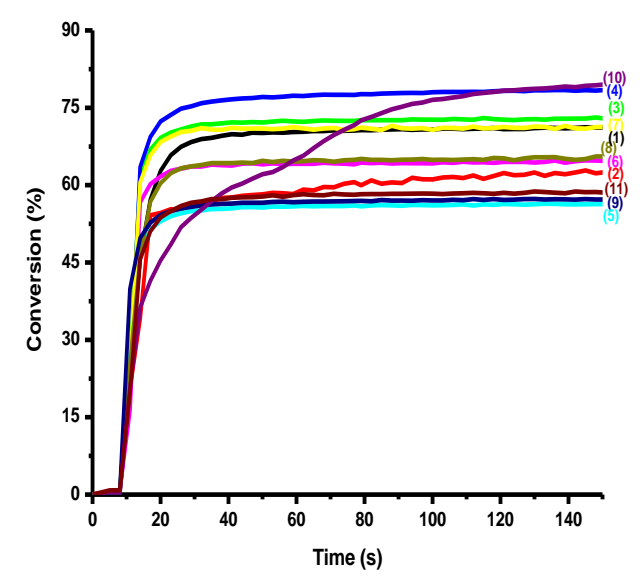

Figure 45. Photopolymerization profiles of TMPTA (acrylate function conversion vs. irradiation time) in laminate (thickness $=25 \mu \mathrm{m}$ ) upon exposure to LED light $\lambda=405 \mathrm{~nm}$ in the presence of: (1) C138/Iod (0.5\%/1\% w/w); (2) C139/Iod (0.5\%/1\% w/w); (3) C140/Iod (0.5\%/1\% w/w); (4) C141/Iod (0.5\%/1\% w/w); (5) C142/Iod (0.5\%/1\% w/w); (6) C143/Iod (0.5\%/1\% w/w); (7) C144/Iod (0.5\%/1\% w/w); (8) C145/Iod (0.5\%/1\% w/w); (9) C146/Iod (0.5\%/1\% w/w); (10) $\mathrm{C} 147 / \operatorname{Iod}(0.5 \% / 1 \% \mathrm{w} / \mathrm{w}) ;$ and $(11) \mathrm{C} 148 / \operatorname{Iod}(0.5 \% / 1 \% \mathrm{w} / \mathrm{w}) ;$ respectively. The irradiation starts for $t=10 \mathrm{~s}$. Reprinted with permission from Hammoud et al. [265]

Table 20. Final monomer conversion obtained for TMPTA using coumarin/Iod $(0.5 \% / 1 \%$ $\mathrm{w} / \mathrm{w})$ as photoinitiating systems after $100 \mathrm{~s}$ of irradiation with LED light $(\lambda=405 \mathrm{~nm})$ in laminate.

\begin{tabular}{|c|c|c|c|c|c|c|c|c|c|c|c|}
\hline PI & C138 & C139 & C140 & C141 & C142 & C143 & C144 & C145 & C146 & C147 & 148 \\
\hline $\begin{array}{c}\text { Final } \\
\text { monomer } \\
\text { conversion } \\
\text { (FC) }(\%)\end{array}$ & 71 & 63 & 73 & 78 & 56 & 65 & 71 & 66 & 57 & 79 & 59 \\
\hline
\end{tabular}




\section{Conclusion}

To conclude, coumarins are versatile structures that are incorporated in photoinitiating systems since 1983. Over the years, almost 150 structures have been tested in photopolymerization. Scope of applications of coumarins has also greatly evolved over the years. Thus, if coumarins were historically used as Type II photoinitiators, recently, Type I photoinitiators have also been proposed, enabling to generate mono-component photoinitiating systems. With aim at simplifying the photocurable resins, coumarin-based iodonium salts have also been designed, providing highly efficient photoinitiating systems activable under visible light. Future works concerning coumarins will certainly consist in developing photoinitiating systems based on charge transfer complexes with coumarins, but also to develop water-soluble coumarins. Indeed, water-soluble coumarins could pave the way towards greener polymerization conditions and the preparation of hydrogels.

\section{Acknowledgments}

Aix Marseille University and the Centre National de la Recherche Scientifique (CNRS) are acknowledged for financial supports.

\section{Conflicts of Interest}

The authors declare no conflict of interest.

\section{References}

[1] J. Lalevée, H. Mokbel, J.-P. Fouassier, Recent Developments of Versatile Photoinitiating Systems for Cationic Ring Opening Polymerization Operating at Any Wavelengths and under Low Light Intensity Sources, Molecules. 20 (2015) 7201-7221. https://doi.org/10.3390/molecules20047201.

[2] M.A. Tehfe, F. Louradour, J. Lalevée, J.-P. Fouassier, Photopolymerization Reactions: On the Way to a Green and Sustainable Chemistry, Applied Sciences. 3 (2013) 490-514. https://doi.org/10.3390/app3020490.

[3] S. Shanmugam, J. Xu, C. Boyer, Photocontrolled Living Polymerization Systems with Reversible Deactivations through Electron and Energy Transfer, Macromolecular Rapid Communications. 38 (2017) 1700143. https://doi.org/10.1002/marc.201700143.

[4] F. Jasinski, P.B. Zetterlund, A.M. Braun, A. Chemtob, Photopolymerization in dispersed systems, Progress in Polymer Science. 84 (2018) 47-88. https://doi.org/10.1016/j.progpolymsci.2018.06.006.

[5] C. Noè, M. Hakkarainen, M. Sangermano, Cationic UV-Curing of Epoxidized Biobased Resins, Polymers. 13 (2021) 89. https://doi.org/10.3390/polym13010089.

[6] Y. Yuan, C. Li, R. Zhang, R. Liu, J. Liu, Low volume shrinkage photopolymerization system using hydrogen-bond-based monomers, Progress in Organic Coatings. 137 (2019) 105308. https://doi.org/10.1016/j.porgcoat.2019.105308.

[7] I.V. Khudyakov, J.C. Legg, M.B. Purvis, B.J. Overton, Kinetics of Photopolymerization of Acrylates with Functionality of 1-6, Ind. Eng. Chem. Res. 38 (1999) 3353-3359. https://doi.org/10.1021/ie990306i. 
[8] S.H. Dickens, J.W. Stansbury, K.M. Choi, C.J.E. Floyd, Photopolymerization Kinetics of Methacrylate Dental Resins, Macromolecules. 36 (2003) 6043-6053. https://doi.org/10.1021/ma021675k.

[9] A. Maffezzoli, A.D. Pietra, S. Rengo, L. Nicolais, G. Valletta, Photopolymerization of dental composite matrices, Biomaterials. 15 (1994) 1221-1228. https://doi.org/10.1016/0142-9612(94)90273-9.

[10] T. Dikova, J. Maximov, V. Todorov, G. Georgiev, V. Panov, Optimization of Photopolymerization Process of Dental Composites, Processes. 9 (2021) 779. https://doi.org/10.3390/pr9050779.

[11] A. Bagheri, J. Jin, Photopolymerization in 3D Printing, ACS Appl. Polym. Mater. 1 (2019) 593-611. https://doi.org/10.1021/acsapm.8b00165.

[12] X. Xu, A. Awad, P. Robles-Martinez, S. Gaisford, A. Goyanes, A.W. Basit, Vat photopolymerization 3D printing for advanced drug delivery and medical device applications, Journal of Controlled Release. 329 (2021) 743-757. https://doi.org/10.1016/j.jconrel.2020.10.008.

[13] A. Andreu, P.-C. Su, J.-H. Kim, C.S. Ng, S. Kim, I. Kim, J. Lee, J. Noh, A.S. Subramanian, Y.-J. Yoon, 4D printing materials for vat photopolymerization, Additive Manufacturing. 44 (2021) 102024. https://doi.org/10.1016/j.addma.2021.102024.

[14] Y. Zhang, L. Josien, J.-P. Salomon, A. Simon-Masseron, J. Lalevée, Photopolymerization of Zeolite/Polymer-Based Composites: toward 3D and 4D Printing Applications, ACS Appl. Polym. Mater. 3 (2021) 400-409. https://doi.org/10.1021/acsapm.0c01170.

[15] H. Zhao, J. Sha, X. Wang, Y. Jiang, T. Chen, T. Wu, X. Chen, H. Ji, Y. Gao, L. Xie, Y. Ma, Spatiotemporal control of polymer brush formation through photoinduced radical polymerization regulated by DMD light modulation, Lab Chip. 19 (2019) 2651-2662. https://doi.org/10.1039/C9LC00419J.

[16] W. Xi, H. Peng, A. Aguirre-Soto, C.J. Kloxin, J.W. Stansbury, C.N. Bowman, Spatial and Temporal Control of Thiol-Michael Addition via Photocaged Superbase in Photopatterning and Two-Stage Polymer Networks Formation, Macromolecules. 47 (2014) 6159-6165. https://doi.org/10.1021/ma501366f.

[17] J. Shao, Y. Huang, Q. Fan, Visible light initiating systems for photopolymerization: status, development and challenges, Polym. Chem. 5 (2014) 4195-4210. https://doi.org/10.1039/C4PY00072B.

[18] A.H. Bonardi, F. Dumur, T.M. Grant, G. Noirbent, D. Gigmes, B.H. Lessard, J.-P. Fouassier, J. Lalevée, High Performance Near-Infrared (NIR) Photoinitiating Systems Operating under Low Light Intensity and in the Presence of Oxygen, Macromolecules. 51 (2018) 1314-1324. https://doi.org/10.1021/acs.macromol.8b00051.

[19] P. Garra, C. Dietlin, F. Morlet-Savary, F. Dumur, D. Gigmes, J.-P. Fouassier, J. Lalevée, Photopolymerization processes of thick films and in shadow areas: a review for the access to composites, Polym. Chem. 8 (2017) 7088-7101. https://doi.org/10.1039/C7PY01778B.

[20] F. Takemura, Dye-sensitized Photopolymerization of Vinyl Monomers. II. Photobleaching of Acridine Yellow in Some Vinyl Monomers, BCSJ. 35 (1962) 1078-1086. https://doi.org/10.1246/bcsj.35.1078.

[21] T. Xue, L. Tang, R. Tang, Y. Li, J. Nie, X. Zhu, Color evolution of a pyrrole-based enone dye in radical photopolymerization formulations, Dyes and Pigments. 188 (2021) 109212. https://doi.org/10.1016/j.dyepig.2021.109212. 
[22] W. Han, H. Fu, T. Xue, T. Liu, Y. Wang, T. Wang, Facilely prepared blue-green light sensitive curcuminoids with excellent bleaching properties as high performance photosensitizers in cationic and free radical photopolymerization, Polym. Chem. 9 (2018) 1787-1798. https://doi.org/10.1039/C8PY00166A.

[23] N. Zivic, M. Bouzrati-Zerrelli, S. Villotte, F. Morlet-Savary, C. Dietlin, F. Dumur, D. Gigmes, J.P. Fouassier, J. Lalevée, A novel naphthalimide scaffold based iodonium salt as a one-component photoacid/photoinitiator for cationic and radical polymerization under LED exposure, Polym. Chem. 7 (2016) 5873-5879.

https://doi.org/10.1039/C6PY01306F.

[24] A.-H. Bonardi, S. Zahouily, C. Dietlin, B. Graff, F. Morlet-Savary, M. Ibrahim-Ouali, D. Gigmes, N. Hoffmann, F. Dumur, J. Lalevée, New 1,8-Naphthalimide Derivatives as Photoinitiators for Free-Radical Polymerization Upon Visible Light, Catalysts. 9 (2019) 637. https://doi.org/10.3390/catal9080637.

[25] J. Zhang, N. Zivic, F. Dumur, P. Xiao, B. Graff, J.P. Fouassier, D. Gigmes, J. Lalevée, Naphthalimide-Tertiary Amine Derivatives as Blue-Light-Sensitive Photoinitiators, ChemPhotoChem. 2 (2018) 481-489. https://doi.org/10.1002/cptc.201800006.

[26] P. Xiao, F. Dumur, J. Zhang, B. Graff, D. Gigmes, J.P. Fouassier, J. Lalevée, Naphthalimide Derivatives: Substituent Effects on the Photoinitiating Ability in Polymerizations under Near UV, Purple, White and Blue LEDs (385, 395, 405, 455, or $470 \mathrm{~nm}$ ), Macromolecular Chemistry and Physics. 216 (2015) 1782-1790. https://doi.org/10.1002/macp.201500150.

[27] P. Xiao, F. Dumur, J. Zhang, B. Graff, D. Gigmes, J.P. Fouassier, J. Lalevée, Naphthalimide-phthalimide derivative based photoinitiating systems for polymerization reactions under blue lights, Journal of Polymer Science Part A: Polymer Chemistry. 53 (2015) 665-674. https://doi.org/10.1002/pola.27490.

[28] J. Zhang, N. Zivic, F. Dumur, P. Xiao, B. Graff, D. Gigmes, J.P. Fouassier, J. Lalevée, A benzophenone-naphthalimide derivative as versatile photoinitiator of polymerization under near UV and visible lights, Journal of Polymer Science Part A: Polymer Chemistry. 53 (2015) 445-451. https://doi.org/10.1002/pola.27451.

[29] J. Zhang, N. Zivic, F. Dumur, P. Xiao, B. Graff, J.P. Fouassier, D. Gigmes, J. Lalevée, N[2-(Dimethylamino)ethyl]-1,8-naphthalimide derivatives as photoinitiators under LEDs, Polym. Chem. 9 (2018) 994-1003. https://doi.org/10.1039/C8PY00055G.

[30] J. Zhang, F. Dumur, P. Xiao, B. Graff, D. Bardelang, D. Gigmes, J.P. Fouassier, J. Lalevée, Structure Design of Naphthalimide Derivatives: Toward Versatile Photoinitiators for Near-UV/Visible LEDs, 3D Printing, and Water-Soluble Photoinitiating Systems, Macromolecules. 48 (2015) 2054-2063. https://doi.org/10.1021/acs.macromol.5b00201.

[31] J. Zhang, N. Zivic, F. Dumur, P. Xiao, B. Graff, J.P. Fouassier, D. Gigmes, J. Lalevée, UV-violet-blue LED induced polymerizations: Specific photoinitiating systems at 365, 385, 395 and 405 nm, Polymer. 55 (2014) 6641-6648. https://doi.org/10.1016/j.polymer.2014.11.002.

[32] P. Xiao, F. Dumur, B. Graff, D. Gigmes, J.P. Fouassier, J. Lalevée, Blue Light Sensitive Dyes for Various Photopolymerization Reactions: Naphthalimide and Naphthalic Anhydride Derivatives., Macromolecules. 47 (2014) 601-608. https://doi.org/10.1021/ma402376x.

[33] P. Xiao, F. Dumur, M. Frigoli, M.-A. Tehfe, B. Graff, J.P. Fouassier, D. Gigmes, J. Lalevée, Naphthalimide based methacrylated photoinitiators in radical and cationic 
photopolymerization under visible light, Polym. Chem. 4 (2013) 5440-5448. https://doi.org/10.1039/C3PY00766A.

[34] G. Noirbent, F. Dumur, Recent advances on naphthalic anhydrides and 1,8naphthalimide-based photoinitiators of polymerization, European Polymer Journal. 132 (2020) 109702. https://doi.org/10.1016/j.eurpolymj.2020.109702.

[35] M. Rahal, H. Mokbel, B. Graff, V. Pertici, D. Gigmes, J. Toufaily, T. Hamieh, F. Dumur, J. Lalevée, Naphthalimide-Based Dyes as Photoinitiators under Visible Light Irradiation and their Applications: Photocomposite Synthesis, 3D printing and Polymerization in Water, ChemPhotoChem. 5 (2021) 476-490. https://doi.org/10.1002/cptc.202000306.

[36] N. Giacoletto, M. Ibrahim-Ouali, F. Dumur, Recent advances on squaraine-based photoinitiators of polymerization, European Polymer Journal. 150 (2021) 110427. https://doi.org/10.1016/j.eurpolymj.2021.110427.

[37] P. Xiao, F. Dumur, T.T. Bui, F. Goubard, B. Graff, F. Morlet-Savary, J.P. Fouassier, D. Gigmes, J. Lalevée, Panchromatic Photopolymerizable Cationic Films Using Indoline and Squaraine Dye Based Photoinitiating Systems, ACS Macro Lett. 2 (2013) 736-740. https://doi.org/10.1021/mz400316y.

[38] V. Launay, A. Caron, G. Noirbent, D. Gigmes, F. Dumur, J. Lalevée, NIR Organic Dyes as Innovative Tools for Reprocessing/Recycling of Plastics: Benefits of the Photothermal Activation in the Near-Infrared Range, Advanced Functional Materials. 31 (2021) 2006324. https://doi.org/10.1002/adfm.202006324.

[39] A. Bonardi, F. Bonardi, G. Noirbent, F. Dumur, C. Dietlin, D. Gigmes, J.-P. Fouassier, J. Lalevée, Different NIR dye scaffolds for polymerization reactions under NIR light, Polym. Chem. 10 (2019) 6505-6514. https://doi.org/10.1039/C9PY01447K.

[40] S. Telitel, F. Dumur, D. Campolo, J. Poly, D. Gigmes, J.P. Fouassier, J. Lalevée, Iron complexes as potential photocatalysts for controlled radical photopolymerizations: A tool for modifications and patterning of surfaces, Journal of Polymer Science Part A: Polymer Chemistry. 54 (2016) 702-713. https://doi.org/10.1002/pola.27896.

[41] J. Zhang, D. Campolo, F. Dumur, P. Xiao, J.P. Fouassier, D. Gigmes, J. Lalevée, Iron complexes as photoinitiators for radical and cationic polymerization through photoredox catalysis processes, Journal of Polymer Science Part A: Polymer Chemistry. 53 (2015) 42-49. https://doi.org/10.1002/pola.27435.

[42] J. Zhang, D. Campolo, F. Dumur, P. Xiao, J.P. Fouassier, D. Gigmes, J. Lalevée, Visiblelight-sensitive photoredox catalysis by iron complexes: Applications in cationic and radical polymerization reactions, Journal of Polymer Science Part A: Polymer Chemistry. 54 (2016) 2247-2253. https://doi.org/10.1002/pola.28098.

[43] J. Zhang, D. Campolo, F. Dumur, P. Xiao, J.P. Fouassier, D. Gigmes, J. Lalevée, Iron Complexes in Visible-Light-Sensitive Photoredox Catalysis: Effect of Ligands on Their Photoinitiation Efficiencies, ChemCatChem. 8 (2016) 2227-2233.

https://doi.org/10.1002/cctc.201600320.

[44] J. Zhang, F. Dumur, P. Horcajada, C. Livage, P. Xiao, J.P. Fouassier, D. Gigmes, J. Lalevée, Iron-Based Metal-Organic Frameworks (MOF) as Photocatalysts for Radical and Cationic Polymerizations under Near UV and Visible LEDs (385-405 nm), Macromolecular Chemistry and Physics. 217 (2016) 2534-2540. https://doi.org/10.1002/macp.201600352.

[45] F. Dumur, Recent advances on ferrocene-based photoinitiating systems, European Polymer Journal. 147 (2021) 110328. https://doi.org/10.1016/j.eurpolymj.2021.110328. 
[46] P. Garra, D. Brunel, G. Noirbent, B. Graff, F. Morlet-Savary, C. Dietlin, V.F. Sidorkin, F. Dumur, D. Duché, D. Gigmes, J.-P. Fouassier, J. Lalevée, Ferrocene-based (photo)redox polymerization under long wavelengths, Polym. Chem. 10 (2019) 1431-1441. https://doi.org/10.1039/C9PY00059C.

[47] N. Karaca, N. Ocal, N. Arsu, S. Jockusch, Thioxanthone-benzothiophenes as photoinitiator for free radical polymerization, Journal of Photochemistry and Photobiology A: Chemistry. 331 (2016) 22-28. https://doi.org/10.1016/j.jphotochem.2016.01.017.

[48] D.K. Balta, N. Cetiner, G. Temel, Z. Turgut, N. Arsu, An annelated thioxanthone as a new Type II initiator, Journal of Photochemistry and Photobiology A: Chemistry. 199 (2008) 316-321. https://doi.org/10.1016/j.jphotochem.2008.06.008.

[49] D.K. Balta, G. Temel, G. Goksu, N. Ocal, N. Arsu, Thioxanthone-Diphenyl Anthracene: Visible Light Photoinitiator, Macromolecules. 45 (2012) 119-125. https://doi.org/10.1021/ma202168m.

[50] S. Dadashi-Silab, C. Aydogan, Y. Yagci, Shining a light on an adaptable photoinitiator: advances in photopolymerizations initiated by thioxanthones, Polym. Chem. 6 (2015) 6595-6615. https://doi.org/10.1039/C5PY01004G.

[51] T.N. Eren, N. Yasar, V. Aviyente, F. Morlet-Savary, B. Graff, J.P. Fouassier, J. Lalevee, D. Avci, Photophysical and Photochemical Studies of Novel ThioxanthoneFunctionalized Methacrylates through LED Excitation, Macromolecular Chemistry and Physics. 217 (2016) 1501-1512. https://doi.org/10.1002/macp.201600051.

[52] J. Qiu, J. Wei, Thioxanthone photoinitiator containing polymerizable N-aromatic maleimide for photopolymerization, J Polym Res. 21 (2014) 559. https://doi.org/10.1007/s10965-014-0559-4.

[53] H. Tar, D. Sevinc Esen, M. Aydin, C. Ley, N. Arsu, X. Allonas, Panchromatic Type II Photoinitiator for Free Radical Polymerization Based on Thioxanthone Derivative, Macromolecules. 46 (2013) 3266-3272. https://doi.org/10.1021/ma302641d.

[54] Q. Wu, X. Wang, Y. Xiong, J. Yang, H. Tang, Thioxanthone based one-component polymerizable visible light photoinitiator for free radical polymerization, RSC Adv. 6 (2016) 66098-66107. https://doi.org/10.1039/C6RA15349F.

[55] Q. Wu, K. Tang, Y. Xiong, X. Wang, J. Yang, H. Tang, High-Performance and Low Migration One-Component Thioxanthone Visible Light Photoinitiators, Macromolecular Chemistry and Physics. 218 (2017) 1600484. https://doi.org/10.1002/macp.201600484.

[56] X. Wu, M. Jin, J.-P. Malval, D. Wan, H. Pu, Visible light-emitting diode-sensitive thioxanthone derivatives used in versatile photoinitiating systems for photopolymerizations, Journal of Polymer Science Part A: Polymer Chemistry. 55 (2017) 4037-4045. https://doi.org/10.1002/pola.28871.

[57] B. Corakci, S.O. Hacioglu, L. Toppare, U. Bulut, Long wavelength photosensitizers in photoinitiated cationic polymerization: The effect of quinoxaline derivatives on photopolymerization, Polymer. 54 (2013) 3182-3187. https://doi.org/10.1016/j.polymer.2013.04.008.

[58] P. Xiao, F. Dumur, D. Thirion, S. Fagour, A. Vacher, X. Sallenave, F. Morlet-Savary, B. Graff, J.P. Fouassier, D. Gigmes, J. Lalevée, Multicolor Photoinitiators for Radical and Cationic Polymerization: Monofunctional vs Polyfunctional Thiophene Derivatives, Macromolecules. 46 (2013) 6786-6793. https://doi.org/10.1021/ma401389t. 
[59] J. Lalevée, M. Peter, F. Dumur, D. Gigmes, N. Blanchard, M.-A. Tehfe, F. MorletSavary, J.P. Fouassier, Subtle Ligand Effects in Oxidative Photocatalysis with Iridium Complexes: Application to Photopolymerization, Chemistry - A European Journal. 17 (2011) 15027-15031. https://doi.org/10.1002/chem.201101445.

[60] J. Lalevée, M.-A. Tehfe, F. Dumur, D. Gigmes, N. Blanchard, F. Morlet-Savary, J.P. Fouassier, Iridium Photocatalysts in Free Radical Photopolymerization under Visible Lights, ACS Macro Lett. 1 (2012) 286-290. https://doi.org/10.1021/mz2001753.

[61] J. Lalevée, F. Dumur, C.R. Mayer, D. Gigmes, G. Nasr, M.-A. Tehfe, S. Telitel, F. Morlet-Savary, B. Graff, J.P. Fouassier, Photopolymerization of N-Vinylcarbazole Using Visible-Light Harvesting Iridium Complexes as Photoinitiators, Macromolecules. 45 (2012) 4134-4141. https://doi.org/10.1021/ma3005229.

[62] M.-A. Tehfe, M. Lepeltier, F. Dumur, D. Gigmes, J.-P. Fouassier, J. Lalevée, Structural Effects in the Iridium Complex Series: Photoredox Catalysis and Photoinitiation of Polymerization Reactions under Visible Lights, Macromolecular Chemistry and Physics. 218 (2017) 1700192. https://doi.org/10.1002/macp.201700192.

[63] S. Telitel, F. Dumur, S. Telitel, O. Soppera, M. Lepeltier, Y. Guillaneuf, J. Poly, F. Morlet-Savary, P. Fioux, J.-P. Fouassier, D. Gigmes, J. Lalevée, Photoredox catalysis using a new iridium complex as an efficient toolbox for radical, cationic and controlled polymerizations under soft blue to green lights, Polym. Chem. 6 (2014) 613-624. https://doi.org/10.1039/C4PY01358A.

[64] S. Telitel, F. Dumur, M. Lepeltier, D. Gigmes, J.-P. Fouassier, J. Lalevée, Photoredox process induced polymerization reactions: Iridium complexes for panchromatic photoinitiating systems, Comptes Rendus Chimie. 19 (2016) 71-78. https://doi.org/10.1016/j.crci.2015.06.016.

[65] F. Dumur, D. Bertin, D. Gigmes, Iridium (III) complexes as promising emitters for solid-state Light-Emitting Electrochemical Cells (LECs), International Journal of Nanotechnology. 9 (2012) 377-395. https://doi.org/10.1504/IJNT.2012.045343.

[66] P. Xiao, F. Dumur, M. Frigoli, B. Graff, F. Morlet-Savary, G. Wantz, H. Bock, J.P. Fouassier, D. Gigmes, J. Lalevée, Perylene derivatives as photoinitiators in blue light sensitive cationic or radical curable films and panchromatic thiol-ene polymerizable films, European Polymer Journal. 53 (2014) 215-222. https://doi.org/10.1016/j.eurpolymj.2014.01.024.

[67] P. Xiao, F. Dumur, B. Graff, D. Gigmes, J.P. Fouassier, J. Lalevée, Red-Light-Induced Cationic Photopolymerization: Perylene Derivatives as Efficient Photoinitiators, Macromolecular Rapid Communications. 34 (2013) 1452-1458. https://doi.org/10.1002/marc.201300383.

[68] F. Dumur, Recent advances on perylene-based photoinitiators of polymerization, European Polymer Journal. 159 (2021) 110734. https://doi.org/10.1016/j.eurpolymj.2021.110734.

[69] H. Chen, G. Noirbent, K. Sun, D. Brunel, D. Gigmes, F. Morlet-Savary, Y. Zhang, S. Liu, P. Xiao, F. Dumur, J. Lalevée, Photoinitiators derived from natural product scaffolds: monochalcones in three-component photoinitiating systems and their applications in 3D printing, Polym. Chem. 11 (2020) 4647-4659. https://doi.org/10.1039/D0PY00568A.

[70] L. Tang, J. Nie, X. Zhu, A high performance phenyl-free LED photoinitiator for cationic or hybrid photopolymerization and its application in LED cationic 3D printing, Polym. Chem. 11 (2020) 2855-2863. https://doi.org/10.1039/D0PY00142B. 
[71] Y. Xu, G. Noirbent, D. Brunel, Z. Ding, D. Gigmes, B. Graff, P. Xiao, F. Dumur, J. Lalevée, Allyloxy ketones as efficient photoinitiators with high migration stability in free radical polymerization and 3D printing, Dyes and Pigments. 185 (2021) 108900. https://doi.org/10.1016/j.dyepig.2020.108900.

[72] Y. Xu, Z. Ding, H. Zhu, B. Graff, S. Knopf, P. Xiao, F. Dumur, J. Lalevée, Design of ketone derivatives as highly efficient photoinitiators for free radical and cationic photopolymerizations and application in 3D printing of composites, Journal of Polymer Science. 58 (2020) 3432-3445. https://doi.org/10.1002/pol.20200658.

[73] H. Chen, G. Noirbent, S. Liu, D. Brunel, B. Graff, D. Gigmes, Y. Zhang, K. Sun, F. Morlet-Savary, P. Xiao, F. Dumur, J. Lalevée, Bis-chalcone derivatives derived from natural products as near-UV/visible light sensitive photoinitiators for $3 \mathrm{D} / 4 \mathrm{D}$ printing, Mater. Chem. Front. 5 (2021) 901-916. https://doi.org/10.1039/D0QM00755B.

[74] S. Liu, Y. Zhang, K. Sun, B. Graff, P. Xiao, F. Dumur, J. Lalevée, Design of photoinitiating systems based on the chalcone-anthracene scaffold for LED cationic photopolymerization and application in 3D printing, European Polymer Journal. 147 (2021) 110300. https://doi.org/10.1016/j.eurpolymj.2021.110300.

[75] N. Giacoletto, F. Dumur, Recent Advances in bis-Chalcone-Based Photoinitiators of Polymerization: From Mechanistic Investigations to Applications, Molecules. 26 (2021) 3192. https://doi.org/10.3390/molecules26113192.

[76] H. Chen, G. Noirbent, Y. Zhang, K. Sun, S. Liu, D. Brunel, D. Gigmes, B. Graff, F. Morlet-Savary, P. Xiao, F. Dumur, J. Lalevée, Photopolymerization and 3D/4D applications using newly developed dyes: Search around the natural chalcone scaffold in photoinitiating systems, Dyes and Pigments. 188 (2021) 109213. https://doi.org/10.1016/j.dyepig.2021.109213.

[77] M. Ibrahim-Ouali, F. Dumur, Recent Advances on Chalcone-based Photoinitiators of Polymerization, European Polymer Journal. (2021) 110688. https://doi.org/10.1016/j.eurpolymj.2021.110688.

[78] H. Chen, G. Noirbent, S. Liu, Y. Zhang, K. Sun, F. Morlet-Savary, D. Gigmes, P. Xiao, F. Dumur, J. Lalevée, In situ generation of Ag nanoparticles during photopolymerization by using newly developed dyes-based three-component photoinitiating systems and the related 3D printing applications and their shape change behavior, Journal of Polymer Science. 59 (2021) 843-859. https://doi.org/10.1002/pol.20210154.

[79] H. Chen, M. Vahdati, P. Xiao, F. Dumur, J. Lalevée, Water-Soluble Visible Light Sensitive Photoinitiating System Based on Charge Transfer Complexes for the 3D Printing of Hydrogels, Polymers. 13 (2021). https://doi.org/10.3390/polym13183195.

[80] M.-A. Tehfe, F. Dumur, E. Contal, B. Graff, F. Morlet-Savary, D. Gigmes, J.-P. Fouassier, J. Lalevée, New insights into radical and cationic polymerizations upon visible light exposure: role of novel photoinitiator systems based on the pyrene chromophore, Polym. Chem. 4 (2013) 1625-1634. https://doi.org/10.1039/C2PY20950K.

[81] S. Telitel, F. Dumur, T. Faury, B. Graff, M.-A. Tehfe, D. Gigmes, J.-P. Fouassier, J. Lalevée, New core-pyrene $\pi$ structure organophotocatalysts usable as highly efficient photoinitiators, Beilstein J. Org. Chem. 9 (2013) 877-890.

https://doi.org/10.3762/bjoc.9.101.

[82] N. Uchida, H. Nakano, T. Igarashi, T. Sakurai, Nonsalt 1-(arylmethyloxy)pyrene photoinitiators capable of initiating cationic polymerization, Journal of Applied Polymer Science. 131 (2014). https://doi.org/10.1002/app.40510. 
[83] A. Mishra, S. Daswal, 1-(Bromoacetyl)pyrene, a novel photoinitiator for the copolymerization of styrene and methylmethacrylate, Radiation Physics and Chemistry. 75 (2006) 1093-1100. https://doi.org/10.1016/j.rad physchem.2006.01.013.

[84] M.-A. Tehfe, F. Dumur, B. Graff, F. Morlet-Savary, D. Gigmes, J.-P. Fouassier, J. Lalevée, Design of new Type I and Type II photoinitiators possessing highly coupled pyrene-ketone moieties, Polym. Chem. 4 (2013) 2313-2324. https://doi.org/10.1039/C3PY21079K.

[85] F. Dumur, Recent advances on pyrene-based photoinitiators of polymerization, European Polymer Journal. 126 (2020) 109564. https://doi.org/10.1016/j.eurpolymj.2020.109564.

[86] A. Al Mousawi, C. Poriel, F. Dumur, J. Toufaily, T. Hamieh, J.P. Fouassier, J. Lalevée, Zinc Tetraphenylporphyrin as High Performance Visible Light Photoinitiator of Cationic Photosensitive Resins for LED Projector 3D Printing Applications, Macromolecules. 50 (2017) 746-753. https://doi.org/10.1021/acs.macromol.6b02596.

[87] G. Noirbent, Y. Xu, A.-H. Bonardi, D. Gigmes, J. Lalevée, F. Dumur, Metalated porphyrins as versatile visible light and NIR photoinitiators of polymerization, European Polymer Journal. 139 (2020) 110019. https://doi.org/10.1016/j.eurpolymj.2020.110019.

[88] M.-A. Tehfe, A. Zein-Fakih, J. Lalevée, F. Dumur, D. Gigmes, B. Graff, F. MorletSavary, T. Hamieh, J.-P. Fouassier, New pyridinium salts as versatile compounds for dye sensitized photopolymerization, European Polymer Journal. 49 (2013) 567-574. https://doi.org/10.1016/j.eurpolymj.2012.10.010.

[89] P. Xiao, M. Frigoli, F. Dumur, B. Graff, D. Gigmes, J.P. Fouassier, J. Lalevée, Julolidine or Fluorenone Based Push-Pull Dyes for Polymerization upon Soft Polychromatic Visible Light or Green Light., Macromolecules. 47 (2014) 106-112. https://doi.org/10.1021/ma402196p.

[90] H. Mokbel, F. Dumur, B. Graff, C.R. Mayer, D. Gigmes, J. Toufaily, T. Hamieh, J.-P. Fouassier, J. Lalevée, Michler's Ketone as an Interesting Scaffold for the Design of High-Performance Dyes in Photoinitiating Systems Upon Visible Light, Macromolecular Chemistry and Physics. 215 (2014) 783-790. https://doi.org/10.1002/macp.201300779.

[91] M.-A. Tehfe, F. Dumur, B. Graff, F. Morlet-Savary, J.-P. Fouassier, D. Gigmes, J. Lalevée, New Push-Pull Dyes Derived from Michler's Ketone For Polymerization Reactions Upon Visible Lights., Macromolecules. 46 (2013) 3761-3770. https://doi.org/10.1021/ma400766z.

[92] H. Mokbel, F. Dumur, C.R. Mayer, F. Morlet-Savary, B. Graff, D. Gigmes, J. Toufaily, T. Hamieh, J.-P. Fouassier, J. Lalevée, End capped polyenic structures as visible light sensitive photoinitiators for polymerization of vinylethers, Dyes and Pigments. 105 (2014) 121-129. https://doi.org/10.1016/j.dyepig.2014.02.002.

[93] S. Telitel, F. Dumur, T. Kavalli, B. Graff, F. Morlet-Savary, D. Gigmes, J.-P. Fouassier, J. Lalevée, The 1,3-bis(dicyanomethylidene)indane skeleton as a (photo) initiator in thermal ring opening polymerization at $\mathrm{RT}$ and radical or cationic photopolymerization, RSC Adv. 4 (2014) 15930-15936. https://doi.org/10.1039/C3RA42819B.

[94] P. Xiao, F. Dumur, B. Graff, F. Morlet-Savary, L. Vidal, D. Gigmes, J.P. Fouassier, J. Lalevée, Structural Effects in the Indanedione Skeleton for the Design of Low Intensity 
300-500 nm Light Sensitive Initiators., Macromolecules. 47 (2014) 26-34. https://doi.org/10.1021/ma402149g.

[95] K. Sun, S. Liu, C. Pigot, D. Brunel, B. Graff, M. Nechab, D. Gigmes, F. Morlet-Savary, Y. Zhang, P. Xiao, F. Dumur, J. Lalevée, Novel Push-Pull Dyes Derived from 1Hcyclopenta[b]naphthalene-1,3(2H)-dione as Versatile Photoinitiators for Photopolymerization and Their Related Applications: 3D Printing and Fabrication of Photocomposites, Catalysts. 10 (2020) 1196. https://doi.org/10.3390/catal10101196.

[96] K. Sun, S. Liu, H. Chen, F. Morlet-Savary, B. Graff, C. Pigot, M. Nechab, P. Xiao, F. Dumur, J. Lalevée, N-ethyl carbazole-1-allylidene-based push-pull dyes as efficient light harvesting photoinitiators for sunlight induced polymerization, European Polymer Journal. 147 (2021) 110331. https://doi.org/10.1016/j.eurpolymj.2021.110331.

[97] M.-A. Tehfe, F. Dumur, B. Graff, F. Morlet-Savary, D. Gigmes, J.-P. Fouassier, J. Lalevée, Push-pull (thio)barbituric acid derivatives in dye photosensitized radical and cationic polymerization reactions under $457 / 473 \mathrm{~nm}$ laser beams or blue LEDs, Polym. Chem. 4 (2013) 3866-3875. https://doi.org/10.1039/C3PY00372H.

[98] K. Sun, H. Chen, Y. Zhang, F. Morlet-Savary, B. Graff, P. Xiao, F. Dumur, J. Lalevée, High-performance sunlight induced polymerization using novel push-pull dyes with high light absorption properties, European Polymer Journal. 151 (2021) 110410. https://doi.org/10.1016/j.eurpolymj.2021.110410.

[99] P. Xiao, F. Dumur, J. Zhang, J.P. Fouassier, D. Gigmes, J. Lalevée, Copper Complexes in Radical Photoinitiating Systems: Applications to Free Radical and Cationic Polymerization upon Visible LEDs, Macromolecules. 47 (2014) 3837-3844. https://doi.org/10.1021/ma5006793.

[100] P. Xiao, F. Dumur, J. Zhang, D. Gigmes, J.P. Fouassier, J. Lalevée, Copper complexes: the effect of ligands on their photoinitiation efficiencies in radical polymerization reactions under visible light, Polym. Chem. 5 (2014) 6350-6357. https://doi.org/10.1039/C4PY00925H.

[101] P. Xiao, J. Zhang, D. Campolo, F. Dumur, D. Gigmes, J.P. Fouassier, J. Lalevée, Copper and iron complexes as visible-light-sensitive photoinitiators of polymerization, Journal of Polymer Science Part A: Polymer Chemistry. 53 (2015) 2673-2684. https://doi.org/10.1002/pola.27762.

[102] P. Garra, M. Carré, F. Dumur, F. Morlet-Savary, C. Dietlin, D. Gigmes, J.-P. Fouassier, J. Lalevée, Copper-Based (Photo)redox Initiating Systems as Highly Efficient Systems for Interpenetrating Polymer Network Preparation, Macromolecules. 51 (2018) 679688. https://doi.org/10.1021/acs.macromol.7b02491.

[103] P. Garra, F. Dumur, F. Morlet-Savary, C. Dietlin, D. Gigmes, J.P. Fouassier, J. Lalevée, Mechanosynthesis of a Copper complex for redox initiating systems with a unique near infrared light activation, Journal of Polymer Science Part A: Polymer Chemistry. 55 (2017) 3646-3655. https://doi.org/10.1002/pola.28750.

[104] P. Garra, F. Dumur, A.A. Mousawi, B. Graff, D. Gigmes, F. Morlet-Savary, C. Dietlin, J.P. Fouassier, J. Lalevée, Mechanosynthesized copper(I) complex based initiating systems for redox polymerization: towards upgraded oxidizing and reducing agents, Polym. Chem. 8 (2017) 5884-5896. https://doi.org/10.1039/C7PY01244F.

[105] H. Mokbel, D. Anderson, R. Plenderleith, C. Dietlin, F. Morlet-Savary, F. Dumur, D. Gigmes, J.-P. Fouassier, J. Lalevée, Copper photoredox catalyst "G1": a new high performance photoinitiator for near-UV and visible LEDs, Polym. Chem. 8 (2017) 5580-5592. https://doi.org/10.1039/C7PY01016H. 
[106] H. Mokbel, D. Anderson, R. Plenderleith, C. Dietlin, F. Morlet-Savary, F. Dumur, D. Gigmes, J.P. Fouassier, J. Lalevée, Simultaneous initiation of radical and cationic polymerization reactions using the "G1" copper complex as photoredox catalyst: Applications of free radical/cationic hybrid photopolymerization in the composites and 3D printing fields, Progress in Organic Coatings. 132 (2019) 50-61. https://doi.org/10.1016/j.porgcoat.2019.02.044.

[107] A.A. Mousawi, A. Kermagoret, D.-L. Versace, J. Toufaily, T. Hamieh, B. Graff, F. Dumur, D. Gigmes, J.P. Fouassier, J. Lalevée, Copper photoredox catalysts for polymerization upon near UV or visible light: structure/reactivity/efficiency relationships and use in LED projector 3D printing resins, Polym. Chem. 8 (2017) 568580. https://doi.org/10.1039/C6PY01958G.

[108] A. Mau, G. Noirbent, C. Dietlin, B. Graff, D. Gigmes, F. Dumur, J. Lalevée, Panchromatic Copper Complexes for Visible Light Photopolymerization, Photochem. 1 (2021). https://doi.org/10.3390/photochem1020010.

[109] A. Mau, C. Dietlin, F. Dumur, J. Lalevée, Concomitant initiation of radical and cationic polymerisations using new copper complexes as photoinitiators: Synthesis and characterisation of acrylate/epoxy interpenetrated polymer networks, European Polymer Journal. 152 (2021) 110457. https://doi.org/10.1016/j.eurpolymj.2021.110457.

[110] M. Abdallah, A. Hijazi, B. Graff, J.-P. Fouassier, G. Rodeghiero, A. Gualandi, F. Dumur, P.G. Cozzi, J. Lalevée, Coumarin derivatives as versatile photoinitiators for 3D printing, polymerization in water and photocomposite synthesis, Polym. Chem. 10 (2019) 872-884. https://doi.org/10.1039/C8PY01708E.

[111] M. Abdallah, F. Dumur, A. Hijazi, G. Rodeghiero, A. Gualandi, P.G. Cozzi, J. Lalevée, Keto-coumarin scaffold for photoinitiators for 3D printing and photocomposites, Journal of Polymer Science. 58 (2020) 1115-1129. https://doi.org/10.1002/pol.20190290.

[112] M. Abdallah, A. Hijazi, F. Dumur, J. Lalevée, Coumarins as Powerful Photosensitizers for the Cationic Polymerization of Epoxy-Silicones under Near-UV and Visible Light and Applications for 3D Printing Technology, Molecules. 25 (2020) 2063. https://doi.org/10.3390/molecules25092063.

[113] M. Abdallah, A. Hijazi, P.G. Cozzi, A. Gualandi, F. Dumur, J. Lalevée, Boron Compounds as Additives for the Cationic Polymerization Using Coumarin Derivatives in Epoxy Silicones, Macromolecular Chemistry and Physics. 222 (2021) 2000404. https://doi.org/10.1002/macp.202000404.

[114] Q. Chen, Q. Yang, P. Gao, B. Chi, J. Nie, Y. He, Photopolymerization of CoumarinContaining Reversible Photoresponsive Materials Based on Wavelength Selectivity, Ind. Eng. Chem. Res. 58 (2019) 2970-2975. https://doi.org/10.1021/acs.iecr.8b05164.

[115] Z. Li, X. Zou, G. Zhu, X. Liu, R. Liu, Coumarin-Based Oxime Esters: Photobleachable and Versatile Unimolecular Initiators for Acrylate and Thiol-Based Click Photopolymerization under Visible Light-Emitting Diode Light Irradiation, ACS Appl. Mater. Interfaces. 10 (2018) 16113-16123. https://doi.org/10.1021/acsami.8b01767.

[116] M. Rahal, H. Mokbel, B. Graff, J. Toufaily, T. Hamieh, F. Dumur, J. Lalevée, Mono vs. Difunctional Coumarin as Photoinitiators in Photocomposite Synthesis and 3D Printing, Catalysts. 10 (2020) 1202. https://doi.org/10.3390/catal10101202.

[117] M. Rajeshirke, M.C. Sreenath, S. Chitrambalam, I.H. Joe, N. Sekar, Enhancement of NLO Properties in OBO Fluorophores Derived from Carbazole-Coumarin Chalcones Containing Carboxylic Acid at the N-Alykl Terminal End, J. Phys. Chem. C. 122 (2018) 14313-14325. https://doi.org/10.1021/acs.jpcc.8b02937. 
[118] M. Rahal, B. Graff, J. Toufaily, T. Hamieh, F. Dumur, J. Lalevée, Design of ketocoumarin based photoinitiator for Free Radical Photopolymerization: Towards 3D printing and photocomposites applications, European Polymer Journal. 154 (2021) 110559. https://doi.org/10.1016/j.eurpolymj.2021.110559.

[119] M. Rahal, B. Graff, J. Toufaily, T. Hamieh, G. Noirbent, D. Gigmes, F. Dumur, J. Lalevée, 3-Carboxylic Acid and Formyl-Derived Coumarins as Photoinitiators in Photo-Oxidation or Photo-Reduction Processes for Photopolymerization upon Visible Light: Photocomposite Synthesis and 3D Printing Applications, Molecules. 26 (2021). https://doi.org/10.3390/molecules26061753.

[120] M. Abdallah, H. Le, A. Hijazi, M. Schmitt, B. Graff, F. Dumur, T.-T. Bui, F. Goubard, J.P. Fouassier, J. Lalevée, Acridone derivatives as high performance visible light photoinitiators for cationic and radical photosensitive resins for 3D printing technology and for low migration photopolymer property, Polymer. 159 (2018) 47-58. https://doi.org/10.1016/j.polymer.2018.11.021.

[121] J. Zhang, F. Dumur, M. Bouzrati, P. Xiao, C. Dietlin, F. Morlet-Savary, B. Graff, D. Gigmes, J.P. Fouassier, J. Lalevée, Novel panchromatic photopolymerizable matrices: $\mathrm{N}, \mathrm{N}^{\prime}$-dibutylquinacridone as an efficient and versatile photoinitiator, Journal of Polymer Science Part A: Polymer Chemistry. 53 (2015) 1719-1727. https://doi.org/10.1002/pola.27615.

[122] H. Mokbel, J. Toufaily, T. Hamieh, F. Dumur, D. Campolo, D. Gigmes, J.P. Fouassier, J. Ortyl, J. Lalevée, Specific cationic photoinitiators for near UV and visible LEDs: Iodonium versus ferrocenium structures, Journal of Applied Polymer Science. 132 (2015). https://doi.org/10.1002/app.42759.

[123] S. Villotte, D. Gigmes, F. Dumur, J. Lalevée, Design of Iodonium Salts for UV or NearUV LEDs for Photoacid Generator and Polymerization Purposes, Molecules. 25 (2020) 149. https://doi.org/10.3390/molecules25010149.

[124] M.A. Tasdelen, V. Kumbaraci, S. Jockusch, N.J. Turro, N. Talinli, Y. Yagci, Photoacid Generation by Stepwise Two-Photon Absorption: Photoinitiated Cationic Polymerization of Cyclohexene Oxide by Using Benzodioxinone in the Presence of Iodonium Salt, Macromolecules. 41 (2008) 295-297. https://doi.org/10.1021/ma7023649.

[125] J.V. Crivello, J.H.W. Lam, Diaryliodonium Salts. A New Class of Photoinitiators for Cationic Polymerization, Macromolecules. 10 (1977) 1307-1315. https://doi.org/10.1021/ma60060a028.

[126] Y. He, W. Zhou, F. Wu, M. Li, E. Wang, Photoreaction and photopolymerization studies on squaraine dyes/iodonium salts combination, Journal of Photochemistry and Photobiology A: Chemistry. 162 (2004) 463-471. https://doi.org/10.1016/S10106030(03)00390-3.

[127] L.I. Jun, L.I. Miaozhen, S. Huaihai, Y. Yongyuan, W. Erjian, Photopolymerization Initiated by Dimethylaminochalcone/Diphenyliodonium Salt Combination System Sensitive to Visible Light, Chinese J. Polym. Sci. 11 (1993) 163-170.

[128] J. Zhang, N. Zivic, F. Dumur, C. Guo, Y. Li, P. Xiao, B. Graff, D. Gigmes, J.P. Fouassier, J. Lalevée, Panchromatic photoinitiators for radical, cationic and thiol-ene polymerization reactions: A search in the diketopyrrolopyrrole or indigo dye series, Materials Today Communications. 4 (2015) 101-108. https://doi.org/10.1016/j.mtcomm.2015.06.007.

[129] P. Xiao, W. Hong, Y. Li, F. Dumur, B. Graff, J.P. Fouassier, D. Gigmes, J. Lalevée, Diketopyrrolopyrrole dyes: Structure/reactivity/efficiency relationship in 
photoinitiating systems upon visible lights, Polymer. 55 (2014) 746-751.

https://doi.org/10.1016/j.polymer.2014.01.003.

[130] P. Xiao, W. Hong, Y. Li, F. Dumur, B. Graff, J.P. Fouassier, D. Gigmes, J. Lalevée, Green light sensitive diketopyrrolopyrrole derivatives used in versatile photoinitiating systems for photopolymerizations, Polym. Chem. 5 (2014) 2293-2300. https://doi.org/10.1039/C3PY01599H.

[131] M. Abdallah, T.-T. Bui, F. Goubard, D. Theodosopoulou, F. Dumur, A. Hijazi, J.-P. Fouassier, J. Lalevée, Phenothiazine derivatives as photoredox catalysts for cationic and radical photosensitive resins for 3D printing technology and photocomposite synthesis, Polym. Chem. 10 (2019) 6145-6156. https://doi.org/10.1039/C9PY01265F.

[132] M.-A. Tehfe, F. Dumur, P. Xiao, B. Graff, F. Morlet-Savary, J.-P. Fouassier, D. Gigmes, J. Lalevée, New chromone based photoinitiators for polymerization reactions under visible light, Polym. Chem. 4 (2013) 4234-4244. https://doi.org/10.1039/C3PY00536D.

[133] J. You, H. Fu, D. Zhao, T. Hu, J. Nie, T. Wang, Flavonol dyes with different substituents in photopolymerization, Journal of Photochemistry and Photobiology A: Chemistry. 386 (2020) 112097. https://doi.org/10.1016/j.jphotochem.2019.112097.

[134] A. Al Mousawi, P. Garra, M. Schmitt, J. Toufaily, T. Hamieh, B. Graff, J.P. Fouassier, F. Dumur, J. Lalevée, 3-Hydroxyflavone and N-Phenylglycine in High Performance Photoinitiating Systems for 3D Printing and Photocomposites Synthesis, Macromolecules. 51 (2018) 4633-4641. https://doi.org/10.1021/acs.macromol.8b00979.

[135] A.A. Mousawi, F. Dumur, P. Garra, J. Toufaily, T. Hamieh, F. Goubard, T.-T. Bui, B. Graff, D. Gigmes, J.P. Fouassier, J. Lalevée, Azahelicenes as visible light photoinitiators for cationic and radical polymerization: Preparation of photoluminescent polymers and use in high performance LED projector 3D printing resins, Journal of Polymer Science Part A: Polymer Chemistry. 55 (2017) 1189-1199. https://doi.org/10.1002/pola.28476.

[136] A. Al Mousawi, M. Schmitt, F. Dumur, J. Ouyang, L. Favereau, V. Dorcet, N. Vanthuyne, P. Garra, J. Toufaily, T. Hamieh, B. Graff, J.P. Fouassier, D. Gigmes, J. Crassous, J. Lalevée, Visible Light Chiral Photoinitiator for Radical Polymerization and Synthesis of Polymeric Films with Strong Chiroptical Activity, Macromolecules. 51 (2018) 5628-5637. https://doi.org/10.1021/acs.macromol.8b01085.

[137] J. Zhang, D. Campolo, F. Dumur, P. Xiao, D. Gigmes, J.P. Fouassier, J. Lalevée, The carbazole-bound ferrocenium salt as a specific cationic photoinitiator upon near-UV and visible LEDs (365-405 nm), Polym. Bull. 73 (2016) 493-507. https://doi.org/10.1007/s00289-015-1506-1.

[138] A. Al Mousawi, F. Dumur, P. Garra, J. Toufaily, T. Hamieh, B. Graff, D. Gigmes, J.P. Fouassier, J. Lalevée, Carbazole Scaffold Based Photoinitiator/Photoredox Catalysts: Toward New High Performance Photoinitiating Systems and Application in LED Projector 3D Printing Resins, Macromolecules. 50 (2017) 2747-2758. https://doi.org/10.1021/acs.macromol.7b00210.

[139] A. Al Mousawi, D.M. Lara, G. Noirbent, F. Dumur, J. Toufaily, T. Hamieh, T.-T. Bui, F. Goubard, B. Graff, D. Gigmes, J.P. Fouassier, J. Lalevée, Carbazole Derivatives with Thermally Activated Delayed Fluorescence Property as Photoinitiators/Photoredox Catalysts for LED 3D Printing Technology, Macromolecules. 50 (2017) 4913-4926. https://doi.org/10.1021/acs.macromol.7b01114.

[140] A. Al Mousawi, P. Garra, F. Dumur, T.-T. Bui, F. Goubard, J. Toufaily, T. Hamieh, B. Graff, D. Gigmes, J.P. Fouassier, J. Lalevée, Novel Carbazole Skeleton-Based 
Photoinitiators for LED Polymerization and LED Projector 3D Printing, Molecules. 22 (2017) 2143. https://doi.org/10.3390/molecules22122143.

[141] A.A. Mousawi, A. Arar, M. Ibrahim-Ouali, S. Duval, F. Dumur, P. Garra, J. Toufaily, T. Hamieh, B. Graff, D. Gigmes, J.-P. Fouassier, J. Lalevée, Carbazole-based compounds as photoinitiators for free radical and cationic polymerization upon near visible light illumination, Photochem. Photobiol. Sci. 17 (2018) 578-585. https://doi.org/10.1039/C7PP00400A.

[142] M. Abdallah, D. Magaldi, A. Hijazi, B. Graff, F. Dumur, J.-P. Fouassier, T.-T. Bui, F. Goubard, J. Lalevée, Development of new high-performance visible light photoinitiators based on carbazole scaffold and their applications in $3 \mathrm{~d}$ printing and photocomposite synthesis, Journal of Polymer Science Part A: Polymer Chemistry. 57 (2019) 2081-2092. https://doi.org/10.1002/pola.29471.

[143] F. Dumur, Recent advances on carbazole-based photoinitiators of polymerization, European Polymer Journal. 125 (2020) 109503. https://doi.org/10.1016/j.eurpolymj.2020.109503.

[144] S. Liu, B. Graff, P. Xiao, F. Dumur, J. Lalevée, Nitro-Carbazole Based Oxime Esters as Dual Photo/Thermal Initiators for 3D Printing and Composite Preparation, Macromolecular Rapid Communications. 42 (2021) 2100207. https://doi.org/10.1002/marc.202100207.

[145] M.-A. Tehfe, F. Dumur, E. Contal, B. Graff, D. Gigmes, J.-P. Fouassier, J. Lalevée, Novel Highly Efficient Organophotocatalysts: Truxene-Acridine-1,8-diones as Photoinitiators of Polymerization, Macromolecular Chemistry and Physics. 214 (2013) 2189-2201. https://doi.org/10.1002/macp.201300362.

[146] P. Xiao, F. Dumur, M.-A. Tehfe, B. Graff, D. Gigmes, J.P. Fouassier, J. Lalevée, Difunctional acridinediones as photoinitiators of polymerization under UV and visible lights: Structural effects, Polymer. 54 (2013) 3458-3466. https://doi.org/10.1016/j.polymer.2013.04.055.

[147] P. Xiao, F. Dumur, M.-A. Tehfe, B. Graff, D. Gigmes, J.P. Fouassier, J. Lalevée, Acridinediones: Effect of Substituents on Their Photoinitiating Abilities in Radical and Cationic Photopolymerization, Macromolecular Chemistry and Physics. 214 (2013) 2276-2282. https://doi.org/10.1002/macp.201300363.

[148] S. Liu, H. Chen, Y. Zhang, K. Sun, Y. Xu, F. Morlet-Savary, B. Graff, G. Noirbent, C. Pigot, D. Brunel, M. Nechab, D. Gigmes, P. Xiao, F. Dumur, J. Lalevée, Monocomponent Photoinitiators based on Benzophenone-Carbazole Structure for LED Photoinitiating Systems and Application on 3D Printing, Polymers. 12 (2020) 1394. https://doi.org/10.3390/polym12061394.

[149] P. Xiao, F. Dumur, B. Graff, D. Gigmes, J.P. Fouassier, J. Lalevée, Variations on the Benzophenone Skeleton: Novel High Performance Blue Light Sensitive Photoinitiating Systems, Macromolecules. 46 (2013) 7661-7667. https://doi.org/10.1021/ma401766v.

[150] J. Zhang, M. Frigoli, F. Dumur, P. Xiao, L. Ronchi, B. Graff, F. Morlet-Savary, J.P. Fouassier, D. Gigmes, J. Lalevée, Design of Novel Photoinitiators for Radical and Cationic Photopolymerizations under Near UV and Visible LEDs (385, 395, and 405 nm)., Macromolecules. 47 (2014) 2811-2819. https://doi.org/10.1021/ma500612x.

[151] S. Liu, D. Brunel, G. Noirbent, A. Mau, H. Chen, F. Morlet-Savary, B. Graff, D. Gigmes, P. Xiao, F. Dumur, J. Lalevée, New multifunctional benzophenone-based photoinitiators with high migration stability and their applications in 3D printing, Mater. Chem. Front. 5 (2021) 1982-1994. https://doi.org/10.1039/D0QM00885K. 
[152] S. Liu, D. Brunel, K. Sun, Y. Zhang, H. Chen, P. Xiao, F. Dumur, J. Lalevée, Novel Photoinitiators Based on Benzophenone-Triphenylamine Hybrid Structure for LED Photopolymerization, Macromolecular Rapid Communications. 41 (2020) 2000460. https://doi.org/10.1002/marc.202000460.

[153] S. Liu, D. Brunel, K. Sun, Y. Xu, F. Morlet-Savary, B. Graff, P. Xiao, F. Dumur, J. Lalevée, A monocomponent bifunctional benzophenone-carbazole type II photoinitiator for LED photoinitiating systems, Polym. Chem. 11 (2020) 3551-3556. https://doi.org/10.1039/D0PY00644K.

[154] J. Zhang, J. Lalevée, J. Zhao, B. Graff, M.H. Stenzel, P. Xiao, Dihydroxyanthraquinone derivatives: natural dyes as blue-light-sensitive versatile photoinitiators of photopolymerization, Polym. Chem. 7 (2016) 7316-7324. https://doi.org/10.1039/C6PY01550F.

[155] H. Mokbel, F. Dumur, J. Lalevée, On demand NIR activated photopolyaddition reactions, Polym. Chem. 11 (2020) 4250-4259. https://doi.org/10.1039/D0PY00639D.

[156] H. Mokbel, B. Graff, F. Dumur, J. Lalevée, NIR Sensitizer Operating under Long Wavelength (1064 nm) for Free Radical Photopolymerization Processes, Macromolecular Rapid Communications. 41 (2020) 2000289. https://doi.org/10.1002/marc.202000289.

[157] V. Launay, F. Dumur, D. Gigmes, J. Lalevée, Near-infrared light for polymer reshaping and re-processing applications, Journal of Polymer Science. n/a (2021). https://doi.org/10.1002/pol.20210450.

[158] A. Caron, G. Noirbent, D. Gigmes, F. Dumur, J. Lalevée, Near-Infrared PhotoInitiating Systems: Photothermal versus Triplet-Triplet Annihilation-Based Upconversion Polymerization, Macromolecular Rapid Communications. 42 (2021) 2100047. https://doi.org/10.1002/marc.202100047.

[159] M.-A. Tehfe, F. Dumur, S. Telitel, D. Gigmes, E. Contal, D. Bertin, F. Morlet-Savary, B. Graff, J.-P. Fouassier, J. Lalevée, Zinc-based metal complexes as new photocatalysts in polymerization initiating systems, European Polymer Journal. 49 (2013) 1040-1049. https://doi.org/10.1016/j.eurpolymj.2013.01.023.

[160] J. Li, X. Zhang, S. Ali, M.Y. Akram, J. Nie, X. Zhu, The effect of polyethylene glycoldiacrylate complexation on type II photoinitiator and promotion for visible light initiation system, Journal of Photochemistry and Photobiology A: Chemistry. 384 (2019) 112037. https://doi.org/10.1016/j.jphotochem.2019.112037.

[161] J. Li, S. Li, Y. Li, R. Li, J. Nie, X. Zhu, In situ monitoring of photopolymerization by photoinitiator with luminescence characteristics, Journal of Photochemistry and Photobiology A: Chemistry. 389 (2020) 112225. https://doi.org/10.1016/j.jphotochem.2019.112225.

[162] J. Li, Y. Hao, M. Zhong, L. Tang, J. Nie, X. Zhu, Synthesis of furan derivative as LED light photoinitiator: One-pot, low usage, photobleaching for light color 3D printing, Dyes and Pigments. 165 (2019) 467-473. https://doi.org/10.1016/j.dyepig.2019.03.011.

[163] Y. Xu, G. Noirbent, D. Brunel, Z. Ding, D. Gigmes, B. Graff, P. Xiao, F. Dumur, J. Lalevée, Novel ketone derivative-based photoinitiating systems for free radical polymerization under mild conditions and 3D printing, Polym. Chem. 11 (2020) 57675777. https://doi.org/10.1039/D0PY00990C.

[164] E.A. Kamoun, A. Winkel, M. Eisenburger, H. Menzel, Carboxylated camphorquinone as visible-light photoinitiator for biomedical application: Synthesis, characterization, 
and application, Arabian Journal of Chemistry. 9 (2016) 745-754.

https://doi.org/10.1016/j.arabjc.2014.03.008.

[165] A. Santini, I.T. Gallegos, C.M. Felix, Photoinitiators in Dentistry: A Review, Prim Dent J. 2 (2013) 30-33. https://doi.org/10.1308/205016814809859563.

[166] I.A. Stringlis, R. de Jonge, C.M.J. Pieterse, The Age of Coumarins in Plant-Microbe Interactions, Plant and Cell Physiology. 60 (2019) 1405-1419. https://doi.org/10.1093/pcp/pcz076.

[167] R.F. Fisher, S.R. Long, Rhizobium-plant signal exchange, Nature. 357 (1992) 655-660. https://doi.org/10.1038/357655a0.

[168] R.A. Dixon, Natural products and plant disease resistance, Nature. 411 (2001) 843-847. https://doi.org/10.1038/35081178.

[169] G.J.B. Gnonlonfin, A. Sanni, L. Brimer, Review Scopoletin - A Coumarin Phytoalexin with Medicinal Properties, Null. 31 (2012) 47-56. https://doi.org/10.1080/07352689.2011.616039.

[170] H.H. Tsai, W. Schmidt, Mobilization of Iron by Plant-Borne Coumarins, Trends in Plant Science. 22 (2017) 538-548. https://doi.org/10.1016/j.tplants.2017.03.008.

[171] I.A. Stringlis, K. Yu, K. Feussner, R. de Jonge, S. Van Bentum, M.C. Van Verk, R.L. Berendsen, P.A.H.M. Bakker, I. Feussner, C.M.J. Pieterse, MYB72-dependent coumarin exudation shapes root microbiome assembly to promote plant health, Proc Natl Acad Sci USA. 115 (2018) E5213. https://doi.org/10.1073/pnas.1722335115.

[172] T.O. Soine, Naturally Occurring Coumarins and Related Physiological Activities, Journal of Pharmaceutical Sciences. 53 (1964) 231-264. https://doi.org/10.1002/jps.2600530302.

[173] F. Borges, F. Roleira, N. Milhazes, L. Santana and E. Uriarte, Simple Coumarins and Analogues in Medicinal Chemistry: Occurrence, Synthesis and Biological Activity, Current Medicinal Chemistry. 12 (2005) 887-916. https://doi.org/10.2174/0929867053507315.

[174] L. Guo, D. Yang, L. Xia, F. Qu, Y. Dou, F. Qu, R. Kong, J. You, A highly water-soluble, sensitive, coumarin-based fluorescent probe for detecting thiols, and its application in bioimaging, New J. Chem. 41 (2017) 15277-15282. https://doi.org/10.1039/C7NJ02391J.

[175] X. Liu, J.M. Cole, P.G. Waddell, T.-C. Lin, J. Radia, A. Zeidler, Molecular Origins of Optoelectronic Properties in Coumarin Dyes: Toward Designer Solar Cell and Laser Applications, J. Phys. Chem. A. 116 (2012) 727-737. https://doi.org/10.1021/jp209925y.

[176] X. Li, F. Huo, Y. Yue, Y. Zhang, C. Yin, A coumarin-based "off-on" sensor for fluorescence selectivily discriminating GSH from Cys/Hcy and its bioimaging in living cells, Sensors and Actuators B: Chemical. 253 (2017) 42-49. https://doi.org/10.1016/j.snb.2017.06.120.

[177] M.-T. Lee, C.-K. Yen, W.-P. Yang, H.-H. Chen, C.-H. Liao, C.-H. Tsai, C.H. Chen, Efficient Green Coumarin Dopants for Organic Light-Emitting Devices, Org. Lett. 6 (2004) 1241-1244. https://doi.org/10.1021/ol049903d.

[178] I. Manolov, C. Maichle-Moessmer, N. Danchev, Synthesis, structure, toxicological and pharmacological investigations of 4-hydroxycoumarin derivatives, European Journal of Medicinal Chemistry. 41 (2006) 882-890. https://doi.org/10.1016/j.ejmech.2006.03.007.

[179] R.G. Harvey, C. Cortez, T.P. Ananthanarayan, S. Schmolka, A new coumarin synthesis and its utilization for the synthesis of polycyclic coumarin compounds with 
anticarcinogenic properties, J. Org. Chem. 53 (1988) 3936-3943.

https://doi.org/10.1021/jo00252a011.

[180] N. Hamdi, V. Passarelli, A. Romerosa, Synthesis, spectroscopy and electrochemistry of new 4-(4-acetyl-5- substituted-4, 5-dihydro-1, 3,4-oxodiazol-2-yl)methoxy)-2Hchromen-2-ones as a novel class of potential antibacterial and antioxidant derivatives, Comptes Rendus Chimie. 14 (2011) 548-555. https://doi.org/10.1016/j.crci.2010.11.001.

[181] Q.Q. Zhu, W. Schnabel, Cationic photopolymerization under visible laser light: polymerization of oxiranes with coumarin/onium salt initiator systems, Polymer. 37 (1996) 4129-4133. https://doi.org/10.1016/0032-3861(96)00248-0.

[182] B.M. Monroe, G.C. Weed, Photoinitiators for free-radical-initiated photoimaging systems, Chem. Rev. 93 (1993) 435-448. https://doi.org/10.1021/cr00017a019.

[183] M.M. Abdul-Monem, Naturally Derived Photoinitiators for Dental and Biomaterials Applications, European Dental Research and Biomaterials Journal. 1 (2021) 72-78.

[184] I. Cazin, E. Rossegger, G. Guedes de la Cruz, T. Griesser, S. Schlögl, Recent Advances in Functional Polymers Containing Coumarin Chromophores, Polymers. 13 (2021). https://doi.org/10.3390/polym13010056.

[185] U. Tong, W. Chen, C. Ritchie, X. Wang, Y.-F. Song, Reversible Light-Driven Polymerization of Polyoxometalate Tethered with Coumarin Molecules, Chemistry A European Journal. 20 (2014) 1500-1504. https://doi.org/10.1002/chem.201303933.

[186] Y. Chen, R.-T. Hong, Synthesis of polyesters containing coumarin dimer components by photopolymerization of 7,7'-coumarinyl polymethylene dicarboxylates, Journal of Polymer Research. 1 (1994) 285-293. https://doi.org/10.1007/BF01374553.

[187] S.R. Trenor, A.R. Shultz, B.J. Love, T.E. Long, Coumarins in Polymers: From Light Harvesting to Photo-Cross-Linkable Tissue Scaffolds, Chem. Rev. 104 (2004) 30593078. https://doi.org/10.1021/cr030037c.

[188] J.K. Oh, V. Stöeva, J. Rademacher, R. Farwaha, M.A. Winnik, Synthesis, characterization, and emulsion polymerization of polymerizable coumarin derivatives, Journal of Polymer Science Part A: Polymer Chemistry. 42 (2004) 3479-3489. https://doi.org/10.1002/pola.20148.

[189] Y. Chen, R.-T. Hong, Photopolymerization of 7,7'-coumarinyl polymethylene dicarboxylates: Fluorescence and kinetic study, Journal of Polymer Science Part A: Polymer Chemistry. 35 (1997) 2999-3008. https://doi.org/10.1002/(SICI)10990518(199710)35:14<2999::AID-POLA21>3.0.CO;2-D.

[190] R. Nazir, P. Danilevicius, A.I. Ciuciu, M. Chatzinikolaidou, D. Gray, L. Flamigni, M. Farsari, D.T. Gryko, $\pi$-Expanded Ketocoumarins as Efficient, Biocompatible Initiators for Two-Photon-Induced Polymerization, Chem. Mater. 26 (2014) 3175-3184. https://doi.org/10.1021/cm500612w.

[191] R. Zhou, X. Sun, R. Mhanna, J.-P. Malval, M. Jin, H. Pan, D. Wan, F. Morlet-Savary, H. Chaumeil, C. Joyeux, Wavelength-Dependent, Large-Amplitude Photoinitiating Reactivity within a Carbazole-Coumarin Fused Oxime Esters Series, ACS Appl. Polym. Mater. 2 (2020) 2077-2085. https://doi.org/10.1021/acsapm.0c00276.

[192] R. Zhou, J.-P. Malval, M. Jin, A. Spangenberg, H. Pan, D. Wan, F. Morlet-Savary, S. Knopf, A two-photon active chevron-shaped type I photoinitiator designed for 3D stereolithography, Chem. Commun. 55 (2019) 6233-6236. https://doi.org/10.1039/C9CC02923K.

[193] W. Qiu, P. Hu, J. Zhu, R. Liu, Z. Li, Z. Hu, Q. Chen, K. Dietliker, R. Liska, Cleavable Unimolecular Photoinitiators Based on Oxime-Ester Chemistry for Two-Photon Three- 
Dimensional Printing, ChemPhotoChem. 3 (2019) 1090-1094. https://doi.org/10.1002/cptc.201900164.

[194] X. Allonas, J.P. Fouassier, M. Kaji, M. Miyasaka, On the Ability of Coumarin Derivatives to Interact with Photoinitiators, Journal of Photopolymer Science and Technology. 13 (2000) 237-241. https://doi.org/10.2494/photopolymer.13.237.

[195] J.P. Fouassier, F. Morlet-Savary, K. Yamashita, S. Imahashi, Visible light-induced polymerization reactions: The seven-role of the electron transfer process in the dye/iron arene complex/amine system, Journal of Applied Polymer Science. 62 (1996) 1877-1885. https://doi.org/10.1002/(SICI)1097-4628(19961212)62:11<1877::AIDAPP12>3.0.CO;2-W.

[196] K. Ramamurthy, E.J.P. Malar, C. Selvaraju, Hydrogen bonded dimers of ketocoumarin in the solid state and alcohol:water binary solvent: fluorescence spectroscopy, crystal structure and DFT investigation, New J. Chem. 43 (2019) 9090-9105. https://doi.org/10.1039/C9NJ01053J.

[197] J.P. Fouassier, F. Morlet-Savary, K. Yamashita, S. Imahashi, The role of the dye/iron arene complex/amine system as a photoinitiator for photopolymerization reactions, Polymer. 38 (1997) 1415-1421. https://doi.org/10.1016/S0032-3861(96)00659-3.

[198] S. Berdzinski, B. Strehmel, V. Strehmel, Photogenerated lophyl radicals in 1-alkyl-3vinylimidazolium bis(trifluoromethylsulfonyl)imides, Photochem. Photobiol. Sci. 14 (2015) 714-725. https://doi.org/10.1039/C4PP00386A.

[199] F. Gao, J. Xu, Y. Yang, Study of Visible Light Photoinduced Polymerization of Methyl Methacrylate Initiated By Biimidazole/Coumarin Dye Systems, Journal of Photopolymer Science and Technology. 12 (1999) 339-342. https://doi.org/10.2494/photopolymer.12.339.

[200] B. Steyrer, P. Neubauer, R. Liska, J. Stampfl, Visible Light Photoinitiator for 3DPrinting of Tough Methacrylate Resins, Materials. 10 (2017). https://doi.org/10.3390/ma10121445.

[201] P. Xiao, J. Zhang, F. Dumur, M.A. Tehfe, F. Morlet-Savary, B. Graff, D. Gigmes, J.P. Fouassier, J. Lalevée, Visible light sensitive photoinitiating systems: Recent progress in cationic and radical photopolymerization reactions under soft conditions, Progress in Polymer Science. 41 (2015) 32-66. https://doi.org/10.1016/j.progpolymsci.2014.09.001.

[202] M.G. Neumann, C.C. Schmitt, G.C. Ferreira, I.C. Corrêa, The initiating radical yields and the efficiency of polymerization for various dental photoinitiators excited by different light curing units, Dental Materials. 22 (2006) 576-584. https://doi.org/10.1016/j.dental.2005.06.006.

[203] J.V. Crivello, D. Bi, Regioselective hydrosilations. IV. The synthesis and polymerization of monomers containing epoxy and alkoxysilane groups, Journal of Polymer Science Part A: Polymer Chemistry. 31 (1993) 3121-3132. https://doi.org/10.1002/pola.1993.080311228.

[204] J.V. Crivello, J.L. Lee, The synthesis, characterization, and photoinitiated cationic polymerization of silicon-containing epoxy resins, Journal of Polymer Science Part A: Polymer Chemistry. 28 (1990) 479-503. https://doi.org/10.1002/pola.1990.080280303.

[205] R.A.A.U. Ranaweera, T.P. Schuman, R. Wang, B.D. Miller, K.V. Kilway, Effect of moisture on cationic polymerization of silicone epoxy monomers, Journal of Applied Polymer Science. 132 (2015). https://doi.org/10.1002/app.41831. 
[206] E. Koliniotou-Koumpia, P. Kouros, D. Dionysopoulos, L. Zafiriadis, Bonding strength of silorane-based composite to Er-YAG laser prepared dentin, Lasers in Medical Science. 30 (2015) 509-516. https://doi.org/10.1007/s10103-013-1353-y.

[207] R. Budreckiene, R. Lazauskaite, G. Buika, J.V. Grazulevicius, Cationic photopolymerization of carbazolyl-containing vinyl ethers, Journal of Photochemistry and Photobiology A: Chemistry. 157 (2003) 117-123. https://doi.org/10.1016/S10106030(03)00076-5.

[208] M. Abdallah, A. Hijazi, J.-T. Lin, B. Graff, F. Dumur, J. Lalevée, Coumarin Derivatives as Photoinitiators in Photo-Oxidation and Photo-Reduction Processes and a Kinetic Model for Simulations of the Associated Polymerization Profiles, ACS Appl. Polym. Mater. 2 (2020) 2769-2780. https://doi.org/10.1021/acsapm.0c00340.

[209] G. Ullrich, P. Burtscher, U. Salz, N. Moszner, R. Liska, Phenylglycine derivatives as coinitiators for the radical photopolymerization of acidic aqueous formulations, Journal of Polymer Science Part A: Polymer Chemistry. 44 (2006) 115-125. https://doi.org/10.1002/pola.21139.

[210] G. Noirbent, F. Dumur, Photoinitiators of polymerization with reduced environmental impact: Nature as an unlimited and renewable source of dyes, European Polymer Journal. 142 (2021) 110109. https://doi.org/10.1016/j.eurpolymj.2020.110109.

[211] Z. Kucybała, I. Pyszka, J. Pączkowski, Development of new dyeing photoinitiators for free radical polymerization based on the $1 \mathrm{H}$-pyrazolo[3,4-b]quinoxaline skeleton. Part 2, J. Chem. Soc., Perkin Trans. 2. (2000) 1559-1567. https://doi.org/10.1039/B000583P.

[212] L. Chen, Q. Yu, Y. Wang, H. Li, BisGMA/TEGDMA dental composite containing high aspect-ratio hydroxyapatite nanofibers, Dental Materials. 27 (2011) 1187-1195. https://doi.org/10.1016/j.dental.2011.08.403.

[213] S. Rüttermann, I. Dluzhevskaya, C. Großsteinbeck, W.H.-M. Raab, R. Janda, Impact of replacing Bis-GMA and TEGDMA by other commercially available monomers on the properties of resin-based composites, Dental Materials. 26 (2010) 353-359. https://doi.org/10.1016/j.dental.2009.12.006.

[214] S. Alizadehgharib, A.-K. Östberg, A. Dahlstrand Rudin, U. Dahlgren, K. Christenson, The effects of the dental methacrylates TEGDMA, Bis-GMA, and UDMA on neutrophils in vitro, Clinical and Experimental Dental Research. 6 (2020) 439-447. https://doi.org/10.1002/cre2.296.

[215] S. Luo, W. Zhu, F. Liu, J. He, Preparation of a Bis-GMA-Free Dental Resin System with Synthesized Fluorinated Dimethacrylate Monomers, International Journal of Molecular Sciences. 17 (2016). https://doi.org/10.3390/ijms17122014.

[216] D.H.A. Besisa, E.M.M. Ewais, Y.M.Z. Ahmed, F.I. Elhosiny, D.V. Kuznetsov, T. Fend, Densification and characterization of SiC-AlN composites for solar energy applications, Renewable Energy. 129 (2018) 201-213. https://doi.org/10.1016/j.renene.2018.05.100.

[217] S. Yadav, S. Gangwar, S. Singh, Micro/Nano Reinforced Filled Metal Alloy Composites: A Review Over Current Development in Aerospace and Automobile Applications, Materials Today: Proceedings. 4 (2017) 5571-5582. https://doi.org/10.1016/j.matpr.2017.06.014.

[218] M. Abdallah, A. Hijazi, B. Graff, J.-P. Fouassier, F. Dumur, J. Lalevée, In Silico Design of Nitrocoumarins as Near-UV Photoinitiators: Toward Interesting Opportunities in Composites and 3D Printing Technologies, ACS Appl. Polym. Mater. 2 (2020) 28902901. https://doi.org/10.1021/acsapm.0c00409. 
[219] M. Abdallah, A. Hijazi, B. Graff, J.-P. Fouassier, F. Dumur, J. Lalevée, In-silico based development of photoinitiators for 3D printing and composites: Search on the coumarin scaffold, Journal of Photochemistry and Photobiology A: Chemistry. 400 (2020) 112698. https://doi.org/10.1016/j.jphotochem.2020.112698.

[220] M. Gajda, R. Rybakiewicz, M. Cieplak, T. Żołek, D. Maciejewska, E. Gilant, P.J. Rudzki, K. Grab, A. Kutner, P. Borowicz, W. Kutner, K.R. Noworyta, Low-oxidationpotential thiophene-carbazole monomers for electro-oxidative molecular imprinting: Selective chemosensing of aripiprazole, Biosensors and Bioelectronics. 169 (2020) 112589. https://doi.org/10.1016/j.bios.2020.112589.

[221] M.B. Camarada, P. Jaque, F.R. Díaz, M.A. del Valle, Oxidation potential of thiophene oligomers: Theoretical and experimental approach, Journal of Polymer Science Part B: Polymer Physics. 49 (2011) 1723-1733. https://doi.org/10.1002/polb.22360.

[222] B. Jousselme, P. Blanchard, M. Oçafrain, M. Allain, E. Levillain, J. Roncali, Electrogenerated poly(thiophenes) derivatized by bipyridine ligands and metal complexes, J. Mater. Chem. 14 (2004) 421-427. https://doi.org/10.1039/B313291A.

[223] B. Jousselme, P. Blanchard, E. Levillain, R. de Bettignies, J. Roncali, Electrochemical Synthesis of C60-Derivatized Poly(thiophene)s from Tailored Precursors, Macromolecules. 36 (2003) 3020-3025. https://doi.org/10.1021/ma034047r.

[224] E. Ay, Z. Raad, O. Dautel, F. Dumur, G. Wantz, D. Gigmes, J.-P. Fouassier, J. Lalevée, Oligomeric Photocatalysts in Photoredox Catalysis: Toward High Performance and Low Migration Polymerization Photoinitiating Systems., Macromolecules. 49 (2016) 2124-2134. https://doi.org/10.1021/acs.macromol.5b02760.

[225] M.-A. Tehfe, J. Lalevée, S. Telitel, E. Contal, F. Dumur, D. Gigmes, D. Bertin, M. Nechab, B. Graff, F. Morlet-Savary, J.-P. Fouassier, Polyaromatic Structures as OrganoPhotoinitiator Catalysts for Efficient Visible Light Induced Dual Radical/Cationic Photopolymerization and Interpenetrated Polymer Networks Synthesis, Macromolecules. 45 (2012) 4454-4460. https://doi.org/10.1021/ma300760c.

[226] J.R. Lawson, R.L. Melen, Recent developments and applications of Lewis acidic boron reagents, in: Organometallic Chemistry: Volume 41, The Royal Society of Chemistry, 2017: pp. 1-27. https://doi.org/10.1039/9781782626923-00001.

[227] J.R. Lawson, R.L. Melen, Tris(pentafluorophenyl)borane and Beyond: Modern Advances in Borylation Chemistry, Inorg. Chem. 56 (2017) 8627-8643. https://doi.org/10.1021/acs.inorgchem.6b02911.

[228] G. Erker, Tris(pentafluorophenyl)borane: a special boron Lewis acid for special reactions, Dalton Trans. (2005) 1883-1890. https://doi.org/10.1039/B503688G.

[229] T. Mori, Y. Yoshigoe, Y. Kuninobu, Control of Multicolor and White Emission by Adjusting the Equilibrium between Fluorophores, Lewis Acids, and Their Complexes in Polymers, Angewandte Chemie International Edition. 58 (2019) 14457-14461. https://doi.org/10.1002/anie.201903408.

[230] Y. Shen, Y. Gu, R. Martin, sp3 C-H Arylation and Alkylation Enabled by the Synergy of Triplet Excited Ketones and Nickel Catalysts, J. Am. Chem. Soc. 140 (2018) 1220012209. https://doi.org/10.1021/jacs.8b07405.

[231] D. Huang, J. Sun, L. Ma, C. Zhang, J. Zhao, Preparation of ketocoumarins as heavy atom-free triplet photosensitizers for triplet - triplet annihilation upconversio, Photochemical \& Photobiological Sciences. 12 (2013) 872-882.

https://doi.org/10.1039/c3pp25416j. 
[232] D.P. Specht, P.A. Martic, S. Farid, Ketocoumarins: A new class of triplet sensitizers, Tetrahedron. 38 (1982) 1203-1211. https://doi.org/10.1016/0040-4020(82)85104-1.

[233] G. Niu, W. Liu, H. Xiao, H. Zhang, J. Chen, Q. Dai, J. Ge, J. Wu, P. Wang, Ketobenzo[h]-Coumarin-Based Near-Infrared Dyes with Large Stokes Shifts for Bioimaging Applications, Chemistry - An Asian Journal. 11 (2016) 498-504. https://doi.org/10.1002/asia.201501026.

[234] J.L.R. Williams, D.P. Specht, S. Farid, Ketocoumarins as photosensitizers and photoinitiators, Polymer Engineering \& Science. 23 (1983) 1022-1024. https://doi.org/10.1002/pen.760231809.

[235] J. Lalevée, L. Zadoina, X. Allonas, J.P. Fouassier, New sulfur-centered radicals as photopolymerization initiating species, Journal of Polymer Science Part A: Polymer Chemistry. 45 (2007) 2494-2502. https://doi.org/10.1002/pola.22012.

[236] H. Salmi, H. Tar, A. Ibrahim, C. Ley, X. Allonas, Ketocoumarin/triazine/thiol as new high speed photoinitiating system for free radical polymerization under visible light in aerated media, European Polymer Journal. 49 (2013) 2275-2279. https://doi.org/10.1016/j.eurpolymj.2013.05.012.

[237] C. Li, L. Luo, S. Wang, W. Huang, Q. Gong, Y. Yang, S. Feng, Two-photon microstructure-polymerization initiated by a coumarin derivative/iodonium salt system, Chemical Physics Letters. 340 (2001) 444-448. https://doi.org/10.1016/S00092614(01)00416-X.

[238] J.V. Crivello, Cationic polymerization - Iodonium and sulfonium salt photoinitiators, in: Initiators - Poly-Reactions - Optical Activity, Springer Berlin Heidelberg, Berlin, Heidelberg, 1984: pp. 1-48.

[239] J.V. Crivello, The discovery and development of onium salt cationic photoinitiators, Journal of Polymer Science Part A: Polymer Chemistry. 37 (1999) 4241-4254. https://doi.org/10.1002/(SICI)1099-0518(19991201)37:23<4241::AID-POLA1>3.0.CO;2-R.

[240] F. Castellanos, J.P. Fouassier, C. Priou, J. Cavezzan, Synthesis, reactivity, and properties of new diaryliodonium salts as photoinitiators for the cationic polymerization of epoxy silicones, Journal of Applied Polymer Science. 60 (1996) 705713. https://doi.org/10.1002/(SICI)1097-4628(19960502)60:5<705::AID-APP7>3.0.CO;2-U.

[241] P.O. Boeira, C.T.W. Meereis, C.E.C. Suárez, S.M. de Almeida, E. Piva, G. da Silveira Lima, Coumarin-based iodonium hexafluoroantimonate as an alternative photoinitiator for experimental dental adhesives resin, Applied Adhesion Science. 5 (2017) 2. https://doi.org/10.1186/s40563-016-0080-6.

[242] C. Ely, L.F.J. Schneider, F.A. Ogliari, C.C. Schmitt, I.C. Corrêa, G. da S. Lima, S.M.W. Samuel, E. Piva, Polymerization kinetics and reactivity of alternative initiators systems for use in light-activated dental resins, Dental Materials. 28 (2012) 1199-1206. https://doi.org/10.1016/j.dental.2012.08.009.

[243] K. IKEMURA, T. ENDO, A review of the development of radical photopolymerization initiators used for designing light-curing dental adhesives and resin composites, Dental Materials Journal. 29 (2010) 481-501. https://doi.org/10.4012/dmj.2009-137.

[244] J.G. Leprince, W.M. Palin, M.A. Hadis, J. Devaux, G. Leloup, Progress in dimethacrylate-based dental composite technology and curing efficiency, Dental Materials. 29 (2013) 139-156. https://doi.org/10.1016/j.dental.2012.11.005.

[245] K. Yoshida, E.H. Greener, Effect of photoinitiator on degree of conversion of unfilled light-cured resin, Journal of Dentistry. 22 (1994) 296-299. https://doi.org/10.1016/03005712(94)90064-7. 
[246] M. Taira, H. Urabe, T. Hirose, K. Wakasa, M. Yamaki, Analysis of Photo-initiators in Visible-light-cured Dental Composite Resins, J Dent Res. 67 (1988) 24-28. https://doi.org/10.1177/00220345880670010401.

[247] F.A. Ogliari, C. Ely, G.S. Lima, M.C.M. Conde, C.L. Petzhold, F.F. Demarco, E. Piva, Onium salt reduces the inhibitory polymerization effect from an organic solvent in a model dental adhesive resin, Journal of Biomedical Materials Research Part B: Applied Biomaterials. 86B (2008) 113-118. https://doi.org/10.1002/jbm.b.30995.

[248] M. Cadenaro, F. Antoniolli, B. Codan, K. Agee, F.R. Tay, E.D.S. Dorigo, D.H. Pashley, L. Breschi, Influence of different initiators on the degree of conversion of experimental adhesive blends in relation to their hydrophilicity and solvent content, Dental Materials. 26 (2010) 288-294. https://doi.org/10.1016/j.dental.2009.11.078.

[249] F.R. Tay, N.M. King, B.I. Suh, D.H. Pashley, Effect of delayed activation of light-cured resin composites on bonding of all-in-one adhesives, J Adhes Dent. 3 (2001) 207-225.

[250] E. Caló, V.V. Khutoryanskiy, Biomedical applications of hydrogels: A review of patents and commercial products, European Polymer Journal. 65 (2015) 252-267. https://doi.org/10.1016/j.eurpolymj.2014.11.024.

[251] L.A. Sharpe, A.M. Daily, S.D. Horava, N.A. Peppas, Therapeutic applications of hydrogels in oral drug delivery, Null. 11 (2014) 901-915. https://doi.org/10.1517/17425247.2014.902047.

[252] E.M. Ahmed, Hydrogel: Preparation, characterization, and applications: A review, Journal of Advanced Research. 6 (2015) 105-121. https://doi.org/10.1016/j.jare.2013.07.006.

[253] A. Gualandi, G. Rodeghiero, E. Della Rocca, F. Bertoni, M. Marchini, R. Perciaccante, T.P. Jansen, P. Ceroni, P.G. Cozzi, Application of coumarin dyes for organic photoredox catalysis, Chem. Commun. 54 (2018) 10044-10047. https://doi.org/10.1039/C8CC04048F.

[254] M.-A. Tehfe, J. Lalevée, S. Telitel, J. Sun, J. Zhao, B. Graff, F. Morlet-Savary, J.-P. Fouassier, Iridium complexes incorporating coumarin moiety as catalyst photoinitiators: Towards household green LED bulb and halogen lamp irradiation, Polymer. 53 (2012) 2803-2808. https://doi.org/10.1016/j.polymer.2012.05.009.

[255] M.-H. Larraufie, R. Pellet, L. Fensterbank, J.-P. Goddard, E. Lacôte, M. Malacria, C. Ollivier, Visible-Light-Induced Photoreductive Generation of Radicals from Epoxides and Aziridines, Angewandte Chemie International Edition. 50 (2011) 4463-4466. https://doi.org/10.1002/anie.201007571.

[256] T. Courant, G. Masson, Photoredox-Initiated $\alpha$-Alkylation of Imines through a ThreeComponent Radical/Cationic Reaction, Chemistry - A European Journal. 18 (2012) 423-427. https://doi.org/10.1002/chem.201103062.

[257] K. Zeitler, Photoredox Catalysis with Visible Light, Angewandte Chemie International Edition. 48 (2009) 9785-9789. https://doi.org/10.1002/anie.200904056.

[258] J.D. Nguyen, J.W. Tucker, M.D. Konieczynska, C.R.J. Stephenson, Intermolecular Atom Transfer Radical Addition to Olefins Mediated by Oxidative Quenching of Photoredox Catalysts, J. Am. Chem. Soc. 133 (2011) 4160-4163. https://doi.org/10.1021/ja108560e.

[259] J. Sun, W. Wu, H. Guo, J. Zhao, Visible-Light Harvesting with Cyclometalated Iridium(III) Complexes Having Long-Lived 3IL Excited States and Their Application in Triplet-Triplet-Annihilation Based Upconversion, European Journal of Inorganic Chemistry. 2011 (2011) 3165-3173. https://doi.org/10.1002/ejic.201100501. 
[260] J. Lalevée, M. El-Roz, X. Allonas, J. Pierre Fouassier, Free-radical-promoted cationic photopolymerization under visible light in aerated media: New and highly efficient silane-containing initiating systems, Journal of Polymer Science Part A: Polymer Chemistry. 46 (2008) 2008-2014. https://doi.org/10.1002/pola.22535.

[261] J. Lalevée, A. Dirani, M. El-Roz, X. Allonas, J.P. Fouassier, Germanes as efficient coinitiators in radical and cationic photopolymerizations, Journal of Polymer Science Part A: Polymer Chemistry. 46 (2008) 3042-3047. https://doi.org/10.1002/pola.22644.

[262] M.A. Tehfe, J. Lalevée, X. Allonas, J.P. Fouassier, Long Wavelength Cationic Photopolymerization in Aerated Media: A Remarkable Titanocene/Tris(trimethylsilyl)silane/Onium Salt Photoinitiating System., Macromolecules. 42 (2009) 8669-8674. https://doi.org/10.1021/ma9016696.

[263] R. Souane, M.A. Tehfe, J. Lalevée, D. Gigmes, J.P. Fouassier, New Initiating Systems for Thermal Cationic Polymerization at Ambient Temperature with in situ Formation of $\mathrm{Ag}(0)$ Nanoparticles: A Silane/Silver Salt Combination, Macromolecular Chemistry and Physics. 211 (2010) 1441-1445. https://doi.org/10.1002/macp.201000002.

[264] Z. Li, X. Zou, F. Shi, R. Liu, Y. Yagci, Highly efficient dandelion-like near-infrared light photoinitiator for free radical and thiol-ene photopolymerizations, Nature Communications. 10 (2019) 3560. https://doi.org/10.1038/s41467-019-11522-0.

[265] J. Lalevée, F. Hammoud, N. giacoletto, G. Noirbent, B. Graff, A. Hijazi, M. Nechab, D. Gigmes, F. Dumur, Substituent Effects on Photoinitiation Ability of Coumarin-Based Oxime-Ester Photoinitiators for Free Radical Photopolymerization, Mater. Chem. Front. (2021). https://doi.org/10.1039/D1QM01310F.

[266] Y.-H. Li, Y.-C. Chen, Triphenylamine-hexaarylbiimidazole derivatives as hydrogenacceptor photoinitiators for free radical photopolymerization under UV and LED light, Polym. Chem. 11 (2020) 1504-1513. https://doi.org/10.1039/C9PY01605H.

[267] S. Chen, M. Jin, J.-P. Malval, J. Fu, F. Morlet-Savary, H. Pan, D. Wan, Substituted stilbene-based oxime esters used as highly reactive wavelength-dependent photoinitiators for LED photopolymerization, Polym. Chem. 10 (2019) 6609-6621. https://doi.org/10.1039/C9PY01330J.

[268] Y. Pang, S. Fan, Q. Wang, D. Oprych, A. Feilen, K. Reiner, D. Keil, Y.L. Slominsky, S. Popov, Y. Zou, B. Strehmel, NIR-Sensitized Activated Photoreaction between Cyanines and Oxime Esters: Free-Radical Photopolymerization, Angewandte Chemie International Edition. 59 (2020) 11440-11447. https://doi.org/10.1002/anie.202004413.

[269] J. Xu, G. Ma, K. Wang, J. Gu, S. Jiang, J. Nie, Synthesis and photopolymerization kinetics of oxime ester photoinitiators, Journal of Applied Polymer Science. 123 (2012) 725-731. https://doi.org/10.1002/app.34551.

[270] D.E. Fast, A. Lauer, J.P. Menzel, A.-M. Kelterer, G. Gescheidt, C. Barner-Kowollik, Wavelength-Dependent Photochemistry of Oxime Ester Photoinitiators, Macromolecules. 50 (2017) 1815-1823. https://doi.org/10.1021/acs.macromol.7b00089.

[271] W. Wang, M. Jin, H. Pan, D. Wan, Phenylthioether thiophene-based oxime esters as novel photoinitiators for free radical photopolymerization under LED irradiation wavelength exposure, Progress in Organic Coatings. 151 (2021) 106019. https://doi.org/10.1016/j.porgcoat.2020.106019.

[272] X. Ma, D. Cao, H. Fu, J. You, R. Gu, B. Fan, J. Nie, T. Wang, Multicomponent photoinitiating systems containing arylamino oxime ester for visible light photopolymerization, Progress in Organic Coatings. 135 (2019) 517-524. https://doi.org/10.1016/j.porgcoat.2019.06.027. 
[273] W. Wang, M. Jin, H. Pan, D. Wan, Remote effect of substituents on the properties of phenyl thienyl thioether-based oxime esters as LED-sensitive photoinitiators, Dyes and Pigments. 192 (2021) 109435. https://doi.org/10.1016/j.dyepig.2021.109435.

[274] S. Jauk, R. Liska, Photoinitiators with Functional Groups 9: New Derivatives of Covalently Linked Benzophenone-amine Based Photoinitiators, Null. 45 (2008) 804810. https://doi.org/10.1080/10601320802300453.

[275] Z.-H. Lee, F. Hammoud, A. Hijazi, B. Graff, J. Lalevée, Y.-C. Chen, Synthesis and free radical photopolymerization of triphenylamine-based oxime ester photoinitiators, Polym. Chem. 12 (2021) 1286-1297. https://doi.org/10.1039/D0PY01768J. 